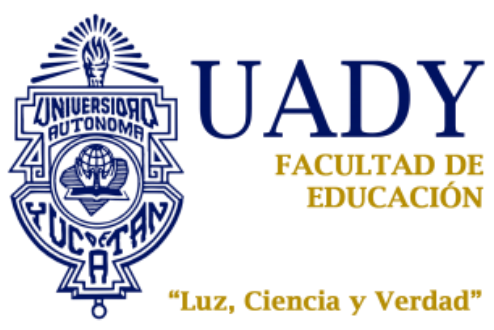

\title{
FACTORES ASOCIADOS AL ACOSO ESCOLAR EN UN CENTRO DE EDUCACIÓN SUPERIOR DE LA CIUDAD DE MÉRIDA
}

\author{
Julio Isaac Vega Cauich
}

Tesis elaborada para obtener el Grado de Maestro en Investigación Educativa

Tesis dirigida por:

Edith J. Cisneros Chacón

Roger M. Patrón Cortés

Mérida, Yucatán

Agosto de 2018 
Méridin, Yucatán a 3 de mayo de 2018.

Dr. Pedro Joses Canto Herrera

Jefe de la Unidad de Posgradó Investigrición

Facultad de Educaciơn, UADY

PRESENTE

Los abajo firmantes mienbros del Comité Revisor nombrado por la dirección de la Facultad de Educación y en respuesta a sti solicitud para revisar la tesis:

\section{"FACTORES ASOCIADOS AL ACOSO ESCOLAR EN UN CENTRO DE EDUCACIÓN SUPERIOR DE LA CIUDAD DE MÉRIDA* "}

Presentado por JULIO ISAAC VEGA CAUICH para obtener el grado de MAESTRO EN INVESTIGACIÓN EDUCATIVA, le comunicamos que el trabajo cumple con los requisitos de contenido y presentación establecidos por este Comité y por el Comité de Examen Profesional, de Especialización y de Grado, por lo tanto el dictamen que emitimos es de:

\section{Aprobado}

Por lo que puede proceder a la etapa de presentación y defensa del mismo.

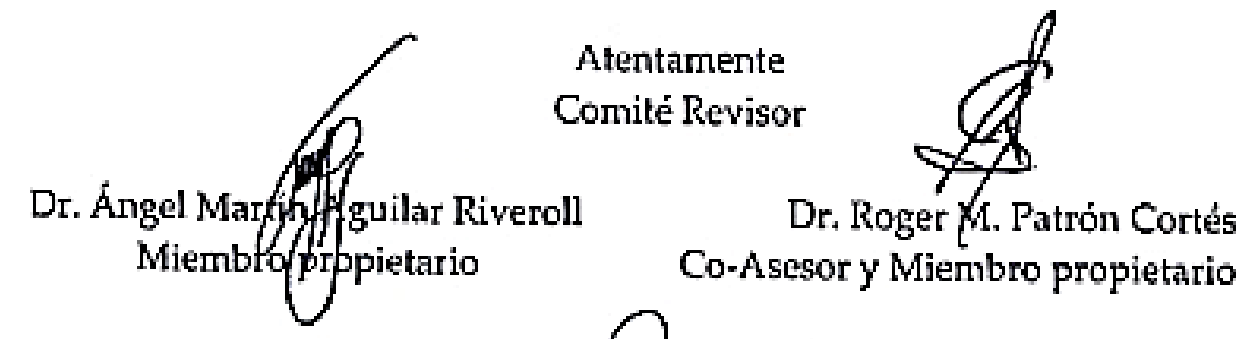

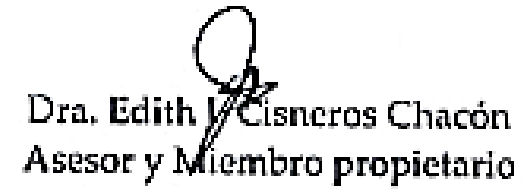

C.p. Expediente del alumno en Conirol Escolar Ce.p. Interesado 


\section{Declaratoria}

Declaro que esta tesis es mi propio trabajo, con excepción de las citas en las que he dado crédito a sus autores, asimismo afirmo que este trabajo no ha sido presentado para la obtención de algún título, grado académico o equivalente.

Julio Isaac Vega Cauich 
Agradezco al apoyo brindado por el Consejo Nacional de Ciencia y Tecnología (CONACYT) por haberme otorgado la beca No. 443272 durante el periodo de agosto de 2016 a julio de 2018 para la realización de mis estudios de maestría que concluye con la tesis como producto final de la Maestría en Investigación Educativa de la Universidad Autónoma de Yucatán. 


\section{Dedicatoria}

Quisiera dedicar esta tesis a mi madre y a mi padre. Quienes me dejaron la mejor herencia posible que un padre puede dejar a su hijo: la educación. Gracias a ellos desde pequeño sabía que quería y debía seguir estudiando. La conclusión de mi maestría no es más que el fruto de sus esfuerzos y su gran trabajo como padres.

También le dedico mi tesis a mis hermanos, sus parejas y mis sobrinos. Quienes no me dejaron de apoyar un solo día. Apoyándome cada quien de diferentes maneras. Espero que este trabajo les inspire a ser mejores cada día, especialmente a mis sobrinos, que aún tienen un largo camino por delante.

También dedico mi tesis a mis colegas y socios de Foco Rojo. Nuestras apasionadas pláticas sobre ciencia y prevención de la violencia fueron una gran fuente de inspiración para desarrollar y continuar con este trabajo. Espero que este estudio sea el inicio de muchos proyectos que tengamos en el futuro.

Finalmente, también quiero dedicar mi tesis a todos aquellos alumnos que han sufrido maltrato y acoso escolar. Espero sinceramente que la ciencia pueda ayudar a prevenir este fenómeno. 


\section{Agradecimientos}

Primero que nada, debo agradecer a mi asesora, la Dra. Edith Cisneros-Cohernour, quien desde el inicio me permitió elegir un tema que me apasiona, y que a lo largo de dos años no hizo más que apoyarme en todo lo posible. No puedo expresar con simples palabras mi gratitud, pero sin duda este trabajo jamás hubiese sido posible sin su apoyo incondicional.

También quiero agradecer a mis demás miembros de comité, el Dr. Roger Patrón Cortés y el Dr. Ángel Aguilar Riveroll. Por su tiempo dedicado a revisar mis avances y por la confianza depositada en mí.

Quiero agradecer también al personal y alumnos de las dos escuelas que me abrieron las puertas tanto en el estudio piloto como en la fase final del estudio. Su apoyo fue crucial para esta tesis.

De igual forma, agradezco también a aquellos que me ayudaron en la recolección y captura de datos: a mi prima Yolanda Vega, mi compañero David Martín, y mi colega Aarón Euán. Sin su ayuda mi trabajo no hubiese sido igual de eficiente, y sin duda no tendría datos que analizar. Su ayuda fue medular para mi tesis.

También quiero agradecer a otras personas que me apoyaron en diversas formas. En particular al Dr. Jesús Jornet y su equipo de trabajo, así como a mi amigo Manuel May, quienes hicieron de mi estancia en Valencia una de las mejores experiencias de vida. También a la Dra. Gina Villagómez, pues sus observaciones y pláticas fueron cruciales para una parte fundamental de la discusión.

A todos ustedes ¡Muchas gracias! Este trabajo no podría haber existido sin su apoyo. 


\section{Resumen}

Las investigaciones sobre bullying o acoso escolar son cuantiosas, y cada año han ido aumentando aún más. Sin embargo, lo cierto es que el conocimiento que se tiene de este fenómeno en el nivel superior no es tan abundante como con otros niveles educativos como primaria o secundaria. La mayoría de la información sobre los factores asociados y predictores del acoso escolar que se tienen en la actualidad, aunque consistentes, han sido encontrados en muestras de niveles básicos. Es por ello por lo que el presente estudio, busca identificar cuáles son los factores que están asociados al acoso escolar en el nivel superior.

Para dar respuesta a ello, se diseñó un estudio observacional, de tipo retrospectivo, transversal y con un alcance correlacional. El estudio fue realizado en una muestra no probabilística de estudiantes de una universidad privada del noreste de Mérida. Mediante la adaptación del instrumento llamado California Bullying Victimization Scale, se evalúo el acoso escolar tanto en víctimas como en agresores, y se describieron sus prevalencias y formas de expresión. De igual forma, con la aplicación de otros instrumentos que miden diversos constructos (como empatía, agresión, clima escolar, violencia familiar o asociación delictiva), se evaluó si los factores consistentemente asociados al acoso en niveles básicos también son significativos en el nivel superior. Para ello, se realizaron modelos estadísticos utilizando la técnica de regresión logística para identificar los factores asociados con el diagnóstico de acoso escolar, siguiendo un marco interpretativo del modelo ecológico de Brofrenbrenner.

Los resultados señalan que cerca del $20 \%$ de los alumnos sufren acoso escolar, mientras que un $13 \%$ realizan agresiones a sus compañeros. Las formas más usuales de agresión corresponden a agresiones de tipo indirecta o relacional (como la exclusión social, el esparcir rumores o el cyberbullying), y suelen manifestarse de forma principal en el salón de clases. No se encontró relación entre la edad y el sexo en las diversas formas de expresión. Con respecto a los factores asociados, los modelos realizados para víctimas señalan que la agresión reactiva, la satisfacción escolar y la violencia familiar estuvieron asociados a experimentar acoso escolar, especialmente las dos primeras. Por su parte, los modelos para agresores resaltaron factores como la agresión proactiva, la orientación no 
heterosexual, la popularidad, la satisfacción escolar y el tener amigos con conductas antisociales. Especialmente las cuatro primeras. En general, los análisis de adecuación señalan que los modelos para agresores fueron mejores que el modelo para víctimas, aunque en ambos casos los factores asociados permitían una clasificación de diagnóstico mejor que el azar.

Las implicaciones de los resultados obtenidos señalan que existe el acoso escolar en el nivel superior, y que su dinámica es diferente a la observada en los niveles básicos. Además, no todos los factores identificados en los niveles educativos inferiores fueron significativos en los alumnos universitarios, por lo que se sugiere continuar con el estudio de este fenómeno en el nivel superior. En particular, la orientación no heterosexual como un factor de riesgo para ser agresor, puede estar relacionada con los roles de género con los cuales se identifican los participantes, y con la particularidad de que el acoso de tipo relacional es más prevalente en este nivel educativo y con un menor reproche social. Finalmente, se sugiere la necesidad de modelos específicos para víctimas con un mejor ajuste de los encontrados en este estudio, así como la exploración de las consecuencias del acoso escolar en el nivel superior.

Palabras clave: acoso escolar, bullying, cyberbullying, prevalencia, educación superior. 


\section{Tabla de contenido}

Resumen / vi

Tabla de contenido / viii

Tablas / xii

Figuras / xiii

Capítulo / 1. Introducción 1

Antecedentes / 1

Planteamiento del problema / 2

Pregunta de investigación / 3

Objetivos / 3

Objetivo General / 3

Objetivos específicos / 3

Hipótesis / 3

Justificación / 4

Definición de términos / 5

Capítulo 2. Revisión de la literatura / 8

1. El concepto de Acoso Escolar / 8

Definición / 8

Términos relacionados al acoso escolar / 10

Actores involucrados en el acoso escolar / 12

2. Tipos de Acoso Escolar / 14

3. Prevalencia del acoso escolar / 15

4. Consecuencias del acoso escolar / 17

5. Legislación y normatividad sobre el bullying / 19

6. Medición del acoso escolar / 21

Observaciones / 21

Valoración de maestros / 22

Nominaciones entre pares (métodos sociométricos) / 22

Cuestionarios y escalas auto-informadas / 23

Mejores instrumentos en la actualidad / 24 
Conclusiones acerca de la medición del acoso escolar / 27

7. Factores de riesgo del Acoso Escolar / 28

Factores de riesgo individuales / 29

Factores de riesgo escolares / 30

Factores de riesgo familiares / 30

Factores de riesgo comunitarios / 31

8. El estudio del Acoso Escolar en México / 32

9. El acoso escolar en la educación superior / 35

Principales hallazgos en el nivel superior / 36

El acoso escolar a nivel superior en México / 37

Capítulo 3. Método / 40

Población / 41

Muestra / 41

Escenario / 42

Variables e Instrumentos / 42

Acoso Escolar / 42

Sexo / 43

Edad / 43

Ser diferente / 44

Empatía / 45

Agresión / 45

Impulsividad / 46

Actitudes pro-criminales / 47

Desempeño escolar / 47

Popularidad / 48

Calidad de la relación con el profesor / 48

Manejo de la coexistencia en el centro (claridad de las reglas) / 49

Satisfacción escolar / 49

Estilos de Crianza / 50

Violencia familiar / 50 
Asociación delictiva / 51

Uso de las Tecnologías de la Información y la Comunicación / 51

Recolección de datos / 52

Análisis de datos / 53

Consideraciones éticas / 55

Capítulo 4. Resultados / 56

Análisis descriptivo / 56

Prevalencia general del Acoso Escolar / 56

Prevalencia de víctimas y agresores por sexo / 57

Prevalencia y edad / 59

Frecuencias de los tipos de victimización / 59

Lugares donde ocurre el acoso escolar / 61

Acciones institucionales ante el acoso / 62

Diferencias de la agresión-victimización directa e indirecta según el sexo / 63

Agresión indirecta en hombres y mujeres / 63

Agresión directa en hombres y mujeres / 64

Relación entre la agresión-victimización directa e indirecta con la edad / 65

Factores de riesgo y protección individuales / 66

Factores individuales de las víctimas / 66

Factores individuales para los agresores / 67

Factores de riesgo y protección escolares / 68

Factores escolares para las víctimas / 69

Factores escolares para los agresores / 70

Factores de riesgo y protección familiares / 70

Factores familiares para las víctimas / 71

Factores familiares para los agresores / 71

Factores de riesgo y protección comunitarios / 72

Factores comunitarios para las víctimas / 72

Factores comunitarios para los agresores / 73

Aportación de las variables agrupado según el modelo ecológico / 74 
Aportación de los niveles según el modelo ecológico para víctimas / 74 Aportación de los niveles según el modelo ecológico para agresores / 76 Simplificación de los modelos ecológicos para víctimas y agresores / 78

Modelo simplificado para víctimas / 79

Modelo simplificado para agresores / 80

Capítulo 5. Conclusiones / 83

Discusión / 83

Sobre prevalencias y descriptivos / 83

Sobre los factores de riesgo y los modelos / 85

Conclusiones / 87

Recomendaciones / 88

Referencias / 91

Apéndice A. Estudios de bullying en México hasta marzo de 2017. / 111

Apéndice B. Especificación de las variables y preguntas del instrumento / 119

Apéndice C. Consentimiento informado / 122 


\section{Tablas}

Tabla 1. Prevalencia del acoso escolar tradicional o ciberacoso para víctimas y agresores (Fuente: Adaptado de Modecki et al., 2014). I 16

Tabla 2. Instrumentos de evaluación de bullying que consideran los cinco componentes propuestos según Vivolo-Kantor et al. (2014). / 25

Tabla 3. Paradigma y diseño de las investigaciones sobre bullying en México. / 34

Tabla 4. Planificación de las variables a incluir en los modelos. / 54

Tabla 5. Diferencias en victimización y agresión indirecta entre hombres y mujeres. / 64

Tabla 6. Diferencias en victimización y agresión directa entre hombres y mujeres. / 65

Tabla 7. Relación entre la edad y la agresión-victimización directa e indirecta. 65

Tabla 8. Modelo de factores individuales para víctimas. / 67

Tabla 9. Modelo de factores individuales para agresores. / 68

Tabla 10. Modelo de factores escolares para víctimas. / 69

Tabla 11. Modelo de factores escolares para agresores. $/ 70$

Tabla 12. Modelo de factores familiares para víctimas. $/ 71$

Tabla 13. Modelo de factores familiares para agresores. $/ 72$

Tabla 14. Modelo de factores comunitarios para víctimas. / 73

Tabla 15. Modelo de factores comunitarios para agresores. 73

Tabla 16. Aportación de los niveles del modelo ecológico para víctimas. $/ 74$

Tabla 17. Modelo ecológico de variables asociadas a la victimización. 175

Tabla 18. Aportación de los niveles del modelo ecológico para agresores. $/ 76$

Tabla 19. Modelo ecológico de variables asociadas a la agresión. 177

Tabla 20. Modelo simplificado para víctimas. $/ 79$

Tabla 21. Modelo simplificado para agresores. / 81 


\section{Figuras}

Figura 1. El acoso escolar y su relación con otros conceptos similares. / 12

Figura 2. Representación de los factores de riesgo según el enfoque ecológico. / 32

Figura 3. Artículos sobre Acoso Escolar publicados en México / 33

Figura 4. Diseño de análisis del acoso escolar y los $k$ factores asociados. / 40

Figura 5. Prevalencia de víctimas de acoso escolar. / 56

Figura 6. Prevalencia de agresores de acoso escolar. / 57

Figura 7. Prevalencia de víctimas, agresores y víctimas-agresores de acoso escolar. / 57

Figura 8. Prevalencia de víctimas por sexo. / 58

Figura 9. Prevalencia de agresores por sexo. / 58

Figura 10. Distribución de las edades según condición de A) víctimas, y B) Agresores. / 59

Figura 11. Prevalencia de los principales tipos de victimización. / 60

Figura 12. Prevalencia de los principales tipos de agresión. / 61

Figura 13. Lugares donde ocurre el acoso. / 61

Figura 14. Acciones realizadas por los maestros/personal ante las situaciones de acoso. / 62

Figura 15. Curva ROC del modelo reducido para víctimas. / 80

Figura 16. Curva ROC del modelo reducido para agresores. / 82 


\section{Capítulo 1.}

\section{Introducción}

\section{Antecedentes}

En la década de los 90 la Asamblea Mundial de la Salud declaró que la violencia es un problema creciente a nivel mundial y de interés fundamental para la salud pública (Organización Mundial de la Salud, 2002). A partir de ello se han hecho grandes esfuerzos por atender y prevenir distintos tipos de violencia que aquejan a la población. Uno de los tipos de violencia que destacan en su expresión interpersonal es la violencia que se da en los planteles escolares conocida como "acoso escolar", "hostigamiento escolar" o popularmente conocida como "bullying".

En México este tipo de violencia es especialmente prevalente, ya que algunos estudios sugieren que nuestro país ocupa los primeros lugares en acoso escolar cuando se compara con otros países (Muñoz Abúndez, 2008; Valadez, 2014). Durante 2007, según estudios realizados por el Instituto Nacional de Evaluación Educativa, cerca de un 15\% de los estudiantes de México estuvieron involucrados en alguna situación de violencia (Muñoz Abúndez, 2008). De forma reciente, según datos de la Encuesta de Cohesión Social para la Prevención de la Violencia y la Delincuencia (Instituto Nacional de Estadística y Geografía, 2014) el 42.6\% de los jóvenes de 12 a 29 años que fueron víctimas del delito o de maltrato fueron agredidos por parte de compañeros de la escuela; y según el Módulo de Ciberacoso de la Encuesta Nacional sobre Disponibilidad y Uso de las TIC en Hogares (Instituto Nacional de Estadística y Geografía, 2015), el 24.5\% de la población mayor de 12 años usuaria de internet reporta haber vivido alguna forma de ciberacoso.

Ciertamente el problema del acoso escolar es un fenómeno actual y necesario de atender. Varios estudios han relacionado el acoso escolar con problemas de salud mental (Albores-Gallo, Sauceda-García, Ruiz-Velasco, y Roque-Santiago, 2011; Alikasifoglu,

Erginoz, Ercan, Uysal, y Albayrak-Kaymak, 2007; Gini y Pozzoli, 2009); que posteriormente se ha asociado con consecuencias aún más graves como el suicidio (Bauman, Toomey, y Walker, 2013; Klomek et al., 2011). Es debido a estas consecuencias que el estudio del acoso escolar ha ido creciendo año con año (Dibomicucci Brazil, Basso Meneghini, de Souza Costa, y Lemes, 2015), lo que ha permitido identificar variables 
predictoras del acoso escolar, y determinar qué programas de atención o prevención son efectivos para disminuir el bullying. De igual forma, la alarmante prevalencia que reportan los estudios de acoso escolar en México ha favorecido la aparición de distintas leyes y políticas públicas encaminadas a su prevención y erradicación (Vega Báez, 2007).

A pesar de lo anterior, lo cierto es que el estudio del acoso escolar se ha centrado en niveles educativos básicos como primaria, secundaria o bachillerato, y poca atención se ha prestado a este fenómeno en estudiantes de niveles superiores como licenciatura o posgrado, tanto a nivel internacional (Dibomicucci Brazil et al., 2015), como a nivel nacional (Valdés Cuervo, Alcántar Nieblas, Tánori Quintana, y Torres Acuña, 2016). La intención de la presente investigación es brindar información que permita comprender de mejor forma este fenómeno en alumnos de nivel superior, tanto en cuestión de prevalencia de este fenómeno, como en los factores que se encuentran asociados a él.

\section{Planteamiento del problema}

La contextualización anterior ha permitido identificar que el estudio del acoso escolar en niveles educativos superiores ha sido poco abordado. La mayoría de la información que se tiene sobre el acoso escolar y las variables asociadas a éste ha sido obtenida gracias a estudios llevados a cabo con muestras de estudiantes de niveles básicos (Dibomicucci Brazil et al., 2015). A pesar de la poca información que se tiene del acoso escolar que viven los jóvenes que cursan niveles educativos equivalentes a la universidad, algunas exploraciones de este fenómeno han permitido saber aspectos relevantes sobre ello. Por ejemplo, se sabe que el tipo de agresión cambia de acuerdo con la edad, pasando de expresiones físicas durante la pubertad y adolescencia, a expresiones menos directas y más relacionales durante la adultez joven (Björkqvist, Lagerspetz, y Kaukiainen, 1992). De igual forma se ha visto que los jóvenes que son usuarios de internet, aquellos que se encuentran en el grupo de edad de 20 a 29 años son los más vulnerables a experimentar situaciones de ciberacoso en México (Instituto Nacional de Estadística y Geografía, 2015).

Es por lo anterior que resulta importante prestar atención al fenómeno de acoso escolar en el nivel superior. Es crucial incrementar la información que se tiene sobre el acoso escolar en jóvenes universitarios, así como las variables que se asocian con él, pues un mejor conocimiento del fenómeno y sus causas permitirá una mejor atención y 
prevención de éste. Lo anterior ha permitido plantear una serie de cuestiones y objetivos que guían la realización de este proyecto de investigación.

\section{Pregunta de investigación}

¿Cuáles son los factores que se encuentran asociados al acoso escolar en estudiantes de una escuela de nivel superior?

\section{Objetivos}

\section{Objetivo General}

Identificar los factores asociados al acoso escolar en una institución de nivel superior de la ciudad de Mérida.

\section{Objetivos específicos}

Describir la prevalencia del acoso escolar y sus diferentes manifestaciones en una institución de nivel superior de la ciudad de Mérida.

Describir los principales lugares donde ocurre el acoso escolar, así como las acciones realizadas por el personal docente ante las situaciones de acoso.

Determinar los factores individuales asociados al acoso escolar, tanto en víctimas como en agresores, en una institución de nivel superior de la ciudad de Mérida.

Determinar los factores escolares asociados al acoso escolar, tanto en víctimas como en agresores, en una institución de nivel superior de la ciudad de Mérida.

Determinar los factores familiares asociados al acoso escolar, tanto en víctimas como en agresores, en una institución de nivel superior de la ciudad de Mérida.

Determinar los factores comunitarios asociados al acoso escolar, tanto en víctimas como en agresores, en una institución de nivel superior de la ciudad de Mérida.

Determinar los factores de riesgo y protección asociados al acoso escolar en una institución de nivel superior de la ciudad de Mérida, según el modelo ecológico.

Determinar un modelo que permita explicar la variación en el acoso escolar con el menor número de variables significativas posibles.

\section{Hipótesis}

$\mathrm{H}_{1}$ : Las mujeres presentarán una mayor frecuencia de acoso indirecto en contraste con los hombres universitarios. 
$\mathrm{H}_{2}$ : Los hombres presentarán una mayor frecuencia de acoso directo en contraste con las mujeres universitarias.

$\mathrm{H}_{3}$ : Existe una relación inversamente proporcional entre el acoso directo y la edad en estudiantes universitarios.

$\mathrm{H}_{4}$ : Existe una relación directamente proporcional entre el acoso indirecto y la edad en estudiantes universitarios.

$\mathrm{H}_{5}$ : Existirán factores a nivel personal asociados de forma significativa al acoso escolar tanto para víctimas como para agresores.

$\mathrm{H}_{6}$ : Existirán factores a nivel escolar asociados de forma significativa al acoso escolar tanto para víctimas como para agresores.

$\mathrm{H}_{7}$ : Existirán factores a nivel familiar asociados de forma significativa al acoso escolar tanto para víctimas como para agresores.

$\mathrm{H}_{8}$ : Existirán factores a nivel comunitario asociados de forma significativa al acoso escolar tanto para víctimas como para agresores.

$\mathrm{H}_{9}$ : Los cuatro niveles de modelo ecológico (personal, escolar, familiar y comunitario) están asociados de forma significativa al acoso escolar tanto en víctimas como en agresores.

$\mathrm{H}_{10}$ : Los factores identificados con el modelo reducido permiten determinar la presencia de acoso escolar con un poder superior al azar.

\section{Justificación}

La relevancia del presente proyecto puede ser analizada a partir de tres perspectivas: la normativa, la teórica y la práctica. Con respecto a relevancia normativa, es evidente la relación entre este estudio y las políticas y recomendaciones nacionales e internacionales que buscan fomentar el derecho humano a una vida libre de violencia. Por ejemplo, en 2015 la ONU propuso una serie de objetivos encaminados al desarrollo sostenible mundial, entre los que destacan el objetivo 4 "Educación de Calidad" y el 16 "Paz, Justicia e Instituciones Sólidas", en donde todos aquellos trabajos encaminados a conocer, atender y prevenir el acoso escolar son esenciales para el logro de estos objetivos.

A nivel nacional también destacan otras normativas importantes. Por ejemplo, en los últimos años en México se ha llevado a cabo una tarea importante en la legislación de 
normas específicamente diseñadas para prevenir y erradicar cualquier tipo de violencia escolar (Vega Báez, 2007). Yucatán no es la excepción; en nuestro estado desde el 2012 existe la "Ley para la Prevención, Combate y Erradicación de la Violencia en el Entorno Escolar del Estado de Yucatán", que en su artículo 10 (incisos IV, V, XIII, XVI, y XVII) establece la necesidad de diagnósticos periódicos del acoso escolar en los planteles educativos, así como la implementación de programas y mecanismos que permitan prevenir y atender este fenómeno (Congreso del Estado de Yucatán, 2012). Es por ello que la información brindada por este trabajo resulta de especial importancia para responder tanto a los objetivos señalados por organismos internacionales, así como para dar respuesta a las normativas nacionales y locales.

De igual forma la información brindada por este trabajo permitirá conocer e integrar información sobre el fenómeno del acoso escolar en los niveles superiores. A pesar de que se conoce que la expresión de la violencia y la agresión va cambiando a lo largo de la vida (Björkqvist et al., 1992) varios autores han manifestado la poca atención que tiene este nivel educativo en el estudio del acoso escolar (Chapell et al., 2004, 2006; Dibomicucci Brazil et al., 2015; Doğruer y Yaratan, 2014; Gibb y Devereux, 2014); e incluso la Asociación Americana de Investigación Educativa ha manifestado la poca información al respecto, por lo que hacen un llamado a encaminar investigaciones sobre este fenómeno en los adultos jóvenes (American Educational Research Association, 2013).

Finalmente, las implicaciones prácticas que puede tener este proyecto son varias. De forma directa, la información obtenida será devuelta a la institución participante con la intención de que el breve diagnóstico sirva para la toma de decisiones por parte de los directivos del centro escolar. De forma indirecta, aportar información novedosa y local sobre el fenómeno del acoso escolar en el nivel superior puede servir para que futuros proyectos de investigación utilicen esta información para fines de realizar mejores intervenciones para atender y prevenir el acoso escolar.

\section{Definición de términos}

Con la intención de comprender mejor la presente investigación, a continuación, se definen una serie de términos relacionados con el acoso escolar. 
Acoso Escolar. Se considera que una persona sufre acoso escolar cuando "es expuesto a acciones negativas por una o más personas en repetidas ocasiones a lo largo del tiempo, y donde se excluyen casos en los cuales dos jóvenes de igual fuerza física o fortaleza psicológica se agreden” (Olweus, 1993, p. 9). Según las definiciones clásicas de acoso escolar, ésta debe tener tres características esenciales para ser considerada como tal: (a) la agresión debe ser intencional, (b) repetida a lo largo del tiempo, y (c) incluye un desbalance del poder. De forma reciente otros autores han propuesto añadir dos elementos al concepto de bullying: (d) la intención del agresor de causar un daño potencial, y (e) el que la víctima perciba un daño (Vivolo-Kantor, Martell, Holland, y Westby, 2014).

$\mathrm{El}$ acoso escolar puede ser manifestado de al menos tres formas particulares: agresión física directa -pegar, empujar, golpear-, agresión verbal directa -poner apodos, amenazar-, y agresión indirecta -esparcir rumores, contar mentiras, persuadir a otros de no llevarse con la persona (Rivers y Smith, 1994). A partir de lo anterior, podemos concluir que el acoso escolar es un tipo de violencia caracterizado por un daño o agresión intencional directa (pegar, empujar, insultar o amenazar) o indirecto (esparcir rumores, ignorar a compañeros, etc.), la cual se da a lo largo del tiempo, e involucra un desbalance de poder entre pares, y se traduce en la experimentación de un daño por parte de la víctima.

Cyberbullying. También conocido como ciberacoso, es un concepto que hace referencia a una forma de expresión del acoso escolar mediante el uso de las tecnologías de la información y comunicación. Así, por ejemplo, algunos autores definen el cyberbullying como un acto intencional y agresivo que se da de forma repetida a lo largo del tiempo por una o varias personas, utilizando medios electrónicos de contacto, en contra de una víctima la cual no puede defenderse fácilmente (Slonje y Smith, 2008; Smith y Slonje, 2010).

Factores de riesgo y protección. Conceptualmente, los factores de riesgo "son condiciones o variables asociadas con una menor probabilidad de resultados positivos y una mayor probabilidad de resultados negativos o socialmente indeseables" (Jessor, Turbin, y Costa, 1998; p. 195). Los factores de protección o factores protectores "tienen el efecto inverso: aumentan la probabilidad de resultados positivos y disminuyen la probabilidad de consecuencias negativas de la exposición al riesgo" (Jessor, Turbin, y Costa, 1998; p. 195). Los factores de riesgo y protección pueden analizarse desde diversas perspectivas. Una de 
ellas es a partir del actor que genera o recibe la violencia, es decir, factores protectores y de riesgo para víctimas o bien para agresores; los cuales pueden variar de un actor a otro. Por ejemplo, la cantidad de amigos es un factor de riesgo para los agresores, pero protector para las víctimas de acoso escolar (Álvarez-García, García, y Núñez, 2015). 


\section{Capítulo 2.}

\section{Revisión de la literatura}

\section{El concepto de Acoso Escolar}

\section{Definición}

El Acoso Escolar, Hostigamiento Escolar o Bullying fue descrito por primera vez en 1973 por Dan Olweus en su libro Aggression in the Schools: Bullies and Whipping Boys. En su definición clásica, Olweus (1993, p. 9) menciona que una persona sufre acoso escolar cuando "es expuesto a acciones negativas por una o más personas en repetidas ocasiones a lo largo del tiempo, y donde se excluyen casos en los cuales dos jóvenes de igual fuerza física o fortaleza psicológica se agreden”. Sin bien la definición propuesta por Olweus data de los años 70, de forma reciente, se han realizado intentos sistemáticos y consensuados para brindar una definición de bullying univoca. Al respecto, destaca la propuesta de los Centros para el Control y la Prevención de Enfermedades de Estados Unidos (CDC), que en su informe Bullying surveillance among youths: Uniform definitions for public health and recommended data elements define al bullying como:

Cualquier comportamiento agresivo indeseado realizado por otro joven o grupo de jóvenes que no son hermanos o parejas actuales, y que involucra un desbalance de poder observado o percibido y que se repite en múltiples ocasiones o es altamente probable que se repita. El acoso escolar puede infringir daño en la víctima incluyendo daño físico, psicológico, social o educativo (Gladden, Vivolo-Kantor, Hamburger, y Lumpkin, 2014, p. 7).

De forma simultánea a la definición brindada por los Centros para el Control y la Prevención de Enfermedades de Estados Unidos, los investigadores Volk, Dane y Marini (2014) propusieron una definición que ha sido aceptada por algunos investigadores líderes en el estudio del acoso escolar (Volk, Veenstra, y Espelage, 2017). La definición propuesta sugiere que "El bullying es un comportamiento dirigido a una meta, que daña a otro individuo dentro de un contexto de desequilibrio de poder" (p. 328). Esta definición, en contraste a la propuesta por Olweus o el CDC, no incluye la repetición de la conducta, en el sentido de que Volk y sus colegas señalan que incluso una sola conducta puede tener consecuencias graves si la severidad de la conducta es demasiada grande. Además, 
replantea la intencionalidad de hacer daño, ya que este componente puede ser complicado de valorar, y sugiere que el acoso es una conducta dirigida hacia una meta, una característica más sencilla de poder evaluar. Sin embargo, al igual que las definiciones anteriores, conserva el desbalance de poder. Esto es especialmente relevante ya que los investigadores de acoso escolar sugieren el desbalance de poder como un elemento fundamental y característico del bullying que lo diferencian de otras formas de agresión (Volk et al., 2017; Ybarra, Espelage, y Mitchell, 2014).

Según las definiciones de acoso escolar anteriores, se puede destacar que el acoso escolar debe tener tres características esenciales para ser considerado como tal: (a) la agresión debe ser buscar hacer daño de forma intencional a la víctima o en términos de Volk, orientada a una meta (el simple juego "agresivo" no es acoso escolar, si la víctima no sufre una especie de daño físico o emocional, no puede ser considerado como bullying, ya que esta no es la finalidad del juego agresivo); (b) debe ser una relación entre pares donde se incluye un desbalance del poder, bien sea porque alguno de los pares es superior al otro en algún aspecto (como fuerza física, inteligencia, popularidad, etc.), o bien porque la víctima es sobrepasada en número por los agresores; y (c) las agresiones deben ser en forma repetida a lo largo del tiempo, por ejemplo si un alumno pierde el temperamento y golpea a un alumno pequeño para desquitar su frustración tampoco sería acoso escolar a menos que el agresor realice el acto de forma persistente (Cornell y Bandyopadhyay, 2010; Vivolo-Kantor et al., 2014).

De forma reciente, otros autores han propuesto añadir dos elementos al concepto de bullying, cuya intención ha sido delimitar aún más el fenómeno. El primer elemento nuevo es la existencia de una intención por parte del agresor de causar daño potencial; y el segundo componente adicional señala que la víctima experimenta un daño real o percibido (Vivolo-Kantor et al., 2014). Con respecto al primero, retoma la propuesta de Volk de que no se requiere la repetición, pero si la percepción de que las conductas de acoso podrían repetirse en un futuro inmediato. El segundo, por su parte, considera la necesidad de que la víctima perciba un daño por la conducta realizada. Estos componentes característicos del acoso escolar han sido ampliamente aceptados por los académicos, que describen este fenómeno como una tipología específica de violencia y victimización entre iguales. Los 
estudios han podido identificar que estas agresiones pueden ocurrir en al menos tres formas particulares: agresión física directa, agresión verbal directa y agresión indirecta (Rivers y Smith, 1994).

\section{Términos relacionados al acoso escolar}

Si bien el término "acoso escolar" ha sido bien definido por parte de las investigaciones que lo abordan, lo cierto es que en muchas ocasiones suele ser malinterpretado, confundido e incluso utilizado de forma indistinta con otros términos relacionados. Es común, por ejemplo, que se utilice de forma indistinta con el concepto de violencia escolar, victimización entre pares o el mobbing. A continuación, se describen algunos términos relacionados y se contrastan con el concepto de acoso escolar para clarificar sus diferencias.

Cyberbullying: este término hace referencia a una forma de expresión del acoso escolar mediante el uso de las tecnologías de la información y comunicación. Así, por ejemplo, algunos autores definen el cyberbullying como un acto intencional y agresivo que se da de forma repetida a lo largo del tiempo por una o varias personas, utilizando medios electrónicos de contacto, en contra de una víctima la cual no puede defenderse fácilmente (Slonje y Smith, 2008; Smith y Slonje, 2010). Algunas investigaciones han señalado que es una forma especial de expresión del bullying relacional e indirecto, más que una forma distinta de acoso escolar (Smith y Slonje, 2010; Varjas, Henrich, y Meyers, 2009).

Violencia escolar: la violencia escolar es un término más inclusivo que el bullying, ya que involucra cualquier tipo de violencia que ocurra dentro de las instalaciones de un plantel escolar (Eisenbraun, 2007; Furlong y Morrison, 2000; García Montañez y Ascencio Martínez, 2015). El término, nacido en los Estados Unidos, es un reflejo de los problemas de violencia ocurridos como los homicidios en masa en las escuelas, el pandillerismo o la portación de armas por parte de los alumnos (Furlong y Morrison, 2000). De esta forma, la violencia escolar puede incluir al bullying y otras formas de victimización entre pares, así como la victimización que ocurre entre maestros-alumnos; sin embargo, sabiendo que el concepto de violencia escolar incluye otros tipos de violencia diferentes al acoso escolar, hay que recalcar que no deben considerarse como sinónimos (García Montañez y Ascencio Martínez, 2015). 
Victimización entre pares. Este concepto se ha definido como "una forma de abuso entre iguales en la cual un menor es el blanco frecuente de agresión por sus pares" (Kochenderfer y Ladd, 1996, p. 1305). Si bien esta forma de abuso no es exclusiva del contexto escolar, su similitud con el acoso escolar es evidente al incluir el componente de una agresión intencional y repetida hacia un igual. Sin embargo, las definiciones teóricas e incluso la evidencia empírica sustentan que la victimización entre pares y el acoso escolar se dan en contextos similares (Hunter, Boyle, y Warden, 2007), pero bien diferenciados, ya que el acoso escolar incluye el componente un desequilibrio de poder, que impide que la víctima pueda utilizar sus recursos para defenderse de las agresiones. Lo anterior tiene como resultado que el acoso escolar tenga consecuencias más graves que la victimización entre pares (Hunter et al., 2007).

Mobbing. Finalmente, el mobbing es otro concepto que ha sido frecuentemente utilizado de forma intercambiable con el bullying. Si bien de forma inicial el estudio del bullying comenzó a realizarse con el nombre de mobbing en los países nórdicos (Olweus, 2010); e incluso aún sigue refiriéndose al acoso escolar como mobbing en países como Suecia y Finlandia; la confusión con el término Moob en Estados Unidos provocó que se decidiera renombrar el concepto como bullying en sus publicaciones en inglés. Con el paso del tiempo el término evolucionó hasta lo que actualmente se conoce como Bullying. A pesar de ello, el término mobbing sigue en uso en otros países, e incluso en el ámbito laboral es bastantemente utilizado, haciendo referencia al acoso entre iguales que ocurre dentro de las organizaciones (Escartín, Arrieta, y Rodríguez, 2010). El término de mobbing en su acepción como acoso escolar, es mayormente utilizado en el ámbito europeo, en contraste, el americano ha optado por considerar a este concepto como el equivalente al acoso laboral e incluso utilizando de forma intercambiable con el término "bullying laboral" (workplace bullying).

Ciertamente, el concepto de acoso escolar ha sido utilizado de forma indistinta con otros conceptos similares; sin embargo, como se explicó en párrafos previos, resulta evidente que el concepto está bien diferenciado de otros términos. Por ejemplo, el acoso escolar ciertamente es igual al término mobbing con respecto a sus componentes y origen, sus diferencias solo radican en el contexto en el cual se utilizan, siendo este último un 
término reservado para países nórdicos o en el contexto laboral. Por su parte, el término cyberbullying o ciberacoso, no es más que una modalidad de expresión del acoso escolar, que potencia o agrava las consecuencias del bullying.

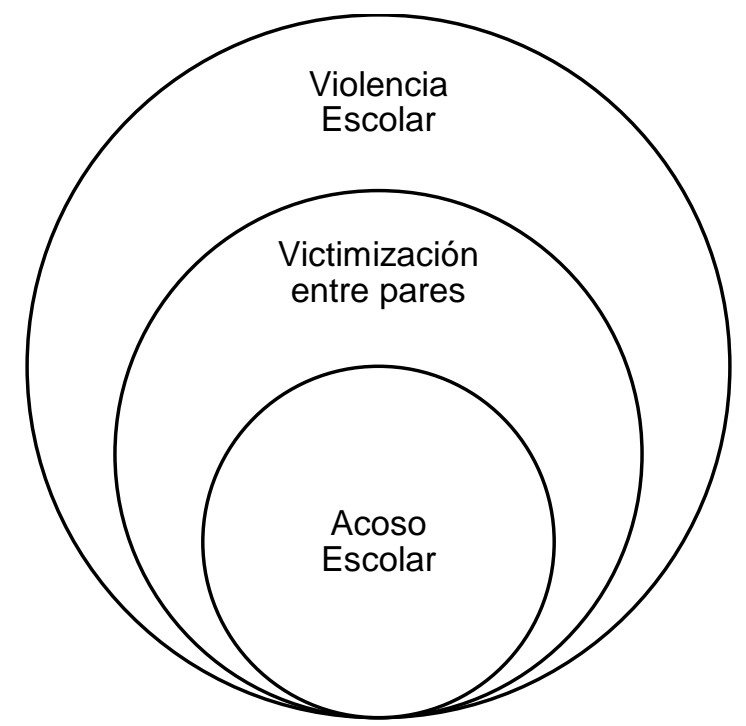

Figura 1. El acoso escolar y su relación con otros conceptos similares (elaboración propia).

Finalmente, tal como se aprecia en la Figura 1, las diferencias entre violencia escolar, victimización entre iguales y acoso escolar radican en el nivel de abarcamiento de ciertas conductas entre estudiantes. La violencia escolar es el término más amplio, donde puede incluirse aquellos actos de violencia que ocurre de estudiante a estudiante (victimización entre pares), y el acoso escolar sería aquel acto de violencia premeditada entre pares que tiene como característica su cronicidad y un desequilibrio de poder.

\section{Actores involucrados en el acoso escolar}

Entender el papel que desempeñan los diferentes actores en esta relación violenta ha sido determinante para el estudio del acoso escolar, por lo que a continuación se detallan los principales hallazgos al respecto.

La mayoría de las investigaciones concuerdan en que los actores involucrados en el acoso escolar pueden ser categorizados en al menos tres grandes tipos: víctimas, agresores y espectadores (Hamburger, Basile, y Vivolo, 2011). Sin embargo, las investigaciones han señalado que los roles de los actores involucrados pueden ser más variados, incluyendo a víctimas, agresores o bullies, asistentes del agresor, los incitadores del agresor, los ajenos al 
acoso, y los defensores de las víctimas (Felix, Sharkey, Green, Furlong, y Tanigawa, 2011; Salmivalli, 1999).

A continuación, se describen las categorías mencionadas y propuestas por Salmivalli (1999). Las víctimas, son aquellos alumnos que son repetida y sistemáticamente hostigados. Éstas son acosadas por parte de los bullies que son agresores activos y que toman la iniciativa para hostigar a la víctima. Los otros actores usualmente son testigos de los episodios de acoso, y a partir de su comportamiento suelen tomar una posición sobre la agresión. Algunos de estos estudiantes se unen con avidez a la intimidación cuando alguien ha iniciado y actúan como asistentes del agresor. Otros, incluso aunque no ataquen activamente a la víctima, ofrecen retroalimentación positiva al agresor. Por ejemplo, cuando ocurre el hostigamiento acuden para observar lo que ocurre, brindando una audiencia para el agresor, o incluso incitándolo con sus risas y gestos. Estos estudiantes, según Salmivalli, pueden ser llamados los reforzadores. Además, un notable número de estudiantes tiende a mantenerse aparte e intentan no tomar ninguna parte, estos son denominados como ajenos al acoso. Sin embargo, su comportamiento también puede reforzar al acoso, ya que incluso al no involucrarse, en cierta forma, están brindando su aprobación al agresor de forma silenciosa. Finalmente, hay que destacar que existen estudiantes cuyo comportamiento es claramente anti-acoso, ya que suelen confortar a la víctima, toman posición al ponerse de su lado, e intentan que los otros finalicen el acoso. Éstos son conocidos como los defensores de la víctima.

Según Salmivalli (1999), solamente entre un 17 a 19\% de los estudiantes toma un rol en favor de la víctima, a pesar de que la mayoría de los estudiantes tenga una actitud negativa hacia el acoso. Mientras que de un 50 a un 58\% asumen un rol que incita o tolera el acoso. Si bien lo anterior puede resultar alarmante, lo cierto es que resulta alentador conocer que existen un número de estudiantes que no solo tiene una actitud anti-acoso, sino que adoptan conductas que intentan evitarlo; por lo que Salmivalli menciona que es un factor de protección importante para intervenir en el acoso escolar, proveyendo adecuado entrenamiento en habilidades sociales y asertividad para los defensores de las víctimas. 


\section{Tipos de Acoso Escolar}

El acoso escolar, como una forma de agresión entre pares, ha sido ampliamente estudiado. Desde la década de los 90 los hallazgos han permitido tener una noción sobre los tipos de agresiones que se pueden expresar en la dinámica del acoso escolar. De forma consistente, se ha señalado la existencia de al menos tres formas de acoso escolar: agresión física directa, agresión verbal directa, y agresión indirecta o relacional (Björkqvist et al., 1992; Olweus, 2010; Rivers y Smith, 1994).

Los primeros estudios sobre acoso escolar realizados en 1992 por Björkqvist, Lagerspetz y Kauliainen lograron identificar estos tipos de acoso a través de técnicas de reducción de datos como el análisis factorial. En este estudio, se encontró que la agresión física directa consiste conductas como causar tropiezos, tomar cosas de la víctima, patear y golpear, tomar venganza durante los juegos, y empujar. Por su parte, la agresión verbal directa en poner nombres y apodos, insultar, tratar de que la víctima parezca tonta, contar abusos, discutir y amenazar. Finalmente la agresión indirecta, que no necesariamente requiere se exprese por medios verbales, también se conoce por otros autores como bullying relacional (Olweus, 2010); sin embargo, ambos términos hacen referencia a comportamientos similares, por lo que algunos autores suelen referirse a ellos como agresión indirecta-relacional. Este tipo de agresión se manifiesta al decir chismes, incitar al rechazo de la víctima, esparcir rumores en venganza, romper contacto con la víctima y pretender desconocerla.

Otra modalidad de agresión que recientemente ha sido estudiada es el ciberacoso. Esta forma particular de expresión del acoso escolar puede manifestarse en al menos siete formas bien identificadas (Smith et al., 2008): por medio de teléfonos celular, que incluye (a) llamadas abusivas; (b) mensajes de texto abusivos; (c) y capturar o enviar fotos y/o vídeos; y por medio del internet, que incluye (d) mandar o recibir correos electrónicos abusivos; (e) ser abusivo en salas de chat; (f) ser abusivo mediante sistemas de mensajería instantánea; y (g) por medio de páginas web, p. ej.: crear páginas que sean abusivas sobre una persona en específico.

Si bien el cyberbullying es considerado como una modalidad del acoso debido a que su prevalencia es menor que el bullying cara-a-cara (Modecki, Minchin, Harbaugh, Guerra, 
y Runions, 2014), y los estudios empíricos señalan una sobreposición entre ambos que sugieren la modalidad electrónica como una forma más de bullying (Waasdorp y Bradshaw, 2015), lo cierto es que el cyberacoso tiene características particulares que el bullying caraa-cara no tiene (Slonje y Smith, 2008). Según Sticca y Perren (2013), se ha señalado que a diferencia del acoso escolar "tradicional", la modalidad electrónica del ciberacoso involucra una audiencia potencialmente más amplia, ya que una vez compartido cualquier contenido, la viralidad del mensaje es imposible de calcular. Otra diferencia es la posibilidad de que las agresiones sean totalmente anónimas, situación que no sucede con el bullying tradicional en el que la víctima conoce plenamente a su agresor. El tiempo también es importante de resaltar, ya que en el acoso escolar las agresiones tienen un principio y fin plenamente identificados, pero en el ciberacoso, debido al formato de transmisión del mensaje, su temporalidad es potencialmente infinita. Finalmente, la supervisión es otro factor diferenciador, ya que en el acoso tradicional puede reducirse las agresiones al implementar una mayor supervisión de lugares donde se presentan los abusos, pero en el cyberbullying esto es prácticamente imposible, ya que no ocurre solamente en la escuela o la casa.

\section{Prevalencia del acoso escolar}

Los estudios sobre acoso escolar que han surgido en las décadas anteriores han permitido conocer la prevalencia de este fenómeno en diferentes contextos, culturas y niveles educativos. La mayoría de los estudios intenta explorar la prevalencia tanto para víctimas como para los agresores; sin embargo, este último grupo no se ha podido estimar en todas las poblaciones. En Inglaterra se estimó que la prevalencia del acoso escolar en alumnos de bachillerato es de $7.9 \%$ para las víctimas y $1.9 \%$ para los agresores (West, 2015). En Latinoamérica destacan los estudios realizados en Brasil, donde se ha podido estimar para alumnos de primaria una prevalencia de $10.2 \%$ para víctimas y $7.1 \%$ para agresores (Rech, Halpern, Tedesco, y Santos, 2013). Otros estudios latinoamericanos únicamente han reportado prevalencias para víctimas, como el caso de Colombia donde se reporta un $20.3 \%$ en alumnos de secundaria (Cassiani-Miranda, Gómez-Alhach, CubidesMunévar, y Hernández-Carrillo, 2014). 
Tabla 1.

Prevalencia del acoso escolar tradicional o ciberacoso para víctimas y agresores (Fuente: Adaptado de Modecki et al., 2014).

\begin{tabular}{cccc}
\hline \multirow{2}{*}{ Tipo } & \multirow{2}{*}{ Prevalencia $(\%)$} & \multicolumn{2}{c}{ Intervalo de Confianza (95\%) } \\
\cline { 3 - 4 } & & Inferior & Superior \\
\hline Victimización & 36.0 & 35.8 & 36.2 \\
Tradicional & 15.2 & 15.1 & 15.4 \\
Electrónica & & & \\
Agresión & 34.5 & 34.3 & 34.8 \\
Tradicional & 15.5 & 15.3 & 15.7 \\
Electrónica & &
\end{tabular}

Finalmente, el estudio de Modecki, Minchin, Harbaugh, Guerra y Runions (2014) requiere una mención especial. Modecki y sus colaboradores realizaron un estudio metaanalítico de 80 investigaciones sobre la prevalencia del acoso escolar tanto en su expresión cara-a-cara como en su modalidad electrónica, abarcando tanto a víctimas como agresores. Tal como se puede apreciar en la Tabla 1, la prevalencia de acoso escolar reportada es alrededor del $36 \%$ en su forma tradicional para las víctimas, y de un 34.5\% para los agresores. Por otra parte, en su modalidad electrónica se reportan prevalencias similares tanto para agresores como para víctimas, con una prevalencia aproximada del $15 \%$ en los estudios analizados.

El estudio llevado a cabo por Modecki y sus colaboradores también aportó información trascendental sobre los factores que pueden afectar la estimación de la prevalencia del acoso escolar. Por ejemplo, utilizar una definición con una clara mención de los tres componentes del acoso escolar aumenta la tasa de prevalencia tanto para el bullying tradicional como para el cyberbullying, aunque su efecto es más marcado en el acoso cara-a-cara. Sin embargo, cuando se usa la palabra "bully" para describir las situaciones de violencia, disminuye la prevalencia estimada para los agresores. De lo anterior, resulta importante a considerar el método de medición para cualquier estudio cuyo propósito sea la estimación de la prevalencia del acoso escolar; ya que ciertamente el método y forma de evaluación impactará en el diagnóstico obtenido. 


\section{Consecuencias del acoso escolar}

Otro aspecto que considerar sobre el acoso escolar, y que sin duda justifican la necesidad de su entendimiento y prevención, son sus consecuencias. Las repercusiones del bullying pueden ser variadas y pueden ir desde problemas escolares hasta el suicidio (Brank, Hoetger, y Hazen, 2012).

En el aspecto académico se ha visto que las víctimas de acoso escolar presentan formas de afrontamiento cuya principal característica es evitar acudir a clases, principalmente con la finalidad de evitar el acoso constante o al propio agresor (Brank et al., 2012; Juvonen y Graham, 2014). Incluso algunas investigaciones sugieren el desarrollo de fobia a la escuela (Bernstein y Watson, 1997; Castillo Rocha y Pacheco Espejel, 2008). Se argumenta que esto se debe a la crisis y estrés que sufre la víctima al no poder enfrentar el problema con sus propios recursos. Este tipo de afrontamiento evitativo se ha señalado como perjudicial a largo plazo; sin embargo, continúa siendo una de las formas más usuales de afrontar el acoso por parte de las víctimas (Newman, Holden, y Delville, 2011). Posiblemente todo lo anterior proporciona una explicación sobre hallazgos que relacionan el acoso escolar como uno de los factores que predicen el abandono escolar (Townsend, Flisher, Chikobvu, Lombard, y King, 2008).

También se ha encontrado que el acoso escolar se relaciona de forma negativa con el desempeño académico de los estudiantes (Juvonen, Wang, y Espinoza, 2011), encontrándose que el sufrir acoso escolar puede explicar una disminución de hasta 1.5 puntos de la calificación de los alumnos (Juvonen et al., 2011; Shetgiri, Espelage, y Carroll, 2015). Esto posiblemente se deba a que las experiencias de victimización impactan de forma negativa en el clima y satisfacción que se tiene con la escuela, pues se ha visto que aquellos estudiantes que sufren la victimización, también se sienten menos satisfechos con la escuela y con las autoridades escolares (Álvarez-García et al., 2015; Juvonen, Espinoza, y Knifsend, 2012; Wang et al., 2014).

Con respecto a los efectos del acoso escolar en la salud mental, varios estudios han señalado la relación entre el acoso escolar y varios trastornos. Se ha determinado que las víctimas de acoso escolar son más propensas a exhibir síntomas de problemas somáticos o de salud como dolores de cabeza, dolor abdominal, problemas para dormir, pérdida del 
apetito y enuresis (Gini y Pozzoli, 2009, 2013). Por ejemplo, existe evidencia que asocia el bullying con los problemas para dormir, demostrando que tanto quienes sufren de bullying como quienes lo realizan, tienen patrones de sueño diferentes de aquellos quienes no sufren o realizan bullying (Hunter, Durkin, Boyle, Booth, y Rasmussen, 2014; Kubiszewski, Fontaine, Potard, y Gimenes, 2014), tienen una peor calidad del sueño (Zhou et al., 2015), y las víctimas muestran un mayor riesgo a presentar pesadillas y terrores nocturnos (Wolke y Lereya, 2014).

Aquellos niños y jóvenes que sufren acoso de igual forma presentan problemas de ansiedad y depresión (Holt et al., 2014). En general, los resultados de éstas investigaciones señalan que aquellos que sufren victimización tienen un mayor riesgo de presentar depresión debido a malas estrategias de afrontamiento (Undheim, Wallander, y Sund, 2016), e incluso tienen mayores probabilidades de presentar depresión clínica en la vida adulta (Bowes, Joinson, Wolke, y Lewis, 2015). Cabe recalcar que esto última está altamente relacionada con la ideación suicida y el suicidio, siendo una variable que se ha visto modera la relación entre acoso escolar y la probabilidad del suicidio (Bauman et al., 2013; Klomek et al., 2011; Schneider, O’Donnell, Stueve, y Coulter, 2012), es por ello que se considera fundamental la depresión y la victimización como un factor de riesgo para el suicidio (Kodish et al., 2016).

Finalmente, también se ha visto que el acoso escolar se relaciona ampliamente con el uso de sustancias (Ttofi, Farrington, Lösel, Crago, y Theodorakis, 2016), tanto por parte de la víctima como del agresor (Alikasifoglu et al., 2007; Gruber y Fineran, 2007). Alguna de las sustancias que se han podido relacionar con el acoso escolar son el consumo de cigarros, marihuana y drogas prescritas en las víctimas y agresores, incluyendo al alcohol en estos últimos (Bradshaw, Waasdorp, Goldweber, y Johnson, 2013).

Es por todo lo anterior que en años recientes se ha visto una urgencia por generar una legislación que permita prevenir e intervenir los casos de acoso escolar, que van desde declaraciones internacionales hasta leyes locales cuya finalidad siempre es la misma: una vida libre de violencia. 


\section{Legislación y normatividad sobre el bullying}

Según el marco normativo realizado por el Centro de Estudios para el Adelanto de las Mujeres y la Equidad de Género (CEAMEG) de la Cámara de Diputados de México (2013), los instrumentos jurídicos internacionales que respalda la prevención y atención del acoso escolar se basan en proporcionar un ambiente seguro y una cultura de paz tanto a niños como niñas, así como eliminar cualquier estereotipo asociado al género; con la finalidad de ayudar a que los niños y niñas tengan un mejor desarrollo integral. En estos se abordan instrumentos como la Convención sobre la eliminación de todas las formas de discriminación contra la mujer; el Pacto Internacional de Derechos Económicos, Sociales y Culturales, la Convención Americana sobre Derechos Humanos (Pacto de San José), la Convención sobre los Derechos del Niño; y los Objetivos de Desarrollo del Milenio de la Organización de las Naciones Unidas.

A nivel nacional también destacan otros instrumentos de gran importancia, como la Constitución, ya que señala que la educación que imparta el Estado está obligada a desarrollar de forma armoniosa todas las facultades de los seres humanos, la justicia y la mejor convivencia. Además, de la misma constitución nace la Ley Federal para Prevenir y Eliminar la Discriminación, la cual menciona que se considera como discriminatorio entre otras cosas:

... ofender, ridiculizar o promover la violencia en los supuestos a que se refiere el artículo $4^{\circ}$ de la Ley a través de mensajes, imágenes en los medios de comunicación; obstaculizar las condiciones mínimas necesarias para el crecimiento y desarrollo saludable, especialmente de las niñas y los niños, así como incitar al odio, la violencia, rechazo, burla, difamación, injuria, persecución o la inclusión (Centro de Estudios para el Adelanto de las Mujeres y la Equidad de Género, 2013, p. 25).

La Ley General de Educación también puede ser utilizada para enmarcar las problemáticas de acoso escolar, ya que en su artículo $7^{\circ}$, fracción VI señala que se debe: Promover el valor de la justicia, de la observancia de la Ley y de la igualdad de los individuos ante ésta, propiciar la cultura de la legalidad, de la paz y la no violencia en cualquier tipo de sus manifestaciones, así como el conocimiento de los Derechos 
Humanos y el respeto de los mismos (Centro de Estudios para el Adelanto de las Mujeres y la Equidad de Género, 2013, p. 25).

Sin embargo, la problemática del acoso escolar ha provocado que los instrumentos anteriores sean insuficientes y muchos estados se han visto en la necesidad de legislar alguna normatividad exclusiva para prevenir y erradicar el acoso escolar (Vega Báez, 2007). Según el marco realizado y difundido por la CEAMEG (2013), los estados que tienen una ley que de manera concreta hace mención del acoso escolar u otro término semejante son solamente 20: Baja California Sur, Campeche, Coahuila, Chihuahua, Ciudad de México, Durango, Guanajuato, Guerrero, Jalisco, Estado de México, Michoacán, Nayarit, Nuevo León, Puebla, Quintana Roo, San Luis Potosí, Tamaulipas, Veracruz, Yucatán y Zacatecas. De estos, solo la mitad contempla alguna forma de sanción.

A nivel local, en el Estado de Yucatán, se cuenta con la "Ley para la Prevención, Combate y Erradicación de la Violencia en el Entorno Escolar del Estado de Yucatán" (2012). Si bien, el nombre hace referencia a la Violencia escolar, lo cierto es que en las definiciones que brinda la ley, se definen claramente los componentes y elementos del acoso escolar. Además, nuestra ley contempla sanciones para los agresores y lineamientos para manejar los conflictos que sucedan como parte de la dinámica del acoso escolar. Hay que hacer énfasis también en que la Ley entre sus diversas estrategias plantea dos especialmente llamativas:1) el diagnóstico periódico del acoso escolar en los planteles educativos (Artículo 10, incisos IV y V); y 2) la implementación de programas y mecanismos que permitan prevenir y atender este fenómeno (Artículo 10, incisos XIII, XVI y XVII).

Los instrumentos anteriores, tanto internacionales, nacionales o locales dejan de manifiesto la complejidad e impacto que tiene el acoso escolar. De tal forma que resulta indispensable la normatividad de este fenómeno para poder impedir sus efectos dañinos en la vida de las personas que afecta. Los cierto es que un paso importante para ello es realizar un adecuado diagnóstico que permita la identificación oportuna del fenómeno; ya que una buena intervención tiene que ser precedida por un buen diagnóstico o evaluación (Crothers y Levinson, 2004). A continuación, se aborda el complejo campo de la medición y evaluación del acoso escolar. 


\section{Medición del acoso escolar}

Existen diversas formas de medición del acoso escolar, todas ellas con diferentes ventajas y desventajas, así como objetivos diversos, entre las que destacan las observaciones, las evaluaciones por maestros, las nominaciones por pares y las encuestas y autoinformes (Cornell y Bandyopadhyay, 2010; Crothers y Levinson, 2004). A continuación, se describen las técnicas anteriores.

\section{Observaciones}

Las observaciones como un método de medición del bullying han sido ampliamente utilizadas. Según Crothers y Levinson (2004) en esta modalidad destacan dos formas de medición: la observación estructurada y la no estructurada. En las observaciones no estructuradas el observador selecciona un lugar y momento en el cual es probable que ocurra el acoso. Se pueden evaluar aspectos del acoso escolar como estatus social, aislamiento y exclusión social. Por su parte, las observaciones estructuradas pueden centrarse en describir y comparar la frecuencia, duración y naturaleza del acoso directo, indirecto, físico y verbal.

Las observaciones proveen un registro objetivo de las interacciones que tienen los niños; sin embargo, el acoso escolar que observan los evaluadores suelen ser expresiones públicas y hasta cierto punto "socialmente esperadas"; ya que muchos de los tipos de acoso escolar que ocurren son encubiertos, u ocurren en lugares donde los observadores no pueden acceder (como vestidores, baños, etc.). Por su parte estas técnicas suelen ser baratas, ya que no requiere muchos recursos; sin embargo, se ha visto que no son útiles para identificar prevalencias, o bien los resultados no son consistentes con el tiempo. También se ha encontrado que los métodos de observación son los menos confiables, porque suelen correlacionarse únicamente con las nominaciones entre pares, pero no con auto-reportes u otras formas de evaluación (Cornell y Bandyopadhyay, 2010). Adicionalmente, las observaciones conllevan algunas limitaciones que pueden ser complicadas desde el punto de vista ético, ya que si el observador atestigua una situación de bullying, se enfrenta al dilema ético de intervenir para evitar un acto que pueda causar daño a la víctima o bien permitir que el acoso suceda para observar su dinámica (Felix et al., 2011). 


\section{Valoración de maestros}

Según Crothers y Levinson (2004), en esta forma de medición a los maestros se les proporciona una lista con los nombres de sus alumnos para que identifiquen quiénes son agresores y víctimas; o bien se les pide que emparejen a los alumnos con ciertos términos descriptivos de comportamientos de acoso. Si bien se ha visto que es un método que suele ser bastante confiable, suele subestimar la prevalencia del acoso escolar, posiblemente debido a que los profesores sólo observan una parte del comportamiento de los alumnos en el salón de clases. Además, se ha mencionado que suele estar influenciado por los sesgos de los maestros, y que muchas veces suelen confundirse ciertos tipos de victimización entre pares con el acoso escolar. A pesar de lo anterior, las valoraciones hechas por maestros son uno de los métodos más rápidos de obtener, ya que solo se requiere la opinión de un profesor y puede evaluar varios alumnos en una sola vez.

\section{Nominaciones entre pares (métodos sociométricos)}

Los métodos sociométricos consisten en que los estudiantes nombran a otros compañeros que suelen ser agresores o bien que suelen victimizar (Marín-Martínez y ReidlMartinez, 2011). Este tipo de mediciones son ideales cuando se planea trabajar e intervenir con clases completas; sin embargo, no son útiles cuando el trabajo involucra a toda la escuela, ya que suelen delimitarse a que los alumnos nominen únicamente a sus compañeros de clases y no a compañeros de otros grados o grupos (Olweus, 2010).

Adicionalmente se ha visto que estos métodos tienen una buena confiabilidad entre aplicaciones, ya que los resultados suelen ser consistentes (Crothers y Levinson, 2004; Olweus, 2010); sin embargo, no son útiles para establecer prevalencia o medir el cambio en el tiempo (incidencia) debido a que suelen estar enfocados en el contexto de un solo grupo y es dependiente del número de estudiantes de éste. También se ha mencionado que suelen medir "reputación", por lo que no son recomendables para evaluar el efecto de programas de intervención; ya que las reputaciones suelen perdurar en el tiempo, y usualmente no son el objetivo de los programas de intervención de acoso escolar (Olweus, 2010).

Finalmente, otra de las limitaciones de la nominación de pares es la necesidad de la participación de todo el grupo. Un solo sujeto que se niegue a participar puede afectar el estado sociométrico y la validez de las puntuaciones del grupo, situación que se dificulta 
cuando algún o algunos de los padres no firma el consentimiento informado o se niega a que su hijo(a) participe en la evaluación (Felix et al., 2011).

\section{Cuestionarios y escalas auto-informadas}

Los auto reportes consisten en preguntar a los participantes sobre conflictos de acoso que han experimentado (Crothers y Levinson, 2004). Es quizás uno de los métodos más eficientes y utilizados para evaluar el acoso escolar; sin embargo, al igual que los métodos anteriores, también tiene una serie de ventajas y desventajas que deben considerarse antes de ser utilizado. Por ejemplo, algunos autores mencionan que las escalas de auto reporte dependen enormemente de la percepción de los estudiantes y de su entendimiento de las preguntas (Cornell y Bandyopadhyay, 2010). Los métodos de autoreporte, a diferencia de otros métodos, permiten la estimación de prevalencia e incidencia del acoso escolar, la cual es información que usualmente los educadores y creadores de políticas públicas necesitan (Felix et al., 2011; Olweus, 2010). Adicionalmente, son especialmente efectivos para evaluar el bullying indirecto-relacional, un tipo de acoso que es difícil de evaluar por medio de observaciones o nominación entre pares (Felix et al., 2011). Sin embargo, un problema muy importante es que no todos los instrumentos toman en cuenta los tres componentes de acoso escolar en la construcción de las escalas o cuestionarios (Cornell y Bandyopadhyay, 2010).

Los estudios con reportes auto-informados suelen dividirse en dos categorías: aquellos que brindan una definición del acoso escolar, conocida como estrategia de autoreporte basada en definición; y aquellos que operacionalizan en sus reactivos la definición del acoso escolar mediante la ejemplificación de comportamientos, estrategia conocida como auto-reporte basado en conductas (Felix et al., 2011; Vivolo-Kantor et al., 2014). La idea de brindar una definición de acoso escolar en las estrategias basadas en definiciones reside en la importancia de medir únicamente el concepto de acoso escolar más que otros tipos de violencia escolar o victimización entre pares; al brindar una definición se presume que los informantes basen sus respuestas en el concepto adecuado de acoso escolar (Felix et al., 2011). Sin embargo, las investigaciones sugieren que, a pesar de proveer una definición sobre acoso escolar en los cuestionarios, los informantes o encuestados solo consideran esta información en las primeras preguntas, y posteriormente suelen utilizar su 
concepción personal sobre acoso escolar para responder las siguientes (Smith, Cowie, Olafsson, y Liefooghe, 2002). Además, el proveer una definición suele afectar el cálculo de la prevalencia, especialmente si la definición utiliza el término "bullying”, ya que se ha visto que disminuye el porcentaje de personas que admite ser perpetradores de violencia (Modecki et al., 2014).

Con respecto a los métodos basados en conductas, la mayoría de estos métodos olvida incluir el componente del desbalance de poder que requiere el concepto de acoso escolar (Felix et al., 2011); sin embargo, algunos estudios sugieren que este componente es de suma importancia, pues es esencial para diferencia el acoso escolar de otras formas de violencia (Olweus, 2010; Ybarra et al., 2014). A pesar de estas limitaciones entre los métodos que ofrecen una definición y los que no, las ventajas de los métodos de autoreporte siguen siendo varias: son fáciles de realizar, tanto en condiciones reales como de laboratorio, pueden evaluar distintas formas de acoso escolar, incluso aquellas que son complicadas de evaluar por medio de observaciones; se puede evaluar la percepción de un desbalance de poder desde el enfoque de la víctima; y toma en cuenta la percepción de la víctima, situación crítica ya que es útil para entender la intencionalidad y el impacto percibido de las agresiones (Felix et al., 2011).

\section{Mejores instrumentos en la actualidad}

En una revisión sistemática llevada a cabo por Vivolo-Kantor y sus colegas (2014), se encontró que de 41 instrumentos identificados que miden acoso escolar, solamente seis de ellos miden los tres elementos esenciales del acoso escolar, y los dos componentes adicionales sugeridos de forma reciente (Ver Tabla 2).

De los instrumentos anteriores destacan cuatro en particular: el Reynolds BullyVictimization Scale for School, debido a que, sin la necesidad de presentar una definición, logra obtener una alta confiabilidad y consistencia interna; el Olweus Bully/Victim Questionnaire, que igualmente presentan una buena consistencia interna, además de ser el instrumento más utilizado para evaluar el acoso escolar; el Swearer Bully Survey pues es muy similar al Olweus y ampliamente utilizado en la investigación; y por último, el California Bullying Vicitmization Scale, ya que al igual que el Reynolds, mide el acoso escolar sin la necesidad de brindar una definición, pero adicionalmente lo realiza utilizando 
una cantidad menor de reactivos. Ciertamente se recomienda para un estudio adecuado del acoso escolar utilizar alguno de estos instrumentos, debido a sus bondades: buenos criterios de validez y confiabilidad, e inclusión de todos los elementos del concepto de bullying.

Tabla 2.

Instrumentos de evaluación de bullying que consideran los cinco componentes propuestos según Vivolo-Kantor et al. (2014).

\begin{tabular}{|c|c|c|c|c|}
\hline Instrumento & Autores & $\begin{array}{l}\text { No. } \\
\text { Ítems }\end{array}$ & Confiabilidad & $\begin{array}{c}\text { Uso de } \\
\text { Definición }\end{array}$ \\
\hline $\begin{array}{l}\text { California Bullying } \\
\text { Victimization Scale }\end{array}$ & $\begin{array}{l}\text { Felix et al. } \\
\text { (2010) }\end{array}$ & 12 & $k=0.71$ & No \\
\hline $\begin{array}{l}\text { Olweus Bully/Victim } \\
\text { Questionnaire }\end{array}$ & $\begin{array}{l}\text { Solberg y } \\
\text { Olweus (2003) }\end{array}$ & 36 & $\begin{array}{l}\text { Victimización }=0.88 \\
\text { Agresión }=0.87\end{array}$ & $\mathrm{Si}$ \\
\hline $\begin{array}{l}\text { Reactive-Proactive } \\
\text { Agression } \\
\text { Questionnaire }\end{array}$ & $\begin{array}{l}\text { Raine et al. } \\
\text { (2004) }\end{array}$ & 23 & $\alpha=0.90$ & No \\
\hline $\begin{array}{l}\text { Reynolds Bully- } \\
\text { Victimization Scale for } \\
\text { Schools }\end{array}$ & $\begin{array}{l}\text { Peters y Bain } \\
\text { (2011) }\end{array}$ & 46 & $\begin{array}{l}\alpha=0.93 \\
\text { Test-retest }=0.81\end{array}$ & No \\
\hline $\begin{array}{l}\text { School Climate and } \\
\text { Bullying Scale }\end{array}$ & $\begin{array}{l}\text { McConville y } \\
\text { Cornell (2003) }\end{array}$ & 59 & $\alpha=0.75$ & $\mathrm{Si}$ \\
\hline $\begin{array}{l}\text { The Swearer Bully } \\
\text { Survey }\end{array}$ & $\begin{array}{l}\text { Swearer y Cary } \\
(2003)\end{array}$ & 31 & $\alpha=0.85$ & $\mathrm{Si}$ \\
\hline
\end{tabular}

\section{El California Bully Victimization Scale}

El California Bullying Victimization Scale (CBVS) fue desarrollado en la Universidad de California, en Santa Bárbara por los autores Felix, Sharkey, Grief, Furlong y Tanigawa en 2011 con la finalidad de brindar una medida de autoreporte que evalúe diferentes modalidades de bullying, que puedan ser distinguidas del concepto de victimización por pares sin la necesidad de brindar una definición a los participantes. De igual forma, el instrumento evita el uso del término "bullying" en los reactivos, bajo el supuesto de que al ser un término emocionalmente cargado puede influir en el reporte o no de las conductas de acoso escolar (Modecki et al., 2014). 
El instrumento evalúa los tres componentes del acoso escolar. La intencionalidad de hacer daño se contempla en la formulación de los reactivos al incluir esta intencionalidad en cada oración (p. ej.: ¿Han esparcido chismes o rumores sobre ti de forma cruel y dañina?). Por su parte la cronicidad del acoso se evalua en la escala de respuesta, donde se brinda al estudiante cinco opciones: 1=No durante el mes pasado; 2=Una vez el mes pasado; 3=2 o 3 veces el mes pasado; 4=Una vez a la semana; 5=Muchas veces a la semana. Finalmente, el desbalance del poder es evaluado de forma similar a como lo aborda el Swearer Bully Survey (2011), donde al estudiante se le pide compararse con su agresor en una serie de aspectos relevantes (como fuerza, tamaño, inteligencia), y responder si se considera mayor, igual o menor que su agresor en estos aspectos. Finalmente, hay que recalcar que el instrumento fue diseñado para brindar un diagnóstico rápido con el menos número de preguntas (30) que permita identificar a los alumnos que sufren acoso escolar.

El CBVS permite concluir tres posibles resultados para los alumnos: no victimizado; victimizado por pares, víctima de acoso escolar. En el primer caso corresponde a los alumnos que respondieron no haber experimentado durante el mes pasado ningún tipo de agresión cuestionado. En el segundo caso, se considera aquellos que recibieron al menos una vez el mes pasado y que no manifiesta algún tipo de desbalance de poder. Y el tercero, corresponde responder que experimenta al menos algún tipo de agresión de 2 a 3 veces al mes o superior; y que manifiesta al menos un tipo de desbalance de poder con su agresor. Este punto de corte de 2 a 3 veces al mes o superior es utilizado por otras pruebas como el Olweus Bully/Victim Questionnaire (Felix et al., 2011; Olweus, 2010), por lo que se considera como un estándar internacional, y se encuentra validado por medio de estudios empíricos (Solberg y Olweus, 2003). Finalmente, la presencia de al menos un tipo de desbalance de poder se considera como necesario para poder ser considerado como acoso escolar y no otra forma de agresión (Volk et al., 2017; Ybarra et al., 2014).

Según el estudio original (Felix et al., 2011), el CBVS fue implementado inicialmente en dos estudios y con grupos de enfoque para analizar posibles mejoras del instrumento. En su segunda versión se incluyó un reactivo que evalúa acoso sexual considerado como importante de explorar en niveles educativos de secundaria hasta 
bachillerato. Los estudios de validación señalaron que existe confiabilidad test-retest, con coeficientes de Kappa que van de .46 a .64 para la presencia de los diferentes tipos de agresión; y con una tasa de concordancia del $89.6 \%$ entre aplicaciones. La validez concurrente se evalúo con el Swearer Bully Survey, con una tasa de concordancia estadísticamente significativa del $84.5 \%$ entre los dos instrumentos. Finalmente, la validez predictiva se evaluó con el diagnóstico brindado por el CBVS y su asociación prospectiva con otras escalas como satisfacción en la vida, apego escolar y la escala de esperanza en niños, señalando una relación significativa entre el diagnóstico de acoso escolar previo, y una posterior disminución de la satisfacción con la vida, apego escolar y las puntuaciones de la escala de esperanza para niños.

Los resultados anteriores ponen de manifiesto la pertinencia de este instrumento por varias razones: 1) evalúa los tres elementos que componen al acoso escolar; 2) es rápido y fácil de aplicar; 3) no necesita criterios normativos dado que se basa en criterios internacionalmente aceptados para el diagnóstico del acoso escolar; 4) evalúa agresión sexual, que típicamente no es evaluado en otras escalas y que resulta especialmente relevante para niveles educativos superiores; 5) provee resultados adecuados de confiabilidad; 6) provee niveles adecuados de validez con otros criterios externos y con variables relacionadas al acoso escolar.

\section{Conclusiones acerca de la medición del acoso escolar}

Sin embargo, también hay que mencionar que la medición del acoso escolar, especialmente cuando es con finalidades de planificar y llevar a cabo un plan de prevención e intervención, no puede realizarse únicamente a partir de una sola medición. Se recomienda ampliamente utilizar diversos métodos que permitan la evaluación de este fenómeno. Por ejemplo, las investigaciones señalan que tanto los métodos de nominación por pares como los reportes auto-informados aportan medidas complementarias. Utilizando modelos predictivos se ha visto que al incluir las puntuaciones de los dos métodos, los resultados provistos por ambos, hacen aportaciones significativas e independientes para predecir la agresión (Cornell y Bandyopadhyay, 2010). Adicionalmente, resulta importante no solo conocer el acoso escolar, sino también aquellas variables que están asociadas el bullying, y que de alguna forma pueden aportar información para prevenir, intervenir y 
predecir el acoso escolar. A continuación, se hace mención de aquellos factores que las investigaciones han encontrado como asociados de forma consistente con el acoso escolar.

\section{Factores de riesgo del Acoso Escolar}

El estudio del acoso escolar ha aumentado a grandes pasos (Dibomicucci Brazil et al., 2015). Esto ha permitido que se hayan podido identificar de forma consistente ciertas variables que están asociadas al acoso escolar, y que pueden ayudar a crear instrumentos para su predicción. El gran número de estudios sobre el tema han permitido la propuesta de marcos interpretativos que ayuden a entender mejor el fenómeno del acoso escolar. Uno de los marcos interpretativos más ampliamente aceptados es la adaptación del modelo ecológico propuesto por Uri Brofenbrenner (Barboza et al., 2009; Espelage y Swearer, 2010).

El modelo ecológico de Brofenbrenner (1977) hace énfasis en entender la ecología del desarrollo humano como "el estudio científico y continuo de la acomodación mutua, a lo largo de la vida, entre el crecimiento del organismo humano y los cambios ambientales inmediatos donde vive” (p. 514). Este modelo asume que la estimulación entre el desarrollo del lenguaje, cognición, competencia social e integridad física, los niños también se adaptan a su ambiente físico y social inmediato (Swearer y Doll, 2001). Desde esta perspectiva, el desarrollo de conductas antisociales y la inhibición de las actitudes prosociales no reside únicamente en el individuo o el ambiente, sino más bien en una interacción entre ambos. Lo cierto es que este modelo se ha planteado como un enfoque útil para atender otros problemas de salud pública como el uso de tabaco o la obesidad infantil (Dresler-Hawke y Whitehead, 2009); y su extrapolación para abordar el tema del acoso escolar ha sido respaldada por estudios empíricos que señalan consistentemente que aquellos individuos involucrados en situaciones de acoso escolar también experimentan problemas en múltiples áreas como en la familia, grupo de pares, escuela, vecindario o comunidad (Hong y Espelage, 2012).

Desde esta perspectiva, Brofenbrenner (1977) propuso cuatro niveles de análisis para entender la compleja interacción entre el ambiente y los individuos: 1) microsistema; 2) mesosistema; 3) exosistema; y 4) macrosistema. El microsistema se considera el nivel de relación que se da entre el individuo y el contexto inmediato donde se desenvuelve. El 
mesosistema comprende las interrelaciones entre los individuos y los contextos donde se desarrollan en algún punto de sus vidas. Una extensión de este último es el exosistema, que si bien no comprende contextos donde se desarrolla el individuo, abarca estructuras sociales que impregnan e influyen en el mesosistema. Finalmente, el macrosistema, que se diferencia de los anteriores debido a que no se refiere a contextos o ambientes que afectan al individuo, sino prototipos generales como la cultura y subculturas. A partir de lo anterior, las propuestas metodológicas que extrapolan el modelo ecológico al estudio y atención del acoso escolar sugieren la identificación de cuatro grandes agrupaciones de factores de riesgo asociados al acoso escolar: individuales, escolares, familiares y comunitarios (Álvarez-García et al., 2015). A continuación, se describen los principales factores de riesgo estudiados en cada nivel:

\section{Factores de riesgo individuales}

Entre los factores de riesgo individuales se encuentra el sexo. Según numerosos estudios, es más probable que un hombre sea perpetrador de acoso escolar que una mujer (Álvarez-García et al., 2015; Björkqvist et al., 1992; Farrington y Baldry, 2010). De igual forma la edad es una variable ampliamente estudiada y relacionada con el acoso escolar. Conforme los niños van llegando a la adolescencia, aumenta el uso de violencia física, pero conforme van alcanzando la madurez, ésta disminuye (Álvarez-García et al., 2015; Björkqvist et al., 1992; Farrington y Baldry, 2010; Juvonen y Graham, 2014). Ser un alumno diferente también está asociado a ser víctima de bullying, tales como ser de otra etnia o inmigrantes (Álvarez-García et al., 2015; Jimerson, Swearer, y Espelage, 2010), o incluso la orientación sexual (Espelage, Aragon, Birkett, y Koenig, 2008), las cuales son condiciones que aumentan la probabilidades de ser víctimas de acoso escolar.

La empatía y la agresividad también juegan un papel importante en el bullying. Se ha visto que los alumnos que no son empáticos, son impulsivos y agresivos, son más propensos a ser agresores de sus compañeros (Gini, Albiero, Benelli, y Altoè, 2007; Jolliffe y Farrington, 2006b; Mitsopoulou y Giovazolias, 2015; Muñoz, Qualter, y Padgett, 2011). En particular, se ha encontrado que la empatía afectiva está asociada de forma negativa con la agresión, mientras que la empatía cognitiva se asocia negativamente con la victimización (van Noorden, Haselager, Cillessen, y Bukowski, 2014). 
Finalmente, también se ha visto que las actitudes pro-criminales o pensamientos que apoyan y justifican la conducta antisocial se relacionan con el acoso escolar, específicamente al incrementar la probabilidades de que los agresores expresen conductas agresivas (Álvarez-García et al., 2015; Banse, Koppehele-Gossel, Kistemaker, Werner, y Schmidt, 2013).

\section{Factores de riesgo escolares}

Entre los factores de riesgo asociados a la escuela se encuentra el bajo desempeño académico. Se ha visto que los alumnos que tienen un bajo desempeño en la escuela son más propensos a ser agresores (Álvarez-García et al., 2015; Bradshaw et al., 2013). La popularidad y el número de amigos que tienen los jóvenes también es una variable importante, pues se ha visto que los chicos populares son más propensos a ser agresores (Cook, Williams, Guerra, Kim, y Sadek, 2010; de Bruyn, Cillessen, y Wissink, 2009; Farrington y Baldry, 2010; Witvliet et al., 2010). El tamaño y disposición del salón resulta ser una variable que arroja resultados inconclusos y contradictorios en la mayoría de las revisiones sobre el tema (Álvarez-García et al., 2015; Machado Azeredo, Madalena Rinaldi, Leite de Moraes, Bertazzi Levy, y Rossi Menezes, 2015).

Por su parte, la calidad de relación que se tiene con el maestro también es muy relevante. Algunas investigaciones han señalado que los alumnos que reportan actos de acoso escolar son aquellos que tienen una buena relación con su profesor, y que éste responde adecuadamente ante sus avisos (Álvarez-García et al., 2015; Konishi, Hymel, Zumbo, y Li, 2010; Novick y Isaacs, 2010). De igual forma, la presencia de reglas bien definidas y estructuradas ayudan a que sea menos propenso que se presente el acoso escolar, o bien que éste disminuya (Gregory et al., 2010). Finalmente, la satisfacción con la escuela/clase y el involucramiento con la clase también resulta un predictor de bullying, pues se ha observado que es un factor de protección que disminuye la probabilidad de casos de acoso escolar (Álvarez-García et al., 2015; Cook et al., 2010).

\section{Factores de riesgo familiares}

Los factores de riesgo del acoso escolar que están asociados con la familia son principalmente los estilos de crianza y la violencia familiar. Se ha visto que los niños que tienen padres que les brindan apoyo y suficiente control son menos propensos a ser 
agresores (Álvarez-García et al., 2015; Hoeve et al., 2009). Por su parte, se ha encontrado que los agresores tienen una mayor probabilidad de provenir de familias con violencia familiar, por lo que este tipo de violencia ha sido un factor consistentemente asociado con el acoso escolar por parte de los agresores (Baldry, 2003; Espelage, Low, Rao, Hong, y Little, 2014; Hemphill et al., 2012). Sin embargo, a pesar de que la influencia familiar ha sido un factor consistentemente relacionado con el acoso escolar, lo cierto es que otros estudios han reportado que su efecto suele ser pequeño (Cook et al., 2010).

\section{Factores de riesgo comunitarios}

Por su parte, los factores de riesgo asociados a la comunidad son diversos; sin embargo, el tipo de vecindario, o el uso de entretenimiento y medios masivos de comunicación no han tenido resultados consistentes (Álvarez-García et al., 2015). Por su parte, un factor que ha sido asociado de forma plena con el acoso escolar es el tener amigos agresores, que tienen conductas antisociales, o pertenecer a pandillas (Bradshaw et al., 2013; Low y Espelage, 2014; Pepler, Jiang, Craig, y Connolly, 2008; Volk, Craig, Boyce, y King, 2006), esto posiblemente se deba a que los pares con conductas antisociales suelen tener más actitudes y pensamientos pro-criminales que pueden favorecer la expresión de conductas violentas (Banse et al., 2013).

Finalmente, otro factor que ha sido asociado al acoso escolar como un factor de riesgo es el nivel socioeconómico. Si bien su efecto ha resultado significativo para explicar el acoso escolar, el peso de éste resulta más bien ligero; sin embargo, los estudios sobre acoso escolar señalan de forma constante que venir de un nivel socioeconómico bajo está asociado con mayor probabilidad de victimización o agresión (Tippett y Wolke, 2014).

En resumen, resulta evidente y necesario el uso de una perspectiva ecológica (Ver Figura 2) para el estudio y comprensión de los factores asociados al acoso escolar (Barboza et al., 2009; Hong y Espelage, 2012), debido a las bondades que maneja este enfoque, tales como la posibilidad de categorizar los distintos factores de riesgo en los diferentes niveles de la teoría; y el brindar un marco de referencia que permite acotar posibles líneas de acción para prevenir el acoso escolar (Espelage \& Swearer, 2010). 


\section{Macrosistema}

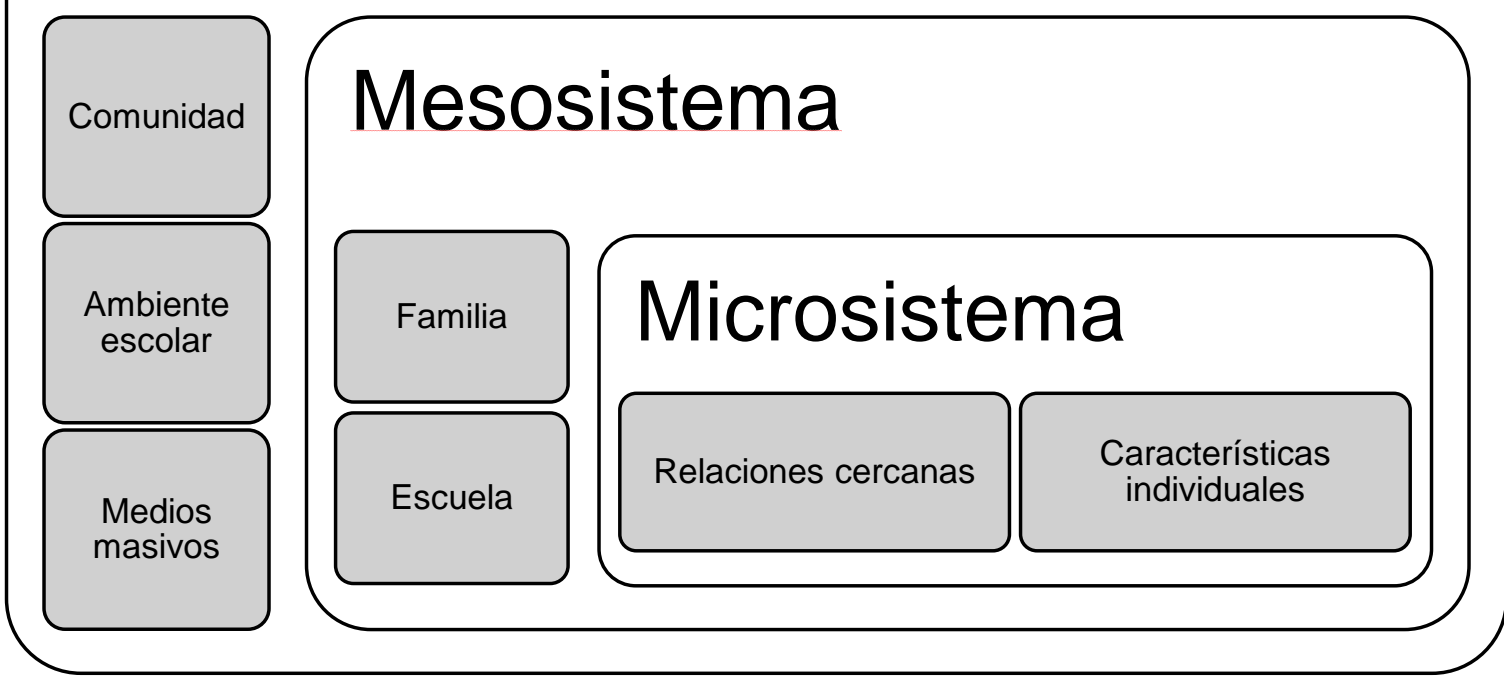

Figura 2. Representación de los factores de riesgo según el enfoque ecológico.

\section{El estudio del Acoso Escolar en México}

La investigación sobre acoso escolar en México ha sido variada en las últimas décadas, ha sido abordado tanto por profesionales de las ciencias sociales como por médicos y epidemiólogos. Para comprender un poco más el estado de su estudio, a continuación, se resumen los resultados de una revisión de las investigaciones realizadas en México hasta marzo de 2017.

Para realizar una revisión sistematizada y abarcativa de estos estudios, se revisaron las bases de datos de Scopus, Web of Science, Scielo, EBSCO y RedALyC utilizando las palabras de búsqueda “bullying” OR “acoso escolar” OR "hostigamiento escolar”. Para evitar los sesgos en la publicación, también se procedió a realizar búsquedas manuales mediante la revisión de las memorias del Congreso Nacional de Investigación Educativa realizado por el COMIE de forma bianual, así como los perfiles de ResearchGate de los autores más frecuentes en la búsqueda a través de las bases de datos. Se localizaron un total de 165 artículos, de los cuales fueron eliminados 34 debido a que fueron artículos duplicados. 
Posterior a ello siguió una fase de screening donde se revisó el título y resumen de las investigaciones para incluir solo aquellos artículos que revisan el tema de acoso escolar. En esta fase se excluyeron 32 artículos que fueron reportes diferentes de una misma investigación, o bien investigaciones que abordaban el bullying laboral, finalizando con un total de 102 artículos para revisar (Ver Apéndice 1).

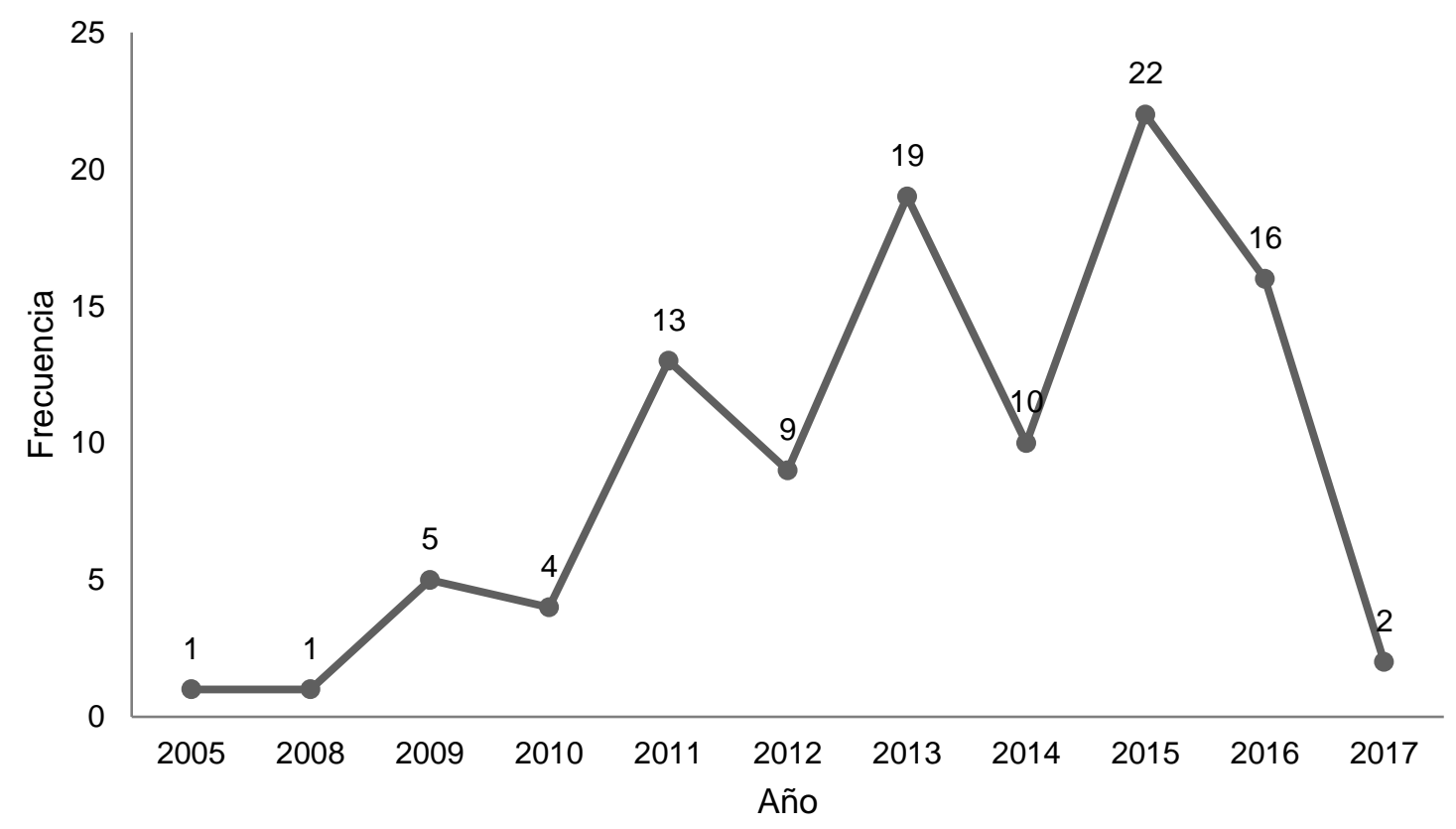

Figura 3. Artículos sobre Acoso Escolar publicados en México

Tal como se puede apreciar en la Figura 3, a partir del 2005 el estudio del acoso escolar en México ha ido creciendo poco a poco. El 57\% de los artículos encontrados fueron publicados en una revista científica, un 30\% en memorias de un congreso y un $13 \%$ como un capítulo de libro. Asimismo, el 79\% de estos artículos fueron investigaciones empíricas, $12 \%$ aportaciones metodológicas (en su mayoría, reportes psicométricos de instrumentos de evaluación) y un $9 \%$ artículos de revisión narrativa/teórica. Con respecto a los diseños y alcances de los estudios publicados, la mayoría de ellos son desde el enfoque cuantitativo correlacional, siguiendo por los descriptivos, y el cualitativo con una metodología fenomenológica (Ver Tabla 3). 
Tabla 3.

Paradigma y diseño de las investigaciones sobre bullying en México.

\begin{tabular}{ccc}
\hline Paradigma/Diseño & Frecuencia & Porcentaje \\
\hline Cualitativo & 17 & 21.5 \\
Estudio de caso & 3 & 3.8 \\
Fenomenológico & 7 & 8.9 \\
Etnográfico & 5 & 6.3 \\
Investigación Acción & 2 & 2.5 \\
Cuantitativo & 61 & 77.2 \\
Descriptivo & 19 & 24.1 \\
Correlacional & 40 & 50.6 \\
Explicativo & 2 & 2.5 \\
Mixto & 1 & 1.3 \\
\hline
\end{tabular}

Por su parte, también se analizó el tipo de acoso escolar, nivel educativo y el reporte de prevalencia que las investigaciones reportan. El bullying tradicional o cara a cara es el más abordado, con un $87.3 \%$ de las investigaciones que reportan haberlo estudiado. El acoso cibernético o ciberbullying también ha sido estudiado, pero en una menor medida, con un $19 \%$ de estudios que abordan esta modalidad de acoso escolar. Con respecto al nivel educativo que reportan, el nivel secundaria es el más frecuente con $48.1 \%$; seguido de bachillerato con $22.8 \%$, primaria con $16.5 \%$, y por último, nivel superior con solo 5 estudios que representan un $6.3 \%$. Finalmente, hay que recalcar que existen estudios que abordan la temática con maestros (6.3\%), e incluso con poblaciones vulnerables o minoritarias como LGBTTTIQ o menores en conflicto con la ley (3.8\%). De todos estos estudios, solo $33(41.8 \%)$ reportan indicadores de prevalencia.

Un aspecto importante por recalcar de todas estas investigaciones es que la mayoría realiza instrumentos ad hoc para la finalidad del estudio. No se encontraron estudios que utilicen instrumentos ampliamente utilizados como el Olweus Bully Victimization Scale o similares. De igual forma, resulta importante destacar el trabajo realizado por ValdésCuervo y su equipo de investigación en Sonora, pues es el grupo con más publicaciones y que de forma consistentemente han estudiado el fenómeno del bullying en México, aunque principalmente enfocados a nivel secundaria y bachillerato. 
Finalmente, a nivel local destacan únicamente los trabajos de Castillo Rocha (Castillo Rocha, 2011; Castillo Rocha y Pacheco Espejel, 2008, 2009) donde explora de forma descriptiva el acoso escolar en Mérida, Yucatán, aportando información valiosa para comprender cómo el temor para acudir a clases es un indicador importante que se asocia con el bullying. Sin embargo, nuevamente estos trabajos han sido realizados solamente con alumnos de secundaria, por lo que su dinámica en otros contextos y niveles educativos se desconoce.

\section{El acoso escolar en la educación superior}

Si bien el estudio del bullying es cuantioso, lo cierto es que la mayoría de las investigaciones han sido realizadas en niveles educativos básicos (primaria, secundaria y bachillerato) no muchos han sido realizados en niveles universitarios (Chapell et al., 2006; Gibb y Devereux, 2014). Lo anterior ha sido señalado por la American Educational Research Association (2013) mencionando que el estudio de bullying en el nivel superior ha sido poco estudiado y que se requiere una mejor comprensión del fenómeno y sus factores en este nivel educativo. Según Dibomicucci Brazil et al., (2015), en una revisión bibliométrica donde analiza los estudios sobre acoso escolar a nivel internacional, solo el 4\% de ellos se enfocó al nivel superior. Este significa que los factores de riesgo mencionados previamente en su mayoría fueron encontrados con muestras de educación básica -especialmente adolescentes-, por lo que resulta relevante hacer una breve revisión sobre los estudios hechos con niveles medio superior y superior. En general, se ha visto que el experimentar acoso escolar durante la educación básica está fuertemente relacionado con experimentarlo durante el bachillerato y la universidad, tanto para víctimas como por los agresores (Chapell et al., 2006; Chen y Huang, 2014; Gibb y Devereux, 2014).

Prevalencia del acoso es el nivel superior: la prevalencia del acoso escolar en estos niveles educativos es variado, yendo desde un $1 \%$ en algunos estudios (Chapell et al., 2004) hasta aproximadamente un 30\% o más en otros (Kowalski, Giumetti, Schroeder, y Reese, 2012; Lindsay y Krysik, 2012; Lucio López y González González, 2012). También se ha estudiado el cyberbullying en el nivel superior, ya que se ha visto como una de las formas más frecuencias de expresión de acoso escolar entre estudiantes universitarios. Se han encontrado prevalencias de cyberbullying que van desde $7.2 \%$ hasta un $43 \%$ para las 
víctimas, y de 7.8\% hasta 8.6\% para los agresores (Chen y Huang, 2014; MacDonald y Roberts-Pittman, 2010; Rospenda, Richman, Wolff, y Burke, 2013; Schenk y Fremouw, 2012)

\section{Principales hallazgos en el nivel superior}

$\mathrm{El}$ acoso escolar en estos contextos debe ser diferenciado de otros comportamientos propios de este nivel educativo, como las novatadas. Sin embargo, suelen estar fuertemente relacionados debido a que en ambos se expresa en forma de acoso o humillación (Allan y Madden, 2012). Usualmente en estos niveles educativos, las formas más comunes de acoso escolar son aquellas que están relacionadas con el acoso indirecto o relacional, como ignorar a compañeros, hablar mal, esparcir rumores, esconder objetos personales, y en su variante directa por medio de insultos o apodos (Hoyos de los Ríos, Llanos Martínez, y Valega Mackenzie, 2012; Mukhtar, 2011); sin embargo, también se ha relacionado con nuevas formas de expresión como el acoso sexual (DeSouza, 2005), o bien agresiones por parte de profesores hacia alumnos (Marraccini, Weyandt, y Rossi, 2015). Hay que hacer mención especial del cyberbullying, ya que es particularmente frecuente el uso de esta modalidad en los niveles medio superior y superior, estando fuertemente relacionado con el bullying cara-a-cara y con el uso de la tecnología y medios de comunicación (Kowalski et al., 2012; Lindsay y Krysik, 2012; Lucio López y González González, 2012; MacDonald y Roberts-Pittman, 2010; West, 2015).

Por su parte, el sexo sigue siendo una variable relacionada con la frecuencia y el tipo de expresión del acoso escolar: los varones siguen siendo más propensos a ser víctimas de acoso escolar, tanto por parte de sus compañeros, como por profesores (Chapell et al., 2004; DeSouza, 2005; Marraccini et al., 2015). Sin embargo, las mujeres no están exentas de ser víctimas o perpetradoras de acoso escolar, ya que como se mencionó antes, suelen expresar la violencia de forma más sutil que los hombres a partir de medios indirectos o mediante el uso de tecnología (Björkqvist et al., 1992; Brock, Oikonomidoy, Wulfing, Pennington, y Obenchain, 2014).

En cuanto a sus consecuencias, de manera semejante al acoso escolar en niveles básicos, se relaciona con problemas de ajuste escolar, pudiendo llevar al abandono escolar por parte de las víctimas (Gibb y Devereux, 2014; Townsend et al., 2008) pero a diferencia 
de éstos, también aparece otro efecto secundario: el consumo y abuso de alcohol (Rospenda et al., 2013; Ttofi et al., 2016). Se ha visto que es común que los estudiantes de éstos niveles educativos suelan afrontar el acoso por medio de la evitación, lo que si bien puede funcionar de manera inicial, a lo largo del tiempo tienen mayores consecuencias negativas debido a que prolonga el estrés (Newman et al., 2011; Schenk y Fremouw, 2012) y ha sido relacionado con ideación e intentos suicidas y problemas de salud mental (Schenk y Fremouw, 2012). Los agresores por otra parte, exhiben un mayor distrés psicológico, tendencias agresivas y suelen involucrarse de forma más frecuente con actos ilegales o criminales (Schenk, Fremouw, y Keelan, 2013).

\section{El acoso escolar a nivel superior en México}

En México, los estudios sobre acoso escolar son mucho menores en nivel superior que en otros niveles educativos inferiores (Valdés Cuervo et al., 2016). El presente trabajo encontró al menos cinco estudios del fenómeno en estudiantes universitarios. A continuación, se explica brevemente cada uno de ellos.

En su estudio de corte cualitativo Velázquez Reyes (2009) relata cómo es el impacto de las agresiones del cyberbullying en la vida de las víctimas, a partir de la perspectiva de ellas mismas. Si bien el estudio no presenta información sobre la prevalencia de este fenómeno a nivel superior, ofrece información valiosa al profundizar sobre estas experiencias. Entre sus hallazgos, destaca la omnipresencia de este tipo de acoso, pues a diferencia del bullying cara a cara o tradicional, las agresiones no ocurren únicamente en el salón de clases, sino también mientras el alumno está en la calle o incluso en su propia casa. Aunado a esto, está la penetración que tienen las tecnologías de la información en la vida de los estudiantes universitarios, ya que a diferencia de otros niveles educativos, usualmente la mayoría de los universitarios tiene un celular, o utiliza cotidianamente el internet (Instituto Nacional de Estadística y Geografía, 2015).

Posteriormente, en 2011, Velázquez Reyes presenta una ponencia en el Congreso Nacional de Investigación Educativa, donde a partir de una metodología cuantitativa ahora ofrece información sobre la prevalencia del uso de tecnología de información para agredir a otros estudiantes en una muestra de alumnos universitarios de la Universidad Autónoma del Estado de México. Sus resultados señalan que más del 90\% de los estudiantes encuestados 
tiene un celular y cerca de un $81 \%$ tiene una computadora en casa. Con respecto al hostigamiento, solamente un $7.35 \%$ reconoció haber ciberacosado a alguien. Sin embargo, un $30.6 \%$ mencionó haber sido acosado vía online.

De igual forma, Ramos Herrera y Vázquez Valls (2011) investigaron sobre el acoso escolar en la Universidad de Guadalajara. Encontraron que cerca de un $20 \%$ de los alumnos encuestados reportan haber observado algún tipo de violencia, siendo las más frecuentes las burlas, insultos, gritos y discusiones (agresión verbal directa); cometido en mayor medida por otros compañeros de clase o bien, en segundo lugar, por profesores. Sin embargo, hay que recalcar que a pesar de que el trabajo menciona que evalúa bullying, el reporte no menciona haber evaluado el desbalance de poder, por lo que resulta más preciso mencionar que es probable que en realidad se haya explorado la violencia escolar en general, y no el acoso escolar.

Por su parte, el estudio realizado por Dorantes Carrión (2015) en la Universidad Veracruzana señala que el cyberbullying es una de las formas de violencia más prevalente en la universidad (12 a 14\%), seguido en segundo lugar la violencia sexual (10 a 11\%). De estos, son las mujeres las que son más vulnerables a sufrir de ciberacoso. La autora hace hincapié en el manejo del ciberacoso para denigrar y esparcir rumores a los alumnos, usando como ejemplo el caso relatado de una mujer. Además, en sus resultados señala que son los estudiantes más jóvenes (de los primeros semestres) lo que se hallan una situación más vulnerable para ser víctimas y perpetradores de ciberacoso.

Finalmente, Prieto Quezada, Carillo Navarro y Lucio López (2015) también exploraron el bullying y cyberbullying a nivel superior en la Universidad de Guadalajara, a través de encuestas y un muestro probabilístico y representativo de más de 2,000 estudiantes. Entre sus resultados encontró que poco más del 80 y del $70 \%$ de los alumnos dedica entre 30 minutos y 4 horas al internet y a utilizar su teléfono inteligente respectivamente. También se identificó que entre el 20 y $40 \%$ de los alumnos han sido víctima de violencia; mientras que un 30\% acepta haber agredido a sus compañeros usando medios electrónicos. Una vez determinado el uso de internet y teléfonos móviles y la presencia de ciberacoso, Prieto Quezada y sus colegas identificaron que las formas más frecuentes en las que las víctimas son ciberacosadas es a través de insultos (38\%) seguidas 
de las burlas (29\%) y expresiones de acoso sexual (23\%). Por su parte, los agresores manifiestan ciberacosar por medio de insultos (27\%), burlas (26\%) y palabras ofensivas en el muro del Facebook de la víctima (14\%).

En este estudio, también evaluaron las formas de bullying tradicional. Los resultados arrojan que la forma más frecuencia de acoso es la exclusión de actividades escolares (35\%), seguido de violencia verbal (25\%), esconder cosas (15\%), acoso sexual (13\%) y robo de pertenencias (12\%). Sin embargo, nuevamente cabe recalcar que la descripción del instrumento no hace mención de la evaluación del componente de desbalance de poder, por lo que posiblemente este estudio también haya evaluado violencia en general, o bien victimización entre iguales. En conclusión, los autores mencionan la importancia de atender la presencia de acoso escolar en contextos universitarios, donde el acoso tradicional sigue sucediendo, y donde incluso es expresado ahora por medio de las tecnologías de la información y comunicación.

Si bien, como se puede apreciar, el estudio del acoso escolar a nivel superior en México es escaso, lo cierto es que las investigaciones actuales aportan información relevante al respecto. Por una parte, se ha demostrado que el acoso escolar en este nivel educativo está presente, y una de sus formas de expresión más habitual es el ciberacoso. Por otro, se concluye que el acoso de tipo físico es menos frecuente que en otros niveles educativos, lo cual concuerda con los estudios sobre agresividad realizados a nivel mundial (Björkqvist et al., 1992). Además, llama la atención que los estudios encontrados pueden haber evaluado conceptos como violencia escolar y victimización entre pares, y no necesariamente el acoso escolar, ya que ninguno de los instrumentos utilizados menciona haber medido el desbalance de poder, componente esencial en el bullying para poder ser diferenciado de los otros términos mencionados (Ybarra et al., 2014).

A pesar de lo anterior, lo cierto es que estas aproximaciones dan una idea muy buena sobre la dinámica del acoso escolar y la violencia en el nivel superior en México, y ponen de manifiesto la necesidad de continuar investigando este fenómeno a nivel universitario, para conocer y comprender de una mejor forma esta situación. 


\section{Capítulo 3.}

\section{Método}

El objetivo de este estudio es identificar los factores asociados al acoso escolar en una institución de nivel superior de la ciudad de Mérida. Para dar respuesta al objetivo planteado se realizará un diseño observacional, de tipo transversal, retrospectivo y con alcance descriptivo y correlacional (Argimon Pallás y Jiménez Villa, 2004; Cozby y Bates, 2015; Hernández Sampieri, Fernández Collado, y Baptista Lucio, 2013). Este tipo de estudio se seleccionó dado que la investigación no hará ningún tipo de intervención o manipulación de variables independientes, simplemente se hará una medición u observación de las variables de interés (Cozby y Bates, 2015). Se considera transeccional, puesto que la medición se realizará en un momento determinado sin la intención de dar seguimiento a los participantes (Argimon Pallás y Jiménez Villa, 2004; Cozby y Bates, 2015). Es retrospectivo dado que se indagará en hechos que ya han pasado antes de la investigación, y no posterior a ella (Argimon Pallás y Jiménez Villa, 2004). Finalmente, en vista de que se trata de determinar la asociación entre los factores de riesgo y protección asociados al acoso escolar, así como describir la prevalencia de éste último, el alcance es tanto de tipo correlacional, como descriptivo (Argimon Pallás y Jiménez Villa, 2004; Hernández Sampieri et al., 2013).

La presente investigación busca identificar los factores de riesgo y protección que están asociados al acoso escolar, por lo que se busca responder al diseño de la Figura 4:

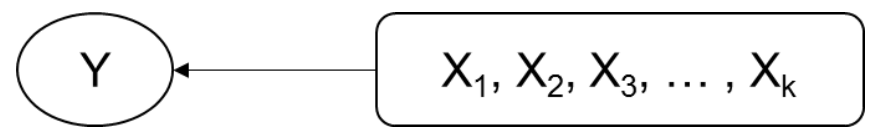

Figura 4. Diseño de análisis del acoso escolar y los $k$ factores asociados.

Donde $Y$ representa a la variable dependiente, en este diseño, el acoso escolar. Tanto el sufrir acoso (victimización), como el realizar conductas de acoso (agresión). Y $X_{i}$ son todos los $k$ factores de riesgo y protección, de los cuales se determinará su asociación con el acoso escolar, y que previamente fueron identificados a partir de la revisión de la literatura. 


\section{Población}

Se considera como población todas las universidades privadas existentes en Mérida, teniendo en su totalidad 12 escuelas, con un total de 14,328 alumnos (7,000 hombres y 7,328 mujeres) registrados en las doce escuelas según los datos de la Asociación Nacional de Universidades e Instituciones de Educación Superior (ANUIES) 2015-2016. Las universidades son caracterizadas según el ANUIES (2014) porque son instituciones educativas

...del tipo superior (generalmente grande o macro) que comprende diversas facultades y que puede agrupar colegios, institutos, departamentos, centros de investigación, escuelas profesionales, etc. Se trata de instituciones que ofrecen por lo menos cinco planes de estudios de licenciatura, o posgrado, en tres distintas áreas del conocimiento, una de las cuales debe ser necesariamente del área de humanidades (p. 10).

\section{Muestra}

La muestra fue conformada por una universidad ubicada en Mérida con una totalidad de 445 alumnos (209 hombres y 236 mujeres). Se utilizó una muestra no probabilística de tipo intencional, pues solamente se tomaron en cuenta a los estudiantes que habían cursado al menos un semestre completo en la institución educativa. De toda la matrícula escolar, se convocaron a participar a todos los alumnos de la escuela, exceptuando a los alumnos de primer semestre, pues su condición de nuevo ingreso limita el proceso de socialización necesario para que se identifique correctamente el acoso escolar.

La muestra final estuvo comprendida por 200 estudiantes, de los cuales el 55.7\% fueron mujeres $(n=108)$ y un $44.3 \%$ hombres $(n=86)$. Un $54.7 \%$ de la muestra fue del turno matutino, y el restante $45.3 \%$ del turno vespertino. El promedio de edad de los participantes fue de 21.4 años con una desviación estándar de 2.44 años. En cuanto las licenciaturas participantes, estuvieron conformadas por las licenciaturas en Nutrición (33\%), Enfermería (17\%), Psicología (15\%), Negocios internacionales (9.5\%), Derecho (9.5\%), Gastronomía (8.5\%), Ventas y mercadotecnia (4.5\%) y Administración (6\%). Se 
tuvo la participación de alumnos del semestre tercero (26\%); cuarto (14\%); quinto (26.5\%); sexto (1\%); séptimo (25.5\%) y décimo (7\%).

\section{Escenario}

La escuela donde se realizó la presente investigación está ubicada en la zona noreste de la ciudad de Mérida. La escuela imparte diez programas de estudios, Ingeniería en Sistemas Computacionales; y las Licenciaturas en Administración, Derecho, Negocios Internacionales, Ventas y Mercadotecnia, Educación, Gastronomía, Enfermería, Nutrición y Psicología. Los programas son impartidos tanto en horario matutino como vespertino, y cada programa cuenta con su propio coordinador que atiende y supervisa tanto a los docentes como el progreso de los alumnos.

\section{Variables e Instrumentos}

El proyecto toma en consideración el acoso escolar, así como diversos factores de riesgo y protección que están asociados a él. A continuación, se especifican las variables del estudio, su conceptualización, y la forma en la que fueron operacionalizados para su medición.

\section{Acoso Escolar}

Conceptualmente se define el acoso escolar o bullying como el acto que sufre una persona cuando "es expuesto a acciones negativas por una o más personas en repetidas ocasiones a lo largo del tiempo, y donde se excluyen casos en los cuales dos jóvenes de igual fuerza física o fortaleza psicológica se agreden” (Olweus, 1993, p. 9).

Operacionalmente, el acoso escolar fue evaluado a partir del California Bullying Victimization Scale-CBVS (Felix et al., 2011), un instrumento que previamente ha sido reportado como uno de los instrumentos que mide los tres elementos que componen el concepto del acoso escolar (Felix et al., 2011; Vivolo-Kantor et al., 2014), y que además evalúa el acoso escolar sin tener que ofrecer una definición del mismo, situación que varios estudios han señalado como favorable para no afectar los cálculos de prevalencia (Modecki et al., 2014; Vivolo-Kantor et al., 2014). El CBVS incluye siete reactivos que evalúan conductas de victimización o agresión, como ser golpeado, esparcir rumores, ser ignorado, entre otros. Las conductas son evaluadas a través de una escala de cinco puntos $(0=$ nunca, 1=una vez el mes pasado; $2=2$ o 3 veces el mes pasado; $3=$ Una vez a la semana; 4= varias 
veces a la semana). Para evaluar el componente del desbalance de poder, el CBVS también les pregunta a los estudiantes qué tan populares, inteligentes, y fuertes son (en otras características relevantes), al compararse con la persona que los agrede o al compararse con la víctima que agreden. El CBVS permite determinar el bullying al identificar aquellos casos que respondieron haber experimentado algún tipo de agresión al menos 2 o 3 veces durante el último mes, y que además manifiestan al menos un tipo de desbalance de poder entre la víctima y el agresor. En estudios previos, el CBVS tiene una confiabilidad testretest de 0.71 (Felix et al., 2011), y manifiesta tener una consistencia interna (alfa de Cronbach) que va de 0.72 a 0.83 (Atik y Guneri, 2012; You et al., 2008). El CBVS fue piloteado previamente en una muestra de estudiantes mexicanos y se encontró una consistencia interna de 0.81 para la escala de victimización, y de 0.87 para la escala de agresión. También se recibió retroalimentación por parte de los estudiantes a través de un grupo de enfoque; a partir de ello se corrigieron palabras o frases para una mejor comprensión del instrumento (Vega Cauich y Cisneros-Cohernour, 2017).

\section{Sexo}

Conceptualmente, según la definición proporcionada por la Real Academia Española, se considera sexo la condición biológica de ser hombre o mujer. Operacionalmente fue evaluada en el apartado de los datos sociodemográficos de la batería de pruebas al preguntarles a los participantes si son hombres o mujeres. La variable fue considerada en su inclusión, debido a que los estudios previos, señalan al sexo como una variable significativamente asociada al acoso escolar, siendo los hombres más propensos que las mujeres a sufrir y realizar actos de agresión (Álvarez-García et al., 2015; Björkqvist et al., 1992; Sentse, Kretschmer, y Salmivalli, 2015).

\section{Edad}

Conceptualmente, según la definición de la Real Academia Española, se considera como edad al tiempo en años, en los que ha vivido la persona. Operacionalmente, esta variable fue evaluada al preguntar en el apartado de los datos sociodemográficos la edad en años que tienen los participantes. La variable fue considerada en vista de la moderación que tiene la edad en la expresión y recepción de conductas violentas. A medida que se alcanza la adolescencia, aumenta la probabilidad de expresar y sufrir bullying físico, para 
posteriormente disminuir conforme se llega a la adultez joven (Álvarez-García et al., 2015; Sentse et al., 2015).

\section{Ser diferente}

Para el criterio de ser diferente, se consideraron tres opciones importantes de forma local: 1) tener ascendencia indígena; 2) ser de origen migrante; y 3) tener una orientación sexual diferente a la heterosexual. Esto fue considerado así porque estudios previos señalan que la etnia y origen son factores de riesgo para sufrir o expresar conductas de acoso escolar (Álvarez-García et al., 2015).

Ascendencia indígena. Se considera tener ascendencia indígena cuando una persona tiene ancestros de las poblaciones originarias de América. En esta investigación, como indicador, se consideró tener ascendencia maya por su importancia cultural y local en nuestro contexto, pues los estudios han señalado que la población maya de Yucatán es uno de los sectores de la población que sufre más discriminación (Comisión de Derechos Humanos del Estado de Yucatán, 2014; Echeverría Echeverría, 2016). Esta variable ha sido evaluada a partir de la presencia de apellidos mayas, debido a que, por tradición, los apellidos pasan de generación en generación, y en el caso de México, incluye tanto el apellido del padre como de la madre. Operacionalmente, esta variable fue medida a partir de identificar la cantidad de apellidos mayas que tienen los participantes (ninguno, uno o ambos), tal como otros estudios han realizado con anterioridad (Vázquez-Vázquez et al., 2013).

Origen migrante. El origen migrante toma en consideración el origen de la persona en relación con dónde nació. Esta variable fue tomada en consideración pues según la Encuesta Estatal sobre Discriminación, en Yucatán, un 44.9\% de los encuestados considera que las personas que provienen de otra parte de la república sufren discriminación (Comisión de Derechos Humanos del Estado de Yucatán, 2014). Operacionalmente, se midió el origen migrante al preguntar en el apartado de los datos sociodemográficos si el participante es originario de Mérida, el interior del estado, otro estado de la república, o bien otro país.

Orientación sexual. La orientación sexual puede definirse como "la atracción amorosa, afectiva, física y sexual que siente una persona, según su sexo. Esta orientación 
puede ser heterosexual, homosexual o bisexual y no es una decisión consciente y meditada" (Lozano Verduzco y Diaz Loving, 2010, p. 136). El tener una orientación no heterosexual ha sido considerado un factor de riesgo para sufrir acoso escolar (Álvarez-García et al., 2015; Baruch-Dominguez, Infante-Xibille, y Saloma-Zuñiga, 2016; Espelage et al., 2017, 2008), es por ello que se consideró incluir esta variable utilizando los ítems que evalúan orientación sexual del modelo de preferencias genéricas validado previamente en México, donde se cuestiona a los participantes si se definen como gay/lesbiana, heterosexual o bisexual en una escala de seis puntos que va de 5 "siempre" a 1 "nunca". La escala tiene un alfa relativamente pequeño $(0.41)$; sin embargo, los estudios de validez confirman que se correlaciona de forma significativa con otros indicadores asociados a la orientación sexual (Lozano Verduzco y Diaz Loving, 2010), lo que señala evidencia de validez.

\section{Empatía}

Conceptualmente, la empatía puede definirse como "una emoción moral, y es considerada como una respuesta afectiva que hace posible la comprensión de la condición o estado emocional de otra persona” (Merino-Soto y Grimaldo-Muchotrigo, 2015, p. 263). Esta variable ha sido previamente asociada con el acoso escolar de forma significativa (Álvarez-García et al., 2015; Gini et al., 2007; Muñoz et al., 2011).

De forma operacional, se consideró una medición de empatía a la puntuación que los participantes obtengan en la Escala Básica de Empatía (Jolliffe y Farrington, 2006a; Merino-Soto y Grimaldo-Muchotrigo, 2015). La Escala Básica de Empatía está conformada por nueve reactivos que se agrupan en dos dimensiones: empatía afectiva (ítems 1, 2, 3 y 6)

y empatía cognitiva (ítems 4, 5, 7, 8 y 9), que se responden a partir de una escala tipo Likert de cinco opciones de respuesta, que va de totalmente en desacuerdo (1), hasta totalmente de acuerdo (5). La consistencia interna reportada en población hispanohablante va de 0.63 a 0.76 (Merino-Soto y Grimaldo-Muchotrigo, 2015). El instrumento también fue incluido en el estudio piloto del CBVS, donde se obtuvieron valores de consistencia interna de 0.77 y 0.63 para las escalas de empatía cognitiva y afectiva respectivamente.

\section{Agresión}

En este trabajo, se toma en consideración el constructo de agresión que puede ser originada de dos formas: agresión proactiva, y agresión reactiva. Conceptualmente, la 
denominada agresión reactiva describe aquellas conductas que se suscitan como reacción a una provocación o a una amenaza percibida (real o imaginada); mientras que la agresión proactiva incluye acciones desencadenadas intencionalmente para resolver conflictos o para conseguir beneficios, recompensas o refuerzos valorados por el agresor (Andreu, Peña, y Ramirez, 2009, p. 38). Esta variable ha sido asociada de forma significativa a la expresión del bullying por parte de los agresores (Álvarez-García et al., 2015).

Operacionalmente, la agresión fue medida a partir de las puntuaciones que los participantes obtengan en el Cuestionario de Agresión Reactiva y Proactiva (Andreu et al., 2009; Raine et al., 2006). Este cuestionario está conformado por 23 reactivos basados en la motivación instrumental (proactiva) y la hostil (reactiva). Los ítems tienen un formato de respuesta de escala de tres puntos según la frecuencia de las situaciones $(0=$ nunca, $1=$ algunas veces; 2 = a menudo). En su versión original, en inglés, la consistencia interna oscila entre 0.81 hasta 0.91 (Raine et al., 2006). En su versión en español, tiene una consistencia interna que va de 0.84 hasta 0.91 para la escala global (Andreu et al., 2009). En el estudio piloto llevado a cabo, el instrumento obtuvo valores de consistencia interna de 0.89 para la escala general, 0.80 para la escala de agresión reactiva, y 0.82 para la escala de agresión proactiva.

\section{Impulsividad}

Conceptualmente, la impulsividad puede ser considerada como:

Un estilo de respuesta caracterizado por responder rápido y sin demasiado análisis, y que se genera cuando los individuos se enfrentan a problemas que cuentan con varias opciones de solución, pero solo una de ellas es la correcta, por esta razón, se relaciona con procesos de evaluación y producción de alternativas (RiañoHernández, Guillen Riquelme, y Buela-Casal, 2015, p. 1078).

Esta variable ha sido asociada de forma significativa con los agresores, pues se ha visto que éstos son más impulsivos y tienden a exhibir más conductas agresivas (ÁlvarezGarcía et al., 2015).

Operacionalmente, se midió la impulsividad a partir de los reactivos 1, 2 y 3 de la sección 4.4 de la Encuesta de Cohesión Social para la Prevención de la Violencia y la Delincuencia (ECOPRED) 2014 (Instituto Nacional de Estadística y Geografía, 2014). Si 
bien la escala no ofrece un índice de consistencia interna como tal, la ventaja del instrumento es que ha sido adaptado de forma representativa en toda la república mexicana, con una muestra de 97,754 jóvenes de 12 a 29 años; razón por la que se considera válida su utilización en el presente estudio. En el estudio piloto llevado a cabo, la escala formada por estos tres ítems tuvo una consistencia interna de 0.72 , considerada como satisfactoria.

\section{Actitudes pro-criminales}

Conceptualmente, las actitudes pro-criminales se refieren a aquellas actitudes que apoyan la conducta criminal y delictiva (Andrews y Bonta, 2010). Esta variable también se asocia con los agresores, encontrando que aquellos jóvenes que tienen actitudes procriminales suelen realizar más conductas asociadas al acoso escolar (Álvarez-García et al., 2015; Banse et al., 2013; Herrenkohl et al., 2000). Las actitudes pro-criminales suelen expresarse en tres formas: justificación de la violencia, identificación criminal (como el admirar a criminales) y el rechazo de la autoridad (Andrews y Bonta, 2010). En este proyecto, se abordará desde la última forma, al evaluar el rechazo de la autoridad, incluyendo a la autoridad escolar.

Operacionalmente, las actitudes pro-criminales fueron medidas por medio de la puntuación que los participantes obtengan al responder la Escala de Actitudes hacia la Autoridad Institucional en adolescentes AAI-A (Cava, Estévez López, Buelga Vázquez, y Musitu Ochoa, 2013). La escala consta de 10 reactivos relativos a la actitud de los jóvenes hacia el profesorado y hacia la policía como figuras de autoridad, y hacia las reglas escolares y la ley como sistemas normativos. La escala se responde mediante opciones de respuesta tipo Likert de cuatro puntos $(1=$ nada de acuerdo; $2=$ algo de acuerdo; $3=$ bastante de acuerdo; 4 = totalmente de acuerdo). La escala ha sido desarrollada con población hispanohablante tanto de España como de México, y muestra una consistencia interna que va de 0.74 a 0.75 . Los análisis de factores de la escala señalan que subyacen dos dimensiones, el primero concerniente a la "Actitud positiva hacia la autoridad" (ítems 1, 2, 5, 6 y 7), y el segundo a la "Actitud positiva hacia la transgresión" (ítems 4, 8, 9 y 10).

\section{Desempeño escolar}

El desempeño escolar ha sido un tema difícil de definir y evaluar; sin embargo, las calificaciones son ampliamente aceptadas como un indicador del desempeño escolar. Se ha 
visto que incluso se correlacionan de forma significativa con otros indicadores del desempeño escolar, como pueden ser las pruebas de aprovechamiento (Carrillo Regalado y Ríos Almodóvar, 2013; Gonzalez, 1988; Tuñón y Poy, 2016). En este trabajo, el desempeño escolar fue operacionalizado a partir de las calificaciones que los alumnos reporten haber obtenido en el curso inmediato anterior.

\section{Popularidad}

Según la Real Academia Española, se puede definir conceptualmente que alguien es popular cuando se es estimado o, al menos, conocido por el público en general. No se identificaron instrumentos que evalúen la popularidad de los alumnos, por lo que se creó un reactivo autoinformado que fue incluido en la sección de datos sociodemográficos. En él, se evalúa la popularidad percibida del alumno al preguntarle cómo se considera en comparación con sus demás compañeros, brindando opciones de respuesta en una escala de cuatro puntos tipo Likert $(1=$ nada popular, $2=$ poco popular, $3=$ algo popular, $4=$ muy popular).

\section{Calidad de la relación con el profesor}

Conceptualmente, esta variable se define como el apoyo que se tiene de los profesores, y el buen trato por parte del personal de la escuela, y cómo éste es percibido por parte del alumno (Álvarez-García et al., 2015). La variable ha sido asociada con el acoso escolar, mostrando que el tener profesores que brindan apoyo a los alumnos, es un factor de protección para las víctimas (Casas, Del Rey, y Ortega-Ruiz, 2013).

Operacionalmente, se consideró como calidad de la relación con el profesor la puntuación obtenida por los participantes en la Escala de Clima Escolar (López, Bilbao, Ascorra, Moya, y Morales, 2014), específicamente en la dimensión de Apoyo Social. La Escala de Clima Escolar está compuesta por 18 ítems, que se responden en una escala tipo Likert con cinco opciones de respuesta $(1=$ totalmente en desacuerdo, hasta $5=$ totalmente

de acuerdo). Los análisis señalan que los reactivos se agrupan en tres factores: apoyo social, normas claras y participación. La escala fue desarrollada y adaptada con población hispanohablante, y reporta niveles de consistencia interna considerados como buenos $(\alpha=$ 0.89). La escala de Apoyo social reporta una consistencia interna de 0.84. En el estudio 
piloto llevado a cabo esta escala reportó una consistencia interna de 0.79 , considerada como satisfactoria.

\section{Manejo de la coexistencia en el centro (claridad de las reglas)}

Conceptualmente, esta variable puede ser entendida como la percepción del alumno sobre la claridad y justicia de las reglas del centro escolar (Álvarez-García et al., 2015); y se ha visto que esta variable se relaciona de forma significativa con el acoso escolar (Álvarez-García et al., 2015; López et al., 2014).

Operacionalmente, se consideró como un indicador del manejo de la coexistencia en el centro la puntuación obtenida por los participantes en la Escala de Clima Escolar (López et al., 2014), específicamente al tomar las puntuaciones de la subescala de normas claras. Como ya se mencionó, la Escala de Clima Escolar está compuesta por 18 ítems, que se responden en una escala tipo Likert con cinco opciones de respuesta $(1=$ totalmente en desacuerdo, hasta $5=$ totalmente de acuerdo). Los análisis muestran que se agrupan en tres factores: apoyo social, normas claras y participación. La dimensión de normas clara reporta una consistencia interna de 0.81 en su estudio original. En el estudio piloto llevado a cabo, la escala de normas claras reporta un índice de 0.74 en su consistencia interna.

\section{Satisfacción escolar}

Conceptualmente, la satisfacción escolar puede definirse como "la evaluación cognitivo-afectiva de la satisfacción con las experiencias escolar” (Luna Soca, 2012, p. 73). Esta variable se menciona como un indicador de la posible existencia de acoso escolar (Álvarez-García et al., 2015).

Operacionalmente, se medió la satisfacción escolar a partir de las preguntas realizadas por Luna Soca (2012) en su estudio sobre satisfacción escolar. La escala considera cinco preguntas que evalúan la satisfacción de los participantes con respecto su relación con los compañeros de clase, con el profesor, con su vida como estudiante, con el centro escolar y con las calificaciones. Las preguntas se responden con una escala que va de $0=$ totalmente en desacuerdo, hasta $10=$ totalmente de acuerdo. En su adaptación al español, reporta una consistencia interna satisfactoria $(\alpha=0.75)$. En el estudio piloto llevado a cabo su consistencia interna también fue satisfactoria $(\alpha=0.84)$. 


\section{Estilos de Crianza}

Conceptualmente, los estilos de crianza pueden ser definidos como "el conjunto de actividades que los padres practican con sus hijos, así como la administración de los recursos disponibles orientados a apoyar el proceso de desarrollo psicológico" (Gaxiola Romero, Frías Armenta, Cuamba Osorio, Franco Betanzos, y Olivas Salido, 2006, p. 116). Una de las aproximaciones más utilizada es la medición de los estilos de crianza basada en dimensiones, específicamente dos: el control (vigilancia) y apoyo/comunicación de los padres con los hijos (Hoeve et al., 2009), que en su combinación dan como resultado los estilos de crianza propuestas originalmente por Diana Baumrid (1971): negligente, democrático, autoritario y permisivo.

Operacionalmente, se evaluaron los estilos de crianza a partir de las 21 preguntas de la sección 2.5 de la Encuesta de Cohesión Social para la Prevención de la Violencia y la Delincuencia (ECOPRED) 2014 (Instituto Nacional de Estadística y Geografía, 2014). Si bien la escala no ofrece un índice de consistencia interna como tal, como ya se mencionó, la ventaja del instrumento es que ha sido adaptado en una muestra representativa en toda la república mexicana, con jóvenes de 12 a 29 años. En el estudio piloto llevado a cabo, esta escala reporta un índice de consistencia interna de 0.75 .

\section{Violencia familiar}

Conceptualmente, se considera violencia familiar a "todas las formas de abuso que tienen lugar en las relaciones entre los miembros de una familia" (Corsi, 1994, p. 2). Según Corsi (1994) se denomina relación de abuso a aquella forma de interacción que, enmarcada en un contexto de desequilibrio de poder, incluye conducta de una de las partes que, por acción o por omisión, ocasionan daño físico y/o psicológico a otro miembro de la relación.

Operacionalmente, se evaluó la violencia familiar a partir de las 11 preguntas de la sección 3.5 de la Encuesta de Cohesión Social para la Prevención de la Violencia y la Delincuencia (ECOPRED) 2014 (Instituto Nacional de Estadística y Geografía, 2014). Esta sección evalúa diferentes formas de abuso que van desde el abuso físico (p. ej. Te empujan, pellizcan o jalonean bruscamente), hasta la negligencia (p. ej., no le dan importancia y no te dicen nada). Todo ello previamente adaptado en una muestra representativa en toda la 
república mexicana, con jóvenes de 12 a 29 años. En el estudio piloto llevado a cabo, esta escala reporta un índice de consistencia interna de 0.84 .

\section{Asociación delictiva}

Conceptualmente, se considera como una asociación delictiva cuando la persona manifiesta el tener amigos delincuentes, es decir, amigos que cometen crímenes o delitos, sean éstos violentos o no (Andrews y Bonta, 2010). Según estos autores, la asociación con amigos delincuentes ha sido uno de los predictores de conducta violenta más consistentes, pues una de las consecuencias de asociarse con delincuentes, es que aumenta la oportunidad para aprender una variedad de comportamientos criminales, especialmente comportamiento antisocial encubierto.

Operacionalmente, la asociación delictiva fue evaluada a partir de los reactivos 5 a 17 de la sección 4.3 de la Encuesta de Cohesión Social para la Prevención de la Violencia y la Delincuencia (ECOPRED) 2014 (Instituto Nacional de Estadística y Geografía, 2014). Esta sección evalúa diferentes formas de influencia de pares con actitudes pro-criminales, tales como consumir sustancias, maltratar personas y animales, vandalismo o ser arrestado. La versión de la ECOPRED 2014 se responde a partir de un estilo de respuesta dicotómico de sí o no; el cual, como ya se mencionó, ha sido previamente aplicado en una muestra representativa de jóvenes mexicanos. En el estudio piloto llevado a cabo, esta escala reporta un índice de consistencia interna de 0.76 .

\section{Uso de las Tecnologías de la Información y la Comunicación}

Conceptualmente, para esta variable se considera la frecuencia en el uso de diversos servicios tecnológicos. Si bien, esta variable no ha sido consistentemente asociada con el acoso escolar en las revisiones de la literatura (Álvarez-García et al., 2015), se decidió incluirla puesto que se ha visto que el ciberacoso es una modalidad especialmente prevalente entre los adultos jóvenes universitarios (Francisco, Veiga Simão, Ferreira, y Martins, 2015; Gahagan, Vaterlaus, y Frost, 2016; Kowalski et al., 2012; Schenk y Fremouw, 2012; Schenk et al., 2013).

Operacionalmente la frecuencia de uso fue evaluada a través de una escala construida para tal propósito, donde se cuestiona a los participantes que tan frecuentemente usan diversas TIC (computadora, internet, Facebook, WhatsApp, correo electrónico, entre 
otros $)$, proveyendo una escala de respuesta de cinco puntos $(1=$ nunca $/$ no tengo; $2=$ una vez al mes; 3 = una vez a la semana; 4 = una vez al día; 5 = varias veces al día). La escala fue probada previamente en un estudio piloto, donde obtuvo una consistencia interna satisfactoria de 0.78 .

\section{Recolección de datos}

Previo a la realización del estudio se realizaron dos estudios piloto para evaluar la pertinencia de los instrumentos. El instrumento principal, el California Bullying Victimization Scale (CBVS), fue evaluado a través de un grupo de enfoque para identificar la pertinencia del significado de las palabras utilizadas en los reactivos (Vega Cauich y Cisneros-Cohernour, 2017). Posterior a las mejoras realizadas a partir de la retroalimentación del grupo de enfoque, el CBVS fue evaluado en conjunto con los demás instrumentos en una muestra de 44 estudiantes de licenciatura en educación para evaluar la consistencia interna de los instrumentos. Finalmente, se realizaron los cambios necesarios para armar la batería de instrumentos que fue utilizada en la presente investigación. En el Apéndice 2, se pueden apreciar una tabla donde se especifica la variable, su definición conceptual, su forma de medición (definición operacional) y los ítems y páginas que corresponden del instrumento.

La información fue recabada a través de la técnica de encuestas en su modalidad de lápiz y papel (Cozby y Bates, 2015), a través de la inclusión de todos los instrumentos en una sola batería de pruebas. Se pidió la confirmación en el centro escolar para aplicar los cuestionarios en una sola sesión en los diferentes grupos, tanto en turno matutino como vespertino. La aplicación por cada salón duró aproximadamente 30 minutos y fue realizada durante dos días (del 20 al 21 de septiembre de 2017). La información fue recolectada en el horario de clases para asegurar la asistencia y participación de la mayor cantidad de alumnos posibles. A todos los alumnos se les expuso brevemente la finalidad del estudio, y se les brindó una hoja de consentimiento informado (Ver Apéndice 3) dónde los alumnos manifestaron su participación voluntaria e informada en el estudio mediante su firma. Posterior a la recolección de datos, la información fue devuelta al(los) aplicador(es), para su captura. 


\section{Análisis de datos}

Los análisis estadísticos fueron realizados utilizando el software SPSS versión 24 para Windows y fueron realizados en tres etapas: utilizando estadísticos descriptivos, realizando pruebas de hipótesis y considerando modelos predictivos. Sin embargo, cabe recalcar que para la prueba no paramétrica multivariada, se utilizó el paquete MNM del Software R, diseñado especialmente para tal propósito (Nordhausen y Oja, 2011; Oja, 2010).

En la primera etapa se utilizaron estadísticos descriptivos que responderán al primer objetivo de esta investigación, para poder describir la prevalencia del acoso escolar en la muestra seleccionada. Para ello se utilizaron porcentajes para describir tanto la prevalencia de victimización como de agresión, así como los tipos más frecuentes de agresiones en cada caso, los lugares donde ocurre el acoso y la respuesta institucional ante ello.

Posteriormente se realizaron los análisis para comprobar las hipótesis planteadas en cuanto a la diferencia del tipo de acoso escolar con respecto al sexo; y para identificar la relación existente entre el acoso escolar y la edad. Para el primer caso, se realizaron análisis no paramétricos debido a que las variables son a nivel ordinal. Se compararon en hombres y mujeres las diferencias existentes en la expresión de la agresión y victimización tanto directa como indirecta por del estadístico $\mathrm{Q}^{2}$, el cual es una extensión multivariada no paramétrica de la prueba U de Mann-Whitney-Wilcoxon (Oja, 2010) para contrastar de forma simultánea la diferencia entre todos los ítems de agresión directa o indirecta entre hombres y mujeres. Seguidamente, también se hizo un análisis por cada ítem de forma individual por medio de la prueba U de Mann-Whitney-Wilcoxon. Por otra parte, también se analizó la relación existente entre la agresión y victimización tanto directa como indirecta con la edad, por medio de una correlación no paramétrica de Spearman.

Finalmente se utilizaron modelos predictivos, específicamente se utilizaron dos modelos: uno que permitió identificar las variables asociadas a la presencia de victimización y otro que permitió identificar las variables asociadas a la presencia de agresión. Dado que las variables dependientes son de tipo nominal dicotómico, para su análisis se utilizó un modelo de regresión logística (Hosmer, Lemeshow, y Sturdivant, 2013; Pituch y Stevens, 2016). Se decidió el uso de dos modelos, uno para víctimas y uno 
para agresores, donde se incluirán las variables en pasos sucesivos tomando en consideración su pertenencia a los diferentes niveles propuestos por el modelo ecológico (Álvarez-García et al., 2015), tal como se describe en la Tabla 4. De tal forma que no solamente se analizará la aportación para predecir el acoso escolar de las variables de forma individual, sino también la aportación de los diferentes niveles propuestos por el modelo ecológico a partir del análisis de coeficientes de regresión parciales obtenidos.

Tabla 4.

Planificación de las variables a incluir en los modelos.

\begin{tabular}{cccc}
\hline $\begin{array}{c}\text { Factores Individuales } \\
\text { (Bloque-Paso 1) }\end{array}$ & $\begin{array}{c}\text { Factores escolares } \\
\text { (Bloque-Paso 2) }\end{array}$ & $\begin{array}{c}\text { Factores } \\
\text { familiares } \\
\text { (Bloque-Paso 3) }\end{array}$ & $\begin{array}{c}\text { Factores } \\
\text { comunitarios } \\
\text { (Bloque-Paso 4) }\end{array}$ \\
\hline $\begin{array}{c}\text { Sexo } \\
\text { Edad }\end{array}$ & $\begin{array}{c}\text { Desempeño escolar } \\
\text { Popularidad }\end{array}$ & $\begin{array}{c}\text { Estilos de crianza } \\
\text { Violencia } \\
\text { familiar }\end{array}$ & $\begin{array}{c}\text { Asociación delictiva } \\
\text { Uso de TIC }\end{array}$ \\
migración, \\
orientación). & Calidad de la \\
Empatía & relación con el & & \\
Agrofesión & Manejo de la & & \\
Impulsividad & coexistencia en el & & \\
Actitudes pro- & centro & & \\
criminales & Satisfacción escolar & & \\
& & & \\
\hline
\end{tabular}

Finalmente se recurrió a un modelo utilizando el proceso de inclusión de variables con pasos hacia atrás (stepwise), con la intención de obtener el modelo más sencillo posible, donde únicamente se incluyeron aquellas variables que permiten discriminar de forma específica la victimización y la agresión por bullying. El modelo resultante fue utilizado para obtener la puntuación de cada sujeto y poder evaluar sí, en conjunto, las variables resultantes discriminan entre víctimas y no víctimas; y entre agresores y no agresores, más allá de la simple casualidad. Finalmente, la puntuación obtenida también fue evaluada por medio de la Curva ROC, para identificar el poder predictivo de las variables en su conjunto. 


\section{Consideraciones éticas}

La investigación fue previamente aprobada por el Comité de Examen Profesional, de Especialización y de Grado de la Facultad de Educación de la Universidad Autónoma de Yucatán, con el oficio CEPEG-067-016. Se consideró además el cuidar el anonimato por parte de los participantes debido a que la investigación abordó temas sensibles como el acoso escolar, la orientación sexual o la violencia familiar, por lo que todos los instrumentos fueron totalmente anónimos. Además, se planteó que la participación sea totalmente voluntaria, explicándose detalladamente la finalidad y alcance de la investigación a cada participante y recolectando una carta de consentimiento informado firmada por cada uno de ellos. Finalmente, también se resguarda la confidencialidad del centro educativo participante, al omitir cualquier información que pudiese identificar al centro, su personal o sus alumnos. 


\section{Capítulo 4.}

\section{Resultados}

A continuación, se presentan los resultados obtenidos a partir de la metodología previamente planteada. Estos han sido presentados en el orden de presentación de los objetivos del estudio, comenzando por los estadísticos descriptivos (prevalencias), donde se describe la principal variable del estudio -acoso escolar-, para posteriormente presentar los análisis inferenciales que analizan la relación del acoso escolar con las demás variables asociadas.

\section{Análisis descriptivo}

\section{Prevalencia general del Acoso Escolar}

De forma inicial, se planteó identificar la prevalencia del acoso escolar tanto para víctimas como para agresores. En la Figura 5, se observa que 2 de cada 10 alumnos de la muestra obtenida ha experimentado algún evento de acoso escolar en el rol de víctima.

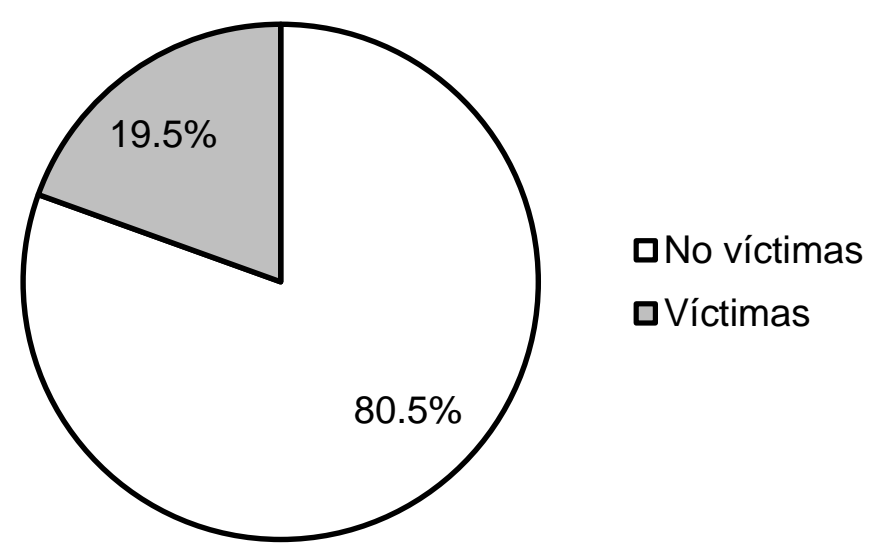

Figura 5. Prevalencia de víctimas de acoso escolar.

Con respecto a los agresores, tal como se aprecia en la Figura 6, aproximadamente un $13 \%$ de los alumnos de la muestra manifiesta haber agredido a algún compañero de forma reiterada en el último mes. 


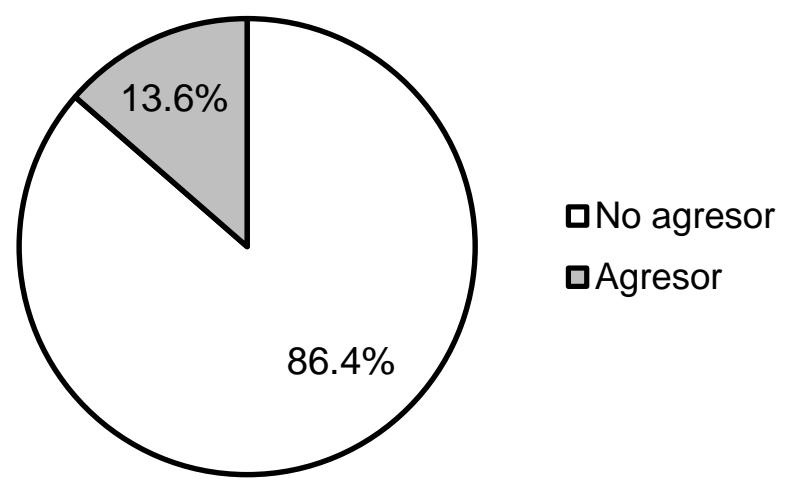

Figura 6. Prevalencia de agresores de acoso escolar.

También se analizó la relación víctima-agresor para identificar aquellos alumnos que fueron víctimas, agresores o ambos. Tal como se aprecia en la Figura 7, la mayor proporción corresponde a las víctimas, seguida de las víctimas-agresores, y finalmente los agresores. Así mismo, se puede apreciar que 1 de cada 4 alumnos de la muestra estuvo involucrado en alguna forma de acoso escolar, ya sea como víctima, o bien como victimario.

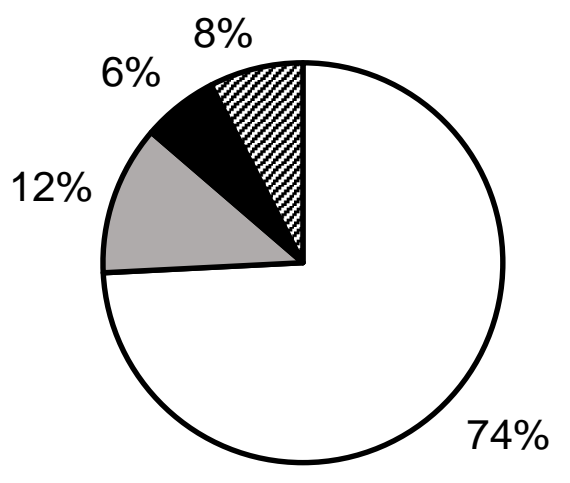

口Sin Acoso

口Víctima

- Agresor

- Víctima-

Agresor

Figura 7. Prevalencia de víctimas, agresores y víctimas-agresores de acoso escolar.

\section{Prevalencia de víctimas y agresores por sexo}

Considerando las diferencias existentes entre sexo, también se consideró pertinente un análisis según el sexo de los participantes. En la Figura 8 se puede apreciar con respecto 
a las víctimas, las mujeres parecen tener una proporción ligeramente mayor de víctimas que los hombres. Sin embargo, estas diferencias no fueron estadísticamente significativas $\left(\chi^{2}=\right.$ $.681, \mathrm{gl}=1, p=.479)$.

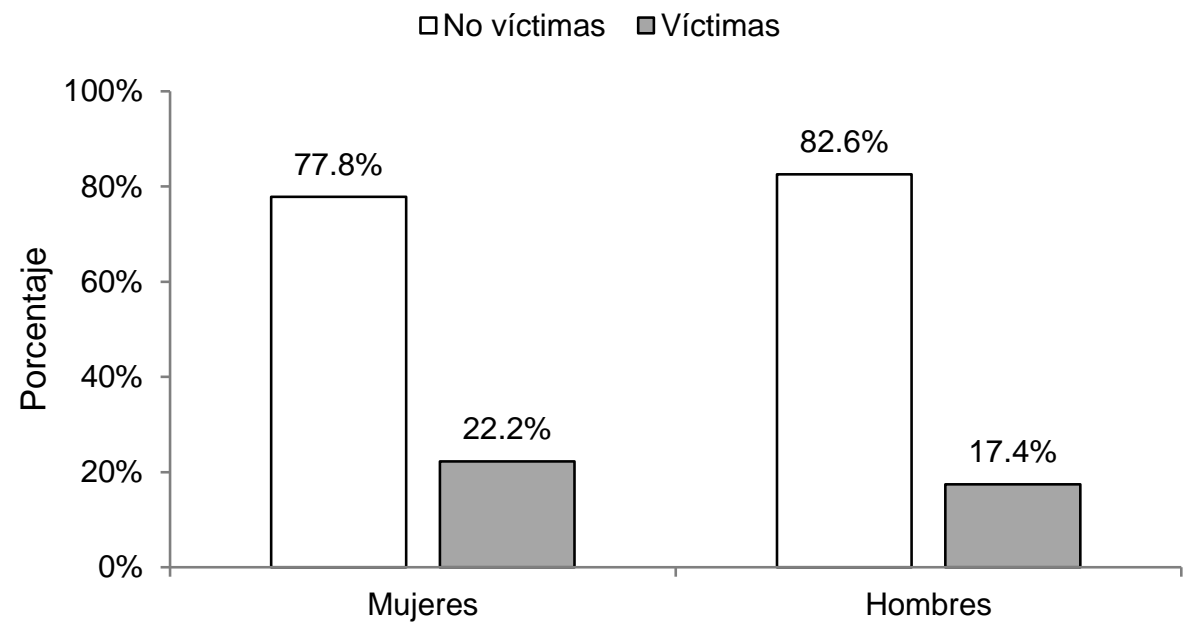

Figura 8. Prevalencia de víctimas por sexo.

En la Figura 9 también se presentan las diferencias existentes de la prevalencia de agresores según el sexo; donde se puede apreciar un patrón inverso, donde se encuentra una proporción ligeramente mayor de hombres que de mujeres quienes agreden a sus demás compañeros. Sin embargo, nuevamente estas diferencias no fueron estadísticamente significativas $\left(\chi^{2}=.997, \mathrm{gl}=1, p=.397\right)$.

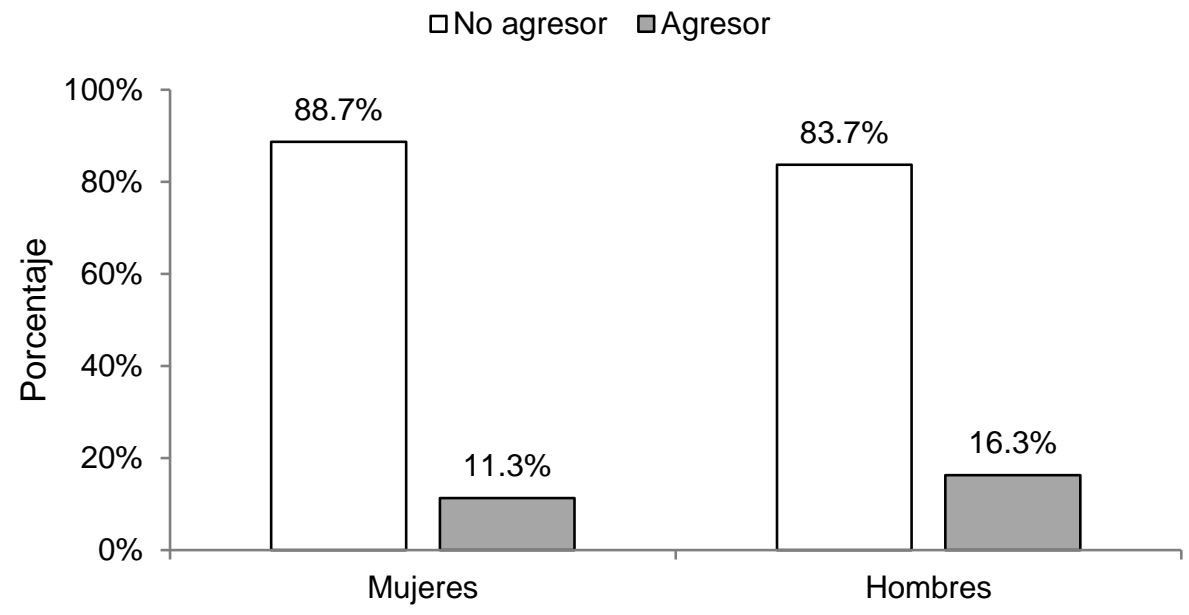

Figura 9. Prevalencia de agresores por sexo. 


\section{Prevalencia y edad}

También se describió la relación entre la edad y las prevalencias según víctimas y agresores. Tal como se observa en la Figura 10, en general se aprecia que la distribución de la edad y el hecho de haber sido identificado como víctima o como agresor, es similar, con edades entre los 20 a 23 años tanto para víctimas como agresores, así como para las personas que no estuvieron involucradas en ninguna forma de acoso escolar.
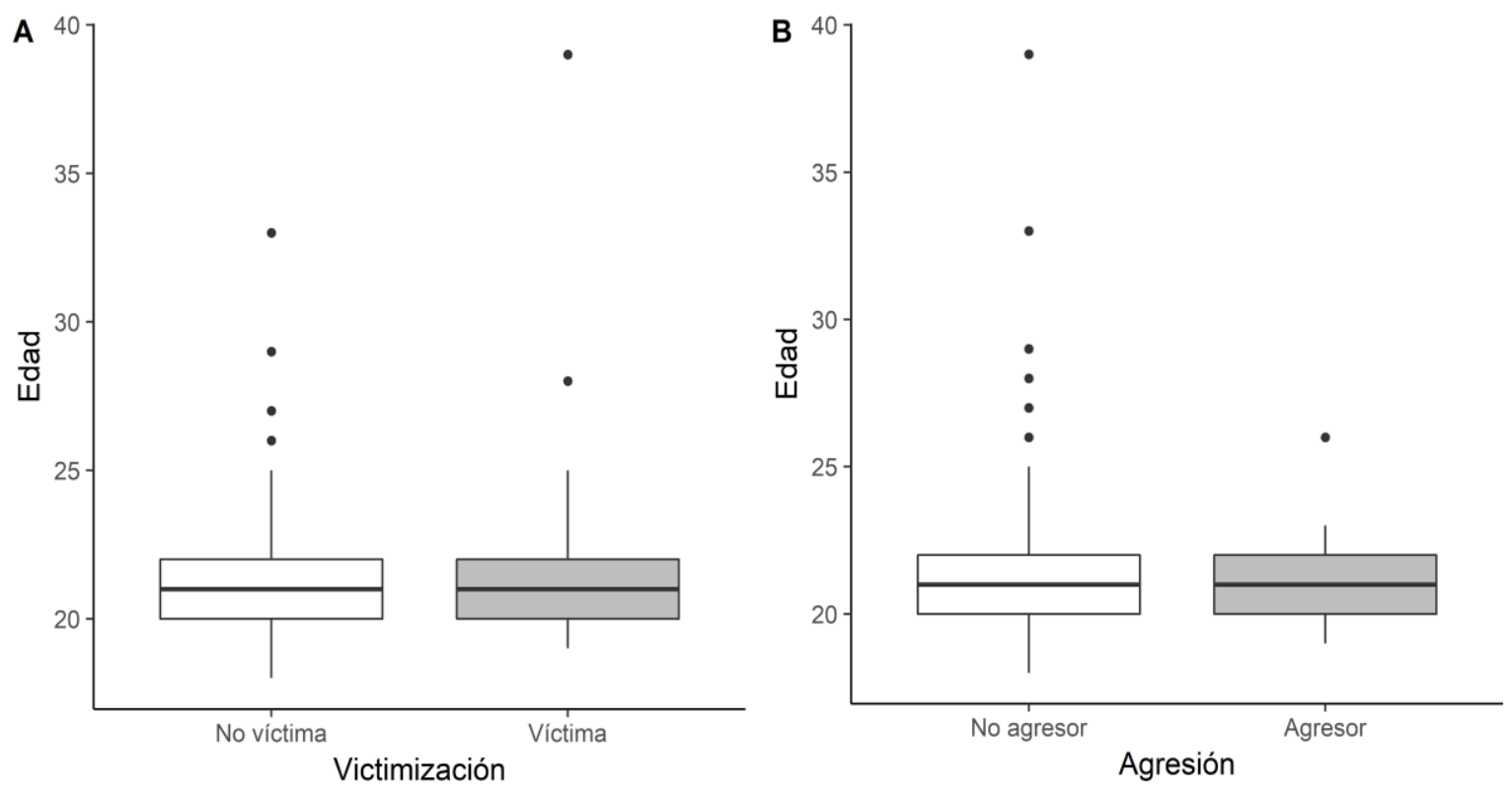

Figura 10. Distribución de las edades según condición de A) víctimas, y B) Agresores.

\section{Frecuencias de los tipos de victimización}

Víctimas. También fue de interés identificar el tipo de conducta más frecuente que experimentaban las víctimas. Esto fue explorado al considerar aquellas conductas intencionalmente dañinas que ocurrieron 3 o más veces en el mes pasado (criterio de intencionalidad y periodicidad) solamente en aquellas personas que fueron identificadas como víctimas. En la Figura 11 se puede apreciar que la mayor conducta experimentada por las víctimas son los rumores y chismes, en segundo lugar, los insultos y burlas, seguido por la exclusión social, el cyberbullying y los comentarios sexuales. Otros tipos de conductas 
experimentadas como las amenazas, la violencia física o el robo y destrucción de objetos personales tuvieron una menor prevalencia.

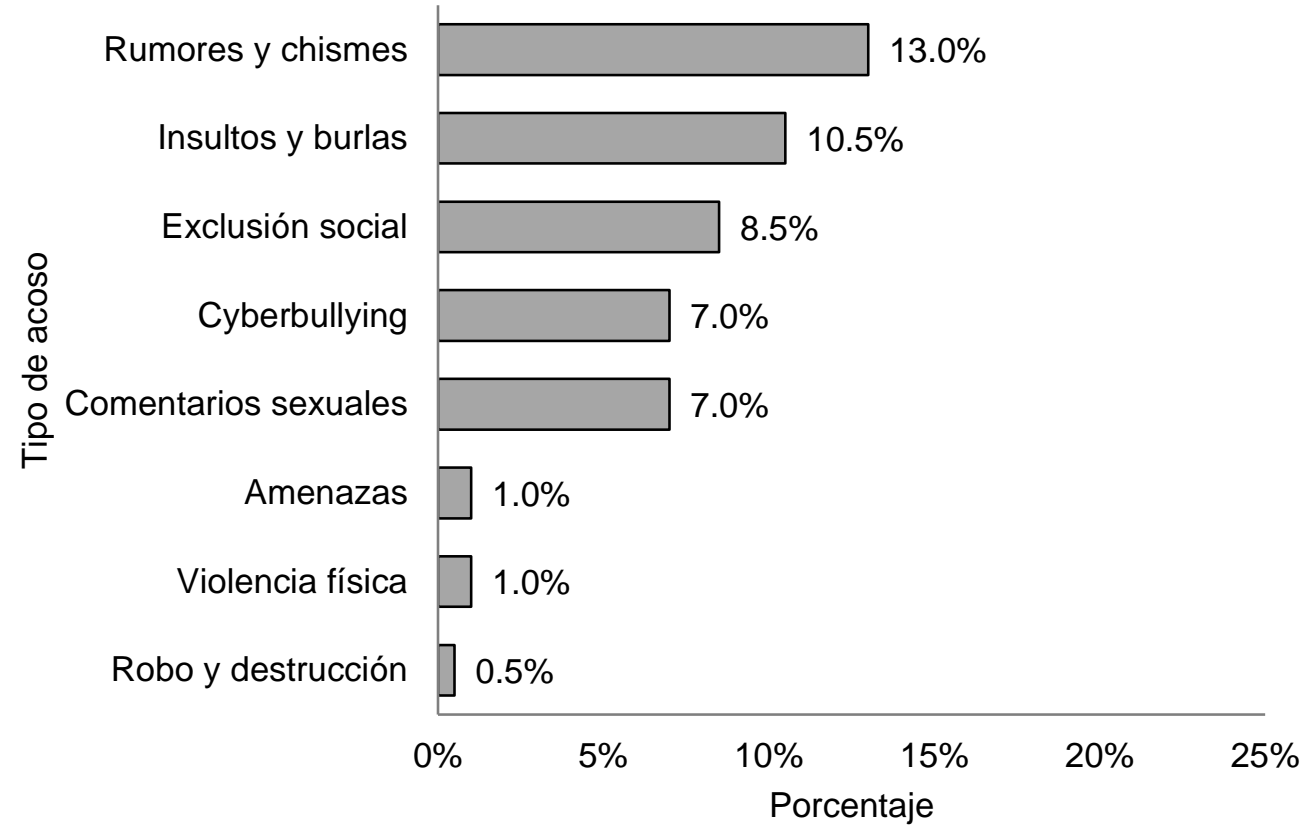

Figura 11. Prevalencia de los principales tipos de victimización.

Agresores. El mismo proceso fue realizado para identificar las conductas más frecuentes realizadas por los agresores. Los resultados fueron relativamente similares para los agresores (Ver Figura 12). En este caso, la conducta principal realizada para agredir fueron los insultos y burlas, en segundo lugar, la exclusión social, seguido del cyberbullying, los comentarios sexuales, los rumores y chismes y la violencia física. Las conductas con una prevalencia considerablemente menor fueron el robo y destrucción de objetos personales, y las amenazas. Si bien los resultados fueron parecidos a los de las víctimas, debido a que en ambos casos prevalecen más las conductas de acoso indirecto/relacional, se nota una prevalencia marcadamente frecuente de insultos y burlas como principal forma de agresión. 


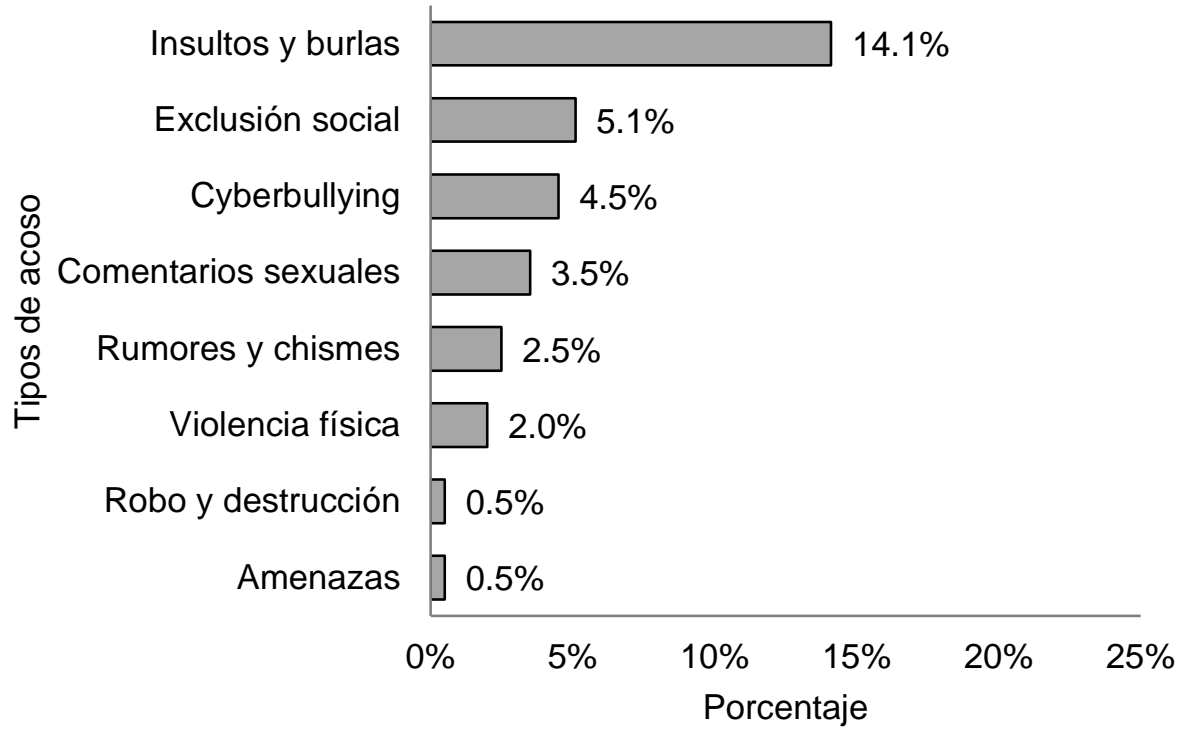

Figura 12. Prevalencia de los principales tipos de agresión.

\section{Lugares donde ocurre el acoso escolar}

También se exploró los lugares donde ocurre el acoso escolar. En la Figura 13, se puede apreciar que el principal lugar en el que ocurre es en las aulas, seguida por las actividades extraescolares, los pasillos y la cafetería de la escuela.

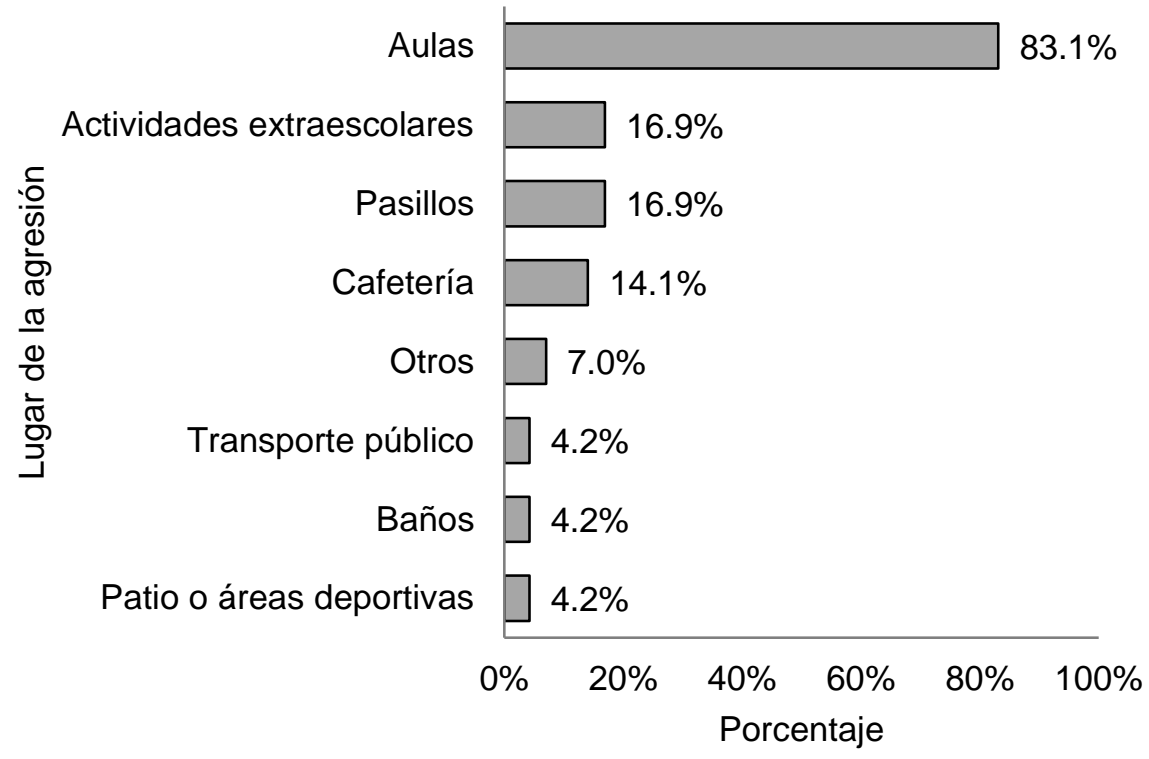

Figura 13. Lugares donde ocurre el acoso. 


\section{Acciones institucionales ante el acoso}

También se exploró las principales acciones realizadas por la institución, ya sea por maestros o por el personal de la escuela, las cuales se presentan en la Figura 14.

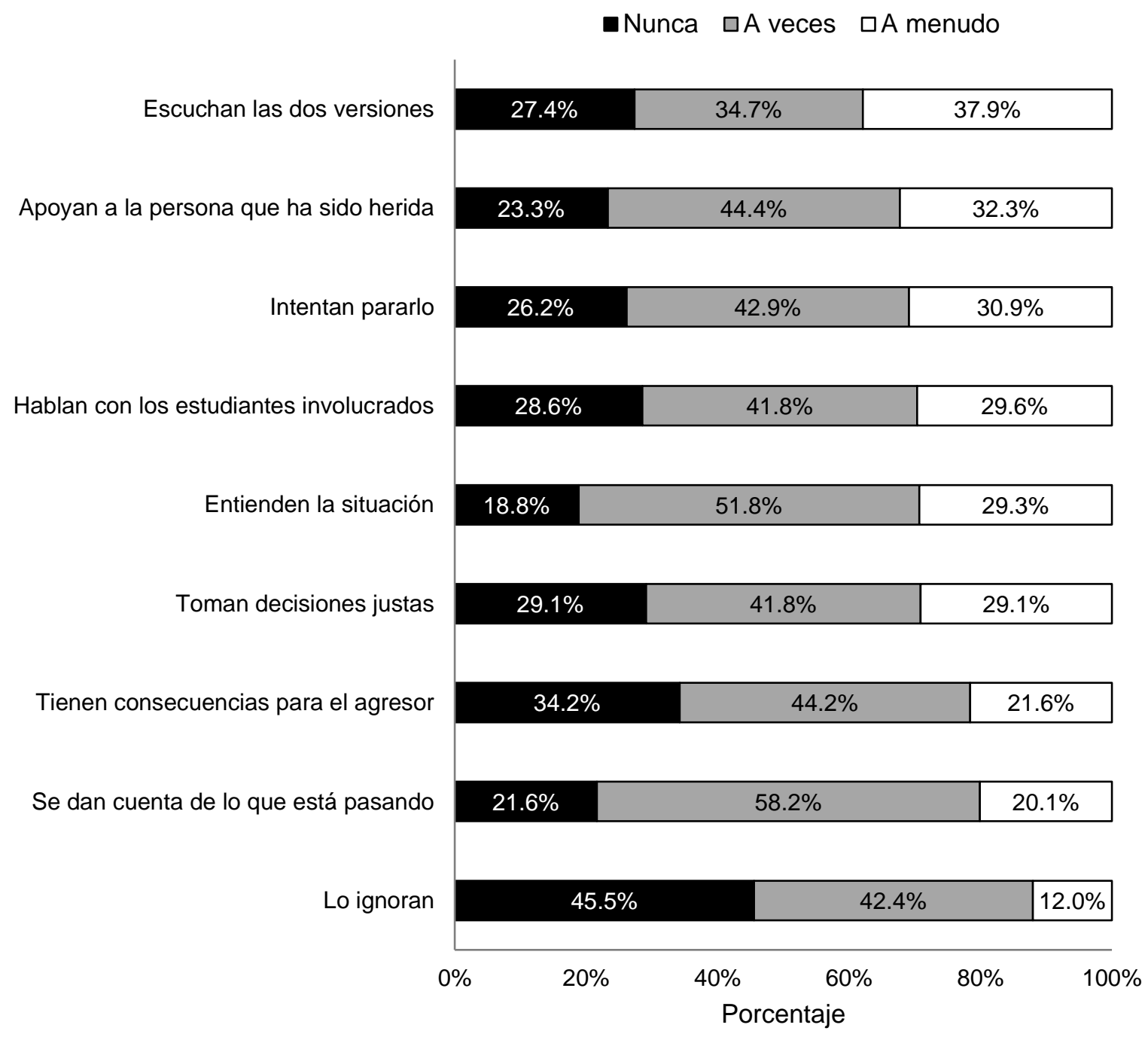

Figura 14. Acciones realizadas por los maestros/personal ante las situaciones de acoso.

Los resultados muestran que un $72.6 \%$ de los participantes considera que se escuchan las dos versiones de lo ocurrido; un $76.7 \%$ de las veces se apoya a la persona que ha sido herida; el $73.8 \%$ de las veces lo intentan parar; un $71.4 \%$ hablan con los estudiantes involucrados; $81.2 \%$ de las veces manifiestan que los profesores o personal entiende la situación; y un $70.9 \%$ considera que se toman decisiones justas. Sin embargo, destacan 
otras respuestas como que el $21.6 \%$ de las veces los profesores o personal no se dan cuenta de la situación que está pasando; solo un 65.8\% de las veces el agresor sufre alguna consecuencia; y que un $54.5 \%$ de las veces la situación es ignorada por los docentes o personal.

\section{Diferencias de la agresión-victimización directa e indirecta según el sexo}

Para probar la hipótesis 1 y 2, que corresponden a que las mujeres presentarán mayor frecuencia en agresión indirecta y menor frecuencia en agresión directa que los hombres, se hizo una comparación de dos grupos independientes. Para ello, según la teoría mencionada por Björkqvist et al. (1992; 1994), se agruparon en agresión directa los ítems del CBVS que evaluaban violencia física, amenazas, y la destrucción o robo de pertenencias; y en agresión indirecta, los reactivos que evaluaban insultos/burlas, esparcir rumores, exclusión social, comentarios sexuales, y cyberbullying; tanto en la escala de víctimas como en la de agresores.

De forma general, se probaron ambas agrupaciones de variables mediante el estadístico no paramétrico multivariado $\mathrm{Q}^{2}$, el cual resulta una extensión multivariada de la prueba U de Mann-Whitney-Wilcoxon, que se utiliza cuando se quiere contrastar variables a nivel ordinal en dos grupos independientes (Oja, 2010). Posteriormente, se probó la diferencia en cada reactivo mediante la prueba de U de Mann-Whitney.

\section{Agresión indirecta en hombres y mujeres}

La agresión indirecta se comparó en hombres y mujeres, tanto con pruebas no paramétricas univariadas como multivariadas; en ambas escalas de víctimas y agresores. Para todas las pruebas se consideró la hipótesis unilateral de que las mujeres presentarán mayor agresión indirecta que los hombres. Los resultados, pueden apreciarse en la Tabla 5.

Los resultados señalan que, de forma global, no existen diferencias entre hombres y mujeres en la expresión de agresión indirecta tanto en víctimas como en agresores; pues ninguno de los estadísticos multivariados de prueba resultó significativo. Sin embargo, cuando se compara a nivel univariado, se pudo encontrar que existe una diferencia entre hombres y mujeres en cuanto al ser víctima en la modalidad de esparcir rumores, siendo las mujeres que suelen percibir una mayor frecuencia de existencia de rumores en su contra. 
Tabla 5 .

Diferencias en victimización y agresión indirecta entre hombres y mujeres.

\begin{tabular}{|c|c|c|c|c|c|c|}
\hline \multirow{2}{*}{ Variable } & \multicolumn{2}{|c|}{ Mujeres } & \multicolumn{2}{|c|}{ Hombres } & \multirow{2}{*}{ Estadístico } & \multirow{2}{*}{ Sig. } \\
\hline & Media & D.E. & Media & D.E. & & \\
\hline Victimización indirecta & & & & & $\mathrm{Q}^{2}=78.71$ & 0.157 \\
\hline Insultos y burlas & 1.47 & 0.98 & 1.42 & 0.94 & $\mathrm{~W}=4810.5$ & 0.284 \\
\hline Esparcir rumores & 1.56 & 1.01 & 1.27 & 0.68 & $\mathrm{~W}=5270.5$ & 0.016 \\
\hline Exclusión & 1.43 & 1.04 & 1.24 & 0.68 & $\mathrm{~W}=4918.5$ & 0.140 \\
\hline Comentarios sexuales & 1.37 & 0.89 & 1.26 & 0.69 & $\mathrm{~W}=4848.0$ & 0.220 \\
\hline Cyberbullying & 1.32 & 0.80 & 1.24 & 0.57 & $\mathrm{~W}=4682.0$ & 0.443 \\
\hline Agresión indirecta & & & & & $\mathrm{Q}^{2}=59.17$ & 0.571 \\
\hline Insultos y burlas & 1.46 & 0.93 & 1.78 & 1.46 & $W=3989.5$ & 0.963 \\
\hline Esparcir rumores & 1.08 & 0.27 & 1.26 & 1.08 & $\mathrm{~W}=4299.0$ & 0.905 \\
\hline Exclusión & 1.26 & 0.67 & 1.20 & 1.26 & $\mathrm{~W}=4634.5$ & 0.300 \\
\hline Comentarios sexuales & 1.08 & 0.34 & 1.23 & 1.08 & $W=4267.5$ & 0.934 \\
\hline Cyberbullying & 1.15 & 0.51 & 1.31 & 1.15 & $\mathrm{~W}=4173.5$ & 0.952 \\
\hline
\end{tabular}

\section{Agresión directa en hombres y mujeres}

La agresión directa también se comparó en hombres y mujeres, tanto con pruebas no paramétricas univariadas como multivariadas; en ambas escalas de víctimas y agresores. Para todas las pruebas se consideró la hipótesis unilateral de que los hombres presentarían mayor agresión directa que las mujeres. Los resultados, pueden apreciarse en la Tabla 6.

Los resultados señalan que, de forma global, no existen diferencias entre hombres y mujeres en la expresión de agresión directa tanto en víctimas como en agresores; pues ninguno de los estadísticos multivariados de prueba resultó significativo. Sin embargo, cuando se compara a nivel univariado, se pudo encontrar que existe una diferencia entre hombres y mujeres en cuanto al ser agresor en la modalidad de expresar amenazas, siendo los hombres quienes suelen agredir con mayor frecuencia al expresar amenazas. Además, en cuanto la agresión por medio de robo o destrucción de objetos, esta fue prácticamente nula, ya que el promedio fue el mínimo posible y con variación mínima o nula. 
Tabla 6.

Diferencias en victimización y agresión directa entre hombres y mujeres.

\begin{tabular}{cccccccc}
\hline \multirow{2}{*}{ Variable } & \multicolumn{3}{c}{ Mujeres } & \multicolumn{2}{c}{ Hombres } & \multirow{2}{*}{ Estadístico } & \multirow{2}{*}{ Sig. } \\
\cline { 2 - 5 } & Media & D.E. & Media & D.E. & & & \\
\hline Victimización directa & & & & & $\mathrm{Q}^{2}=22.95$ & 0.242 \\
Violencia física & 1.06 & 0.33 & 1.06 & 0.35 & $\mathrm{~W}=4653.5$ & 0.532 \\
Amenazas & 1.02 & 0.14 & 1.08 & 0.35 & $\mathrm{~W}=4458.0$ & 0.070 \\
Robo o destrucción & 1.04 & 0.19 & 1.06 & 0.28 & $\mathrm{~W}=4598.0$ & 0.367 \\
Agresión directa & & & & & $\mathrm{Q}^{2}=5.34$ & 0.217 \\
Violencia física & 1.05 & 0.40 & 1.13 & 0.57 & $\mathrm{~W}=4380.0$ & 0.077 \\
Amenazas & 1.01 & 0.10 & 1.07 & 0.30 & $\mathrm{~W}=4295.0$ & 0.028 \\
Robo o destrucción & 1.00 & 0.00 & 1.01 & 0.11 & $\mathrm{~W}=0000.0$ & 1.000 \\
\hline
\end{tabular}

\section{Relación entre la agresión-victimización directa e indirecta con la edad}

Para dar respuesta a las hipótesis sobre la relación directamente proporcional entre la agresión indirecta y la edad; así como la relación inversamente proporcional entre edad y la agresión directa, se realizó una correlación de Spearman entre la edad y cada uno de los ítems que evaluaban tanto agresión indirecta como directa (Tabla 7).

Tabla 7.

Relación entre la edad y la agresión-victimización directa e indirecta.

\begin{tabular}{lcc}
\hline Variable & Victimización & Agresión \\
\hline Indirecta & & \\
Insultos y burlas & 0.052 & 0.104 \\
Esparcir rumores & 0.011 & 0.066 \\
Exclusión & -0.019 & -0.022 \\
Comentarios sexuales & -0.039 & -0.027 \\
Cyberbullying & -0.066 & 0.054 \\
Directa & & \\
Violencia física & -0.002 & 0.103 \\
Amenazas & 0.063 & 0.029 \\
Robo o destrucción & -0.064 & 0.084 \\
\hline
\end{tabular}

Nota: $* p<0.05, * * p<0.01, * * * p<0.001$

Tal como se puede apreciar en la Tabla 7, ninguna de las formas de expresión directa o indirecta tanto de la agresión como de la victimización tuvo una relación con la 
edad. Lo que señala que ni la agresión directa disminuye con la edad, ni la agresión indirecta aumenta con el tiempo.

\section{Factores de riesgo y protección individuales}

Para identificar los factores de riesgo individuales, se realizó un modelo de regresión logística para víctimas y otro para agresores. Este modelo consideró la inclusión por el método jerárquico, ya que solamente se incluyeron variables señaladas como predictoras del acoso escolar por estudios previos o de interés teórico, en este caso, aquellas variables a nivel del individuo. El modelo consideró las siguientes variables: (a) Sexo; (b) Edad; (c) Ser diferente, en este caso, tener ascendencia indígena; origen migrante, y la orientación sexual; (d) empatía afectiva y cognitiva; (e) agresión proactiva y reactiva; (f) impulsividad; y (g) actitudes pro-criminales (hacia la autoridad y hacia la transgresión).

De forma particular, el modelo de víctimas incluye empatía cognitiva, agresión reactiva y actitudes positivas hacia la autoridad; y el modelo de los agresores incluye empatía afectiva, agresión proactiva, y actitudes positivas hacia la transgresión. Esto considerando dos razones: (a) son las variables que los estudios previos han señalado que se asocian con víctimas y agresores respectivamente; y (b) no se incluyen ambos tipos de empatía, agresión o actitudes pro-criminales en un mismo modelo debido a la alta correlación que existe entre las dimensiones, pues esto podría ocasionar problemas de multicolinealidad.

\section{Factores individuales de las víctimas}

El modelo obtenido para víctimas tuvo un ajuste adecuado según lo reportado por la prueba de bondad de ajuste de Hosmer y Lameshow $\left(\chi^{2}=6.16, \mathrm{gl}=8 ; p=.629\right)$. Según el estadístico pseudo-R cuadrada de Nagelkerke, el modelo explica un $15.8 \%$ de la variabilidad de la victimización; con una tasa de clasificación del 65.7\%.

Tal como se puede apreciar en la Tabla 8, ninguna de las variables fue significativas para modelar la victimización. Ni el sexo, edad, ascendencia, orientación sexual, origen, empatía cognitiva, impulsividad o actitudes hacia la autoridad fueron estadísticamente significativas para el modelo de las víctimas. Sin embargo, la agresión reactiva, el origen y las actitudes hacia las autoridades estuvieron marginalmente cercanas a la región de 
rechazo, por lo que sería conveniente explorar estas variables en la presencia de otras variables de control.

Tabla 8.

Modelo de factores individuales para víctimas.

\begin{tabular}{lcccccc}
\hline \multicolumn{1}{c}{ Variables } & B & Wald & Sig. & O.R. & \multicolumn{2}{c}{ I.C. (95\%) para O.R. } \\
\cline { 6 - 8 } Sexo $^{1}$ & -0.256 & 0.324 & 0.569 & 0.774 & 0.320 & 1.870 \\
Edad & -0.070 & 0.429 & 0.512 & 0.932 & 0.755 & 1.151 \\
Ascendencia $^{2}$ & & 3.055 & 0.217 & & & \\
$\quad$ Un apellido maya & -0.876 & 2.035 & 0.154 & 0.417 & 0.125 & 1.387 \\
$\quad$ Dos apellidos mayas & 0.567 & 0.692 & 0.406 & 1.764 & 0.463 & 6.714 \\
Origen $^{3}$ & -0.831 & 3.197 & 0.074 & 0.436 & 0.175 & 1.083 \\
Orientación Sexual $^{4}$ & 0.415 & 0.863 & 0.353 & 1.515 & 0.631 & 3.639 \\
Empatía Cognitiva $_{\text {Agresión Reactiva }}$ & -0.008 & 0.096 & 0.756 & 0.992 & 0.940 & 1.046 \\
Impulsividad $_{\text {Actitud positiva hacia la autoridad }}$ & 0.136 & 3.686 & 0.055 & 1.146 & 0.997 & 1.317 \\
Constante & 0.004 & 0.015 & 0.901 & 1.004 & 0.940 & 1.072 \\
\hline
\end{tabular}

Nota: O.R. = Odds Ratio o razón de momios; Variables ficticias usadas como referencia: 1 = ser mujer; $2=$ No tener apellidos mayas; $3=$ No ser migrante; $4=$ Ser heterosexual.

\section{Factores individuales para los agresores}

El modelo obtenido para los agresores también tuvo un ajuste adecuado según la prueba de bondad de ajuste de Hosmer y Lameshow $\left(\chi^{2}=6.43, \mathrm{gl}=8 ; p=.598\right)$. Según el estadístico pseudo-R cuadrada de Nagelkerke, el modelo explica un $28.5 \%$ de la variabilidad de la agresión, un porcentaje mayor al obtenido en el modelo de las víctimas; con una tasa de clasificación del $82.1 \%$.

Tal como se puede apreciar en la Tabla 9, únicamente la orientación sexual y agresión proactiva fueron significativas para el modelo de los agresores. Ni el sexo, edad, ascendencia, origen, empatía cognitiva, impulsividad o actitudes hacia la transgresión fueron estadísticamente significativas para el modelo de los agresores. En el caso de la 
orientación sexual, tener una orientación diferente a la heterosexual fue un factor de riesgo. Como se puede apreciar por el valor del coeficiente (1.121) y la razón de momios (3.06), tener una orientación diferente a la heterosexual aumenta las posibilidades de ser agresor hasta tres veces. Por su parte, la agresión proactiva, también resultó ser un factor de riesgo. El valor del coeficiente (.397) señala que puntuar más alto en agresión proactiva incrementa más las posibilidades de realizar agresiones -hasta en un $48 \%$ según la razón de momios.

Tabla 9.

Modelo de factores individuales para agresores.

\begin{tabular}{lcccccc}
\hline \multicolumn{1}{c}{ Variables } & B & Wald & Sig. & O.R. & \multicolumn{2}{c}{ I.C. (95\%) para O.R. } \\
\cline { 6 - 8 } Sexo $^{1}$ & -0.647 & 0.970 & 0.325 & 0.523 & 0.144 & 1.898 \\
Edad & -0.083 & 0.414 & 0.520 & 0.920 & 0.714 & 1.186 \\
Ascendencia $^{2}$ & & 2.452 & 0.293 & & & \\
$\quad$ Un apellido maya & -1.111 & 1.762 & 0.184 & 0.329 & 0.064 & 1.698 \\
$\quad$ Dos apellidos mayas & 0.556 & 0.447 & 0.504 & 1.744 & 0.342 & 8.899 \\
Origen $^{3}$ & 0.256 & 0.227 & 0.634 & 1.292 & 0.450 & 3.707 \\
Orientación Sexual $^{4}$ & 1.121 & 4.673 & 0.031 & 3.067 & 1.110 & 8.473 \\
Empatía Afectiva $_{\text {Agresión Proactiva }}$ & -0.005 & 0.045 & 0.832 & 0.995 & 0.946 & 1.046 \\
Impulsividad $_{\text {Actitud positiva hacia la transgresión }}$ & 0.055 & 1.995 & 0.158 & 1.056 & 0.979 & 1.140 \\
Constante & -0.008 & 0.050 & 0.823 & 0.992 & 0.922 & 1.067 \\
\hline
\end{tabular}

Nota: O.R. = Odds Ratio o razón de momios; I.C. = Intervalo de confianza; Variables ficticias usadas como referencia: $1=$ ser mujer; $2=$ No tener apellidos mayas; $3=$ No ser migrante $4=$ Ser heterosexual.

\section{Factores de riesgo y protección escolares}

También se exploraron cuales factores a nivel escolar están asociados con las víctimas y con los agresores. El procedimiento realizado fue exactamente igual al reportado con los factores individuales (método jerárquico), pero utilizando variables a nivel escolar. Específicamente, se consideraron los siguientes: (a) popularidad; (b) relación con el maestro (apoyo social); (c) reglas y convivencia (normas claras); y (d) satisfacción escolar. 
No se incluyó el desempeño escolar (calificaciones) debido a que no todos los alumnos sabían o tenían sus calificaciones; además de que los ciclos escolares no eran iguales para todas las licenciaturas (algunas eran semestrales y otras cuatrimestrales), por lo que las calificaciones no serían un indicador homogéneo para todos. Tanto el modelo de víctimas como el de agresores incluyeron las mismas variables.

\section{Factores escolares para las víctimas}

El modelo obtenido para víctimas tuvo un ajuste adecuado según lo reportado por la prueba de bondad de ajuste de Hosmer y Lameshow $\left(\chi^{2}=1.19, \mathrm{gl}=8 ; p=.997\right)$. Según el estadístico pseudo-R cuadrada de Nagelkerke, el modelo explica un $14.2 \%$ de la variabilidad de la victimización, con una tasa de clasificación del 67\%.

Tal como se puede apreciar en la Tabla 10, únicamente La satisfacción escolar fue significativa para el modelo de las víctimas. Ni la popularidad, relación con el maestro (apoyo social), o las normas claras fueron estadísticamente significativas para el modelo de las víctimas. En el caso de la satisfacción escolar, esta resultó ser un factor de protección. Tal como se puede apreciar por el valor del coeficiente (-.277), el tener una mayor satisfacción con la escuela es un indicador de una menor victimización, ya que los jóvenes con una mayor satisfacción tienen una menor posibilidad de ser víctimas de acoso, -hasta un 39\% menos según la razón de momios.

Tabla 10.

Modelo de factores escolares para víctimas.

\begin{tabular}{lcccccc}
\hline \multicolumn{1}{c}{ Variables } & \multirow{2}{*}{ B } & Wald & Sig. & O.R. & \multicolumn{2}{c}{ I.C. (95\%) para O.R. } \\
\cline { 7 - 8 } Popularidad & 0.143 & 0.430 & 0.512 & 1.154 & 0.752 & 1.771 \\
Apoyo social & -0.028 & 1.013 & 0.314 & 0.973 & 0.921 & 1.027 \\
Normas Claras & -0.036 & 1.379 & 0.240 & 0.965 & 0.909 & 1.024 \\
Satisfacción Escolar & -0.277 & 6.563 & 0.010 & 0.758 & 0.613 & 0.937 \\
Constante & 2.528 & 4.921 & 0.027 & 12.528 & & \\
\hline
\end{tabular}

Nota: O.R. = Odds Ratio o razón de momios; I.C.= Intervalo de confianza. 


\section{Factores escolares para los agresores}

El modelo obtenido para agresores tuvo un ajuste adecuado según lo reportado por la prueba de bondad de ajuste de Hosmer y Lameshow $\left(\chi^{2}=3.42, \mathrm{gl}=8 ; p=.905\right)$. Según el estadístico pseudo-R cuadrada de Nagelkerke, el modelo explica un $13.3 \%$ de la variabilidad de la agresión, con una tasa de clasificación del 80.5\%.

Tal como se puede apreciar en la Tabla 11, tanto la popularidad como la satisfacción escolar fueron estadísticamente significativas para el modelo de los agresores. Ni la relación con el maestro (apoyo social), o las normas claras fueron estadísticamente significativas. En el caso de la popularidad, esta resultó ser un factor de riesgo. Tal como se observa por el valor del coeficiente (.805), ser más popular aumenta las posibilidades de ser agresor, hasta en un 30\% según la razón de momios. Por su parte, la satisfacción escolar resultó ser un factor de protección. Como se aprecia en el valor del coeficiente (-.352), los alumnos que tuvieron una mayor satisfacción escolar tuvieron menos posibilidades de ser agresores. Esta posibilidad era disminuida hasta en un 30\% según la razón de momios.

Tabla 11.

Modelo de factores escolares para agresores.

\begin{tabular}{|c|c|c|c|c|c|c|}
\hline \multirow{2}{*}{ Variables } & \multirow{2}{*}{ B } & \multirow{2}{*}{ Wald } & \multirow{2}{*}{ Sig. } & \multirow{2}{*}{ O.R. } & \multicolumn{2}{|c|}{ I.C. $(95 \%)$ para O.R. } \\
\hline & & & & & Inferior & Superior \\
\hline Popularidad & 0.805 & 8.584 & 0.003 & 2.236 & 1.305 & 3.832 \\
\hline Apoyo social & 0.035 & 1.049 & 0.306 & 1.036 & 0.969 & 1.107 \\
\hline Normas Claras & -0.019 & 0.305 & 0.581 & 0.981 & 0.916 & 1.050 \\
\hline Satisfacción Escolar & -0.352 & 7.227 & 0.007 & 0.703 & 0.544 & 0.909 \\
\hline Constante & -1.983 & 2.112 & 0.146 & 0.138 & & \\
\hline
\end{tabular}

Nota: O.R. = Odds Ratio o razón de momios; I.C.= Intervalo de confianza.

\section{Factores de riesgo y protección familiares}

También se exploraron las variables a nivel familiar que las investigaciones han asociado con el acoso escolar. El procedimiento realizado fue igual al reportado con los factores individuales y escolares (método jerárquico), utilizando las variables: estilos de crianza y violencia familiar, realizando un modelo para víctimas y otro para agresores. 


\section{Factores familiares para las víctimas}

El modelo obtenido para víctimas tuvo un ajuste adecuado según lo reportado por la prueba de bondad de ajuste de Hosmer y Lameshow $\left(\chi^{2}=8.07, \mathrm{gl}=8 ; p=.426\right)$. Sin embargo, según el estadístico pseudo-R cuadrada de Nagelkerke, el modelo explica un $6.8 \%$ de la variabilidad de la victimización; y la tasa de clasificación es apenas superior al $\operatorname{azar}(69.2 \%)$.

Tal como se observa en la Tabla 12 los estilos de crianza no fueron estadísticamente significativos para predecir la victimización, pero si lo fue la presencia de violencia familiar. Tal como se observa por el valor del coeficiente (.016), la violencia familiar puede ser considerada como factor de riesgo, ya que existe una relación directa entre ésta y la victimización, siendo aquellos participantes que sufren violencia en casa quienes más posibilidades tienen de sufrir victimización en la escuela (incrementando hasta un 1.7\% esta posibilidad).

Tabla 12.

Modelo de factores familiares para víctimas.

\begin{tabular}{lcccccc}
\hline \multicolumn{1}{c}{ Variables } & B & Wald & Sig. & O.R. & \multicolumn{2}{c}{ I.C. (95\%) para O.R. } \\
\hline Estilos de crianza & -0.018 & 2.995 & 0.083 & 0.982 & 0.962 & 1.002 \\
Violencia familiar & 0.016 & 3.912 & 0.048 & 1.017 & 1.000 & 1.033 \\
Constante & -0.338 & 0.829 & 0.684 & 0.714 & & \\
\hline
\end{tabular}

Nota: O.R. = Odds Ratio o razón de momios; I.C.= Intervalo de confianza.

\section{Factores familiares para los agresores}

Por su parte, el modelo obtenido para agresores tuvo un ajuste adecuado según lo reportado por la prueba de bondad de ajuste de Hosmer y Lameshow $\left(\chi^{2}=6.36, \mathrm{gl}=8 ; p=\right.$ .606). Sin embargo, según el estadístico pseudo-R cuadrada de Nagelkerke, el modelo explica un 2.8\% de la variabilidad de la agresión, con una tasa de clasificación del 83.2\%. Sin embargo, ninguna variable tuvo significancia estadística para los agresores (Ver Tabla 
13); lo que significa que, a nivel familiar, ni los estilos de crianza o la violencia familiar representan un factor de riesgo o protección para ser agresor.

Tabla 13.

Modelo de factores familiares para agresores.

\begin{tabular}{lcccccc}
\hline \multicolumn{1}{c}{ Variables } & B & Wald & Sig. & O.R. & \multicolumn{2}{c}{ I.C. (95\%) para O.R. } \\
\hline Estilos de crianza & -0.011 & 0.773 & 0.379 & 0.989 & 0.966 & 1.013 \\
Violencia familiar & 0.012 & 1.751 & 0.186 & 1.012 & 0.994 & 1.031 \\
Constante & -1.251 & 1.680 & 0.195 & 0.286 & & \\
\hline
\end{tabular}

Nota: O.R. = Odds Ratio o razón de momios; I.C.= Intervalo de confianza.

Factores de riesgo y protección comunitarios

Finalmente, también se exploraron aquellos factores a nivel social y comunitario asociadas al acoso escolar. De forma específica se consideraron las variables de (a) tener pares con conductas antisociales (asociación delictiva); y (b) uso de las TIC. El procedimiento realizado fue igual al reportado con los factores individuales, escolares y familiares (método jerárquico), creando nuevamente dos modelos: uno para víctimas y otro para agresores.

\section{Factores comunitarios para las víctimas}

El modelo obtenido para víctimas tuvo un ajuste adecuado según lo reportado por la prueba de bondad de ajuste de Hosmer y Lameshow $\left(\chi^{2}=11.08, \mathrm{gl}=8 ; p=.197\right)$. Sin embargo, según el estadístico pseudo-R cuadrada de Nagelkerke, el modelo explica un .5\% de la variabilidad de la victimización; y la tasa de clasificación es apenas superior al azar (59\%). Tal como se apreciar en la Tabla 14, ni el tener pares con conductas antisociales ni el uso de las TIC estuvo asociado de forma estadísticamente significativa a la victimización; por lo que ninguna de estas variables puede ser considerada como un factor de riesgo o protección para las víctimas a nivel comunitario. 
Tabla 14.

Modelo de factores comunitarios para víctimas.

\begin{tabular}{lcccccc}
\hline \multicolumn{1}{c}{ Variables } & B & Wald & Sig. & O.R. & \multicolumn{2}{c}{ I.C. (95\%) para O.R. } \\
\cline { 6 - 8 } & & & & & Inferior & Superior \\
\hline Asociación delictiva & 0.008 & 0.705 & 0.401 & 1.008 & 0.989 & 1.029 \\
Uso de las TIC & -0.001 & 0.001 & 0.980 & 0.999 & 0.959 & 1.041 \\
Constante & -1.598 & 5.201 & 0.022 & 0.202 & & \\
\hline
\end{tabular}

Nota: O.R. = Odds Ratio o razón de momios; I.C.= Intervalo de confianza.

\section{Factores comunitarios para los agresores}

Por su parte, el modelo obtenido para agresores tuvo un ajuste adecuado según lo reportado por la prueba de bondad de ajuste de Hosmer y Lameshow $\left(\chi^{2}=11.29, \mathrm{gl}=8 ; p\right.$ $=.186)$. Según el estadístico pseudo-R cuadrada de Nagelkerke, el modelo explica un $10.9 \%$ de la variabilidad de la agresión, con una tasa de clasificación del 81.3\%.

Tal como se observa en la Tabla 15, si bien el uso de las TIC no estuvo asociado significativamente con la agresión, si lo estuvo el tener pares con conductas antisociales. Según el valor del coeficiente (0.037) esta variable resulta ser un factor de riesgo, pues aquellos que tienen amigos con conductas antisociales, aumentan sus posibilidades de ser agresores (hasta en un 3.7\% según la razón de momios).

Tabla 15.

Modelo de factores comunitarios para agresores.

\begin{tabular}{lcccccc}
\hline \multicolumn{1}{c}{ Variables } & \multirow{2}{*}{ B } & Wald & Sig. & O.R. & \multicolumn{2}{c}{ I.C. (95\%) para O.R. } \\
\hline Asociación delictiva & 0.037 & 10.803 & 0.001 & 1.037 & 1.015 & 1.060 \\
Uso de las TIC & 0.023 & 0.940 & 0.332 & 1.024 & 0.976 & 1.073 \\
Constante & -3.561 & 16.738 & 0.000 & 0.028 & & \\
\hline
\end{tabular}

Nota: O.R. = Odds Ratio o razón de momios; I.C.= Intervalo de confianza. 


\section{Aportación de las variables agrupado según el modelo ecológico}

También se exploró que tanto aportan las variables según el modelo ecológico en conjunto. Esto se realizó con dos funciones: (1) ver como aportan según los grupos de variables para identificar el nivel de intervención que sería idóneo; y (2) ver la asociación de las variables en la presencia de variables de otros niveles. Nuevamente, se consideró construir un modelo para víctimas y otro para agresores; y se incluyeron todas las variables previamente mencionadas.

\section{Aportación de los niveles según el modelo ecológico para víctimas}

Tal como se puede apreciar en la Tabla 16, solamente el nivel escolar representa un bloque de variables que aporta de forma significativa a la explicación de la victimización. Si bien, las variables individuales son cercanas de manera marginal a la región de rechazo, de forma estricta no fueron significativas. Sin embargo, es conveniente considerar tanto las variables a nivel individual como escolar para la intervención con las víctimas, que ambas explican hasta un $25.3 \%$ de la varianza de la victimización, mientras que los factores familiares y comunitarios aportan muy poco para explicar este fenómeno.

Tabla 16.

Aportación de los niveles del modelo ecológico para víctimas.

\begin{tabular}{clcrcc}
\hline Paso & Bloque de Factores & Ji-Cuadrada & gl & \multicolumn{1}{c}{ Sig. } & Varianza explicada acumulada \\
\hline 1 & Individuales & 18.189 & 10 & 0.052 & $15.9 \%$ \\
2 & Escolares & 11.793 & 4 & 0.019 & $25.3 \%$ \\
3 & Familiares & 2.079 & 2 & 0.354 & $26.9 \%$ \\
4 & Comunitarios & 0.037 & 2 & 0.982 & $26.9 \%$ \\
\hline
\end{tabular}

Al incluir todas las variables de todos los niveles en el modelo para víctimas para conocer su influencia ante la presencia de otras variables se obtuvo que el modelo resultante cumple de forma satisfactoria el ajuste para una regresión logística según la prueba de Hosmer y Lameshow $\left(\chi^{2}=7.22, \mathrm{gl}=8 ; p=.513\right)$. Según el estadístico pseudo-R cuadrada de Nagelkerke, el modelo ecológico explica un $26.9 \%$ de la variabilidad de la victimización, con una tasa de clasificación del $71.7 \%$. 
Tabla 17.

Modelo ecológico de variables asociadas a la victimización.

\begin{tabular}{|c|c|c|c|c|c|c|}
\hline \multirow{2}{*}{ Variables } & \multirow{2}{*}{$\mathrm{B}$} & \multirow{2}{*}{ Wald } & \multirow{2}{*}{ Sig. } & \multirow{2}{*}{ O.R. } & \multicolumn{2}{|c|}{ I.C. $(95 \%)$ para O.R. } \\
\hline & & & & & Inferior & Superior \\
\hline \multicolumn{7}{|l|}{ Factores individuales } \\
\hline $\operatorname{Sexo}^{1}$ & -0.351 & 0.453 & 0.501 & 0.704 & 0.253 & 1.958 \\
\hline Edad & -0.136 & 1.191 & 0.275 & 0.873 & 0.684 & 1.114 \\
\hline Ascendencia $^{2}$ & & 3.454 & 0.178 & & & \\
\hline Un apellido maya & -0.689 & 1.110 & 0.292 & 0.502 & 0.139 & 1.809 \\
\hline Dos apellidos mayas & 0.976 & 1.798 & 0.180 & 2.654 & 0.637 & 11.052 \\
\hline Origen $^{3}$ & -0.911 & 2.953 & 0.086 & 0.402 & 0.142 & 1.137 \\
\hline Orientación Sexual $^{4}$ & 0.336 & 0.452 & 0.502 & 1.400 & 0.525 & 3.734 \\
\hline Empatía Cognitiva & 0.013 & 0.165 & 0.685 & 1.013 & 0.953 & 1.077 \\
\hline Agresión Reactiva & 0.170 & 4.103 & 0.043 & 1.185 & 1.006 & 1.397 \\
\hline Impulsividad & -0.015 & 0.171 & 0.679 & 0.985 & 0.917 & 1.058 \\
\hline Actitud positiva hacia la autoridad & -0.022 & 0.142 & 0.706 & 0.978 & 0.872 & 1.098 \\
\hline \multicolumn{7}{|l|}{ Factores escolares } \\
\hline Popularidad & 0.183 & 0.487 & 0.485 & 1.201 & 0.718 & 2.007 \\
\hline Apoyo social & -0.036 & 1.182 & 0.277 & 0.965 & 0.905 & 1.029 \\
\hline Normas Claras & -0.014 & 0.121 & 0.728 & 0.986 & 0.909 & 1.069 \\
\hline Satisfacción Escolar & -0.256 & 3.054 & 0.081 & 0.774 & 0.581 & 1.032 \\
\hline \multicolumn{7}{|l|}{ Factores familiares } \\
\hline Estilos de crianza & -0.022 & 2.020 & 0.155 & 0.979 & 0.950 & 1.008 \\
\hline Violencia familiar & 0.001 & 0.003 & 0.957 & 1.001 & 0.977 & 1.024 \\
\hline \multicolumn{7}{|l|}{ Factores comunitarios } \\
\hline Asociación delictiva & -0.003 & 0.037 & 0.848 & 0.997 & 0.968 & 1.027 \\
\hline Uso de las TIC & 0.001 & 0.001 & 0.973 & 1.001 & 0.945 & 1.061 \\
\hline Constante & 4.175 & 1.323 & 0.250 & 65.012 & & \\
\hline
\end{tabular}

Nota: O.R. $=$ Odds Ratio o razón de momios; Variables ficticias usadas como referencia: $1=$ ser mujer; $2=$ No tener apellidos mayas; $3=$ No ser migrante; $4=$ Ser heterosexual. 
Tal como se puede ver en la Tabla 17, llama la atención que únicamente la variable de agresión reactiva resultara significativa. Esta fue considerada como un factor de riesgo según el valor del coeficiente (0.170) al estar asociada positivamente con la victimización; pues incrementa hasta en un $18 \%$ la posibilidad de victimización en aquellos participantes cuyas puntuaciones en agresión reactiva fueron más altas. Estos resultados, fueron diferentes a los obtenidos al analizar por niveles, lo que sugiere la importancia de tomar en consideración la influencia entre variables de distintos niveles. Específicamente, se concluye que en particular las variables individuales interactúan con las escolares.

\section{Aportación de los niveles según el modelo ecológico para agresores}

Tal como se puede apreciar en la Tabla 18, tanto el bloque de variables a nivel individual como a nivel escolar fueron significativas para explicar la agresión. Por una parte, al incluir las variables individuales, el modelo explica hasta el $28.4 \%$ de la variabilidad de la agresión, y al incluir las escolares el porcentaje aumenta hasta un 43.6\%. Tanto las familiares como las comunitarias aportan de forma mínima para explicar este fenómeno.

Tabla 18.

Aportación de los niveles del modelo ecológico para agresores.

\begin{tabular}{clcccc}
\hline Paso & Bloque de Factores & Ji-Cuadrada & gl & \multicolumn{1}{c}{ Sig. } & Varianza explicada acumulada \\
\hline 1 & Individuales & 29.321 & 10 & 0.001 & $28.4 \%$ \\
2 & Escolares & 18.120 & 4 & 0.001 & $43.6 \%$ \\
3 & Familiares & 1.631 & 2 & 0.443 & $44.9 \%$ \\
4 & Comunitarios & 0.957 & 2 & 0.620 & $45.6 \%$ \\
\hline
\end{tabular}

Al incluir todas las variables de todos los niveles en el modelo para agresores para conocer su influencia ante la presencia de otras variables, se obtuvo que el modelo resultante cumple de forma satisfactoria el ajuste para una regresión logística según la prueba de Hosmer y Lameshow $\left(\chi^{2}=4.13, \mathrm{gl}=8 ; p=.845\right)$. Según el estadístico pseudo-R cuadrada de Nagelkerke, el modelo ecológico explica un $45.6 \%$ de la variabilidad de la victimización, con una tasa de clasificación del $86 \%$. 
Tabla 19.

Modelo ecológico de variables asociadas a la agresión.

\begin{tabular}{|c|c|c|c|c|c|c|}
\hline \multirow{2}{*}{ Variables } & \multirow{2}{*}{ B } & \multirow{2}{*}{ Wald } & \multirow{2}{*}{ Sig. } & \multirow{2}{*}{ O.R. } & \multicolumn{2}{|c|}{ I.C. (95\%) para O.R. } \\
\hline & & & & & Inferior & Superior \\
\hline \multicolumn{7}{|l|}{ Factores individuales } \\
\hline Sexo $^{1}$ & -0.363 & 0.251 & 0.616 & 0.696 & 0.168 & 2.880 \\
\hline Edad & 0.076 & 0.240 & 0.624 & 1.079 & 0.796 & 1.463 \\
\hline Ascendencia $^{2}$ & & 3.955 & 0.138 & & & \\
\hline Un apellido maya & -0.909 & 1.010 & 0.315 & 0.403 & 0.068 & 2.373 \\
\hline Dos apellidos mayas & 1.550 & 2.577 & 0.108 & 4.710 & 0.710 & 31.240 \\
\hline Origen $^{3}$ & 0.976 & 1.950 & 0.163 & 2.654 & 0.674 & 10.444 \\
\hline Orientación Sexual ${ }^{4}$ & 1.300 & 4.235 & 0.040 & 3.670 & 1.064 & 12.663 \\
\hline Empatía Afectiva & -0.005 & 0.028 & 0.867 & 0.995 & 0.941 & 1.053 \\
\hline Agresión Proactiva & 0.393 & 6.105 & 0.013 & 1.481 & 1.085 & 2.023 \\
\hline Impulsividad & -0.035 & 0.531 & 0.466 & 0.966 & 0.879 & 1.061 \\
\hline $\begin{array}{l}\text { Actitud positiva hacia la } \\
\text { transgresión }\end{array}$ & 0.032 & 0.481 & 0.488 & 1.032 & 0.944 & 1.129 \\
\hline \multicolumn{7}{|l|}{ Factores escolares } \\
\hline Popularidad & 1.022 & 6.133 & 0.013 & 2.778 & 1.237 & 6.234 \\
\hline Apoyo social & 0.070 & 2.111 & 0.146 & 1.072 & 0.976 & 1.178 \\
\hline Normas Claras & -0.038 & 0.602 & 0.438 & 0.963 & 0.875 & 1.059 \\
\hline Satisfacción Escolar & -0.673 & 9.546 & 0.002 & 0.510 & 0.333 & 0.782 \\
\hline \multicolumn{7}{|l|}{ Factores familiares } \\
\hline Estilos de crianza & -0.002 & 0.008 & 0.931 & 0.998 & 0.962 & 1.036 \\
\hline Violencia familiar & 0.020 & 1.540 & 0.215 & 1.020 & 0.989 & 1.052 \\
\hline \multicolumn{7}{|l|}{ Factores comunitarios } \\
\hline Asociación delictiva & 0.000 & 0.000 & 0.998 & 1.000 & 0.964 & 1.037 \\
\hline Uso de las TIC & 0.034 & 0.934 & 0.334 & 1.035 & 0.965 & 1.110 \\
\hline Constante & -9.091 & 3.510 & 0.061 & 0.000 & & \\
\hline
\end{tabular}

Nota: O.R. = Odds Ratio o razón de momios; Variables ficticias usadas como referencia: 1 = ser mujer; $2=$ No tener apellidos mayas; $3=$ No ser migrante; $4=$ Ser heterosexual. 
Tal como se aprecia en la Tabla 19, el modelo ecológico para agresores fue más consistente que el de las víctimas. Los factores de riesgo como la orientación sexual, la agresión proactiva y la popularidad continuaron siendo significativos, aumentando la posibilidad de agresión hasta 3.6 veces para la orientación sexual; en un 48\% para la agresión proactiva y casi 3 veces para los participantes que se consideran populares. Por su parte, el único factor de protección, la satisfacción escolar, continúo siendo significativo al disminuir hasta en un $49 \%$ la posibilidad de ser agresor. Únicamente el tener pares antisociales no continúo siendo un factor de riesgo, lo que sugiere que las variables comunitarias pueden ser moderadas por las individuales y escolares.

En conclusión, el trabajo con los agresores puede realizarse tanto a nivel individual como a nivel escolar; y el trabajar los dos niveles en conjunto promete mayores mejoras.

\section{Simplificación de los modelos ecológicos para víctimas y agresores}

Finalmente, siguiendo al principio de parsimonia, se buscó obtener el modelo más sencillo que permita explicar la mayor cantidad de varianza del acoso escolar tanto para víctimas como para agresores. Para ello, nuevamente se realizó una regresión logística con todos los factores del estudio, pero en esta ocasión siguiendo el método de pasos sucesivos con eliminación hacia atrás (step wise regression with backward elimination). Este método computacional permite eliminar variables que no resultaron significativas y conservar aquellas que sí lo fueron en la presencia del demás conjunto de variables. El modelo resultante es un modelo con la menor cantidad de variables que explique la mayor cantidad de varianza posible.

Adicionalmente, gracias al software utilizado, es posible guardar las puntuaciones generadas por el modelo para explorar su adecuación mediante la curva característica operativa del receptor (ROC curve). Esta curva es una representación gráfica de la sensibilidad y especificidad de un clasificador binario, que simplemente representa que tan buenas son las puntuaciones guardadas para clasificar correctamente a las víctimas o agresores (verdaderos positivos - sensibilidad), de las no víctimas o no agresores (verdaderos negativos - especificidad). La finalidad es obtener un modelo cuya área bajo de la curva, sea mejor que el mero azar (50\%). 


\section{Modelo simplificado para víctimas}

El modelo obtenido para las víctimas requirió de 16 pasos realizados de forma automática por el software. Obteniendo un modelo con un ajuste apropiado según la prueba de bondad de ajuste de Hosmer y Lameshow $\left(\chi^{2}=7.52, \mathrm{gl}=8 ; p=.481\right)$. El modelo resultante, con solo dos variables, logra explicar un $16 \%$ de la varianza de la victimización, con un porcentaje de clasificación del 78.6\%.

El modelo obtenido estuvo compuesto por las variables agresión reactiva (factor a nivel individual) y la satisfacción escolar (factor a nivel escolar). Tal como se aprecia en la Tabla 20, por una parte, la agresión reactiva representa un factor de riesgo al estar directamente asociada con la victimización; ya que según la razón de momios puntuar alto en agresión reactiva aumenta hasta un $13 \%$ la posibilidad de ser víctimas. Por otra parte, la satisfacción escolar resultó un factor de protección pues asociada de forma inversa a la victimización, pues en aquellos que tenían una mayor satisfacción, la posibilidad de ser víctimas disminuía hasta en un $31 \%$.

Tabla 20.

Modelo simplificado para víctimas.

\begin{tabular}{|c|c|c|c|c|c|c|}
\hline \multirow{2}{*}{ Variables } & \multirow{2}{*}{ B } & \multirow{2}{*}{ Wald } & \multirow{2}{*}{ Sig. } & \multirow{2}{*}{ O.R. } & \multicolumn{2}{|c|}{ I.C. $(95 \%)$ para O.R. } \\
\hline & & & & & Inferior & Superion \\
\hline Agresión reactiva & 0.124 & 4.711 & 0.030 & 1.132 & 1.012 & 1.266 \\
\hline Satisfacción escolar & -0.372 & 10.982 & 0.001 & 0.690 & 0.553 & 0.859 \\
\hline Constante & -0.781 & 0.337 & 0.561 & 0.458 & & \\
\hline
\end{tabular}

Nota: O.R. = Odds Ratio o razón de momios; I.C.= Intervalo de confianza.

Evaluación del modelo simplificado para las víctimas. Para evaluar el modelo se obtuvieron los valores pronosticados por este modelo (probabilidad pronosticada), y se evaluó utilizando la curva ROC. Tal como se aprecia en la Figura 15, se obtuvo un modelo que permite clasificar a las víctimas mejor que el azar a partir de las puntuaciones en agresión reactiva y satisfacción escolar. Se obtuvo un área bajo la curva de 78\%, con un 
intervalo de confianza del $95 \%$ que va del $69.1 \%$ al $86.9 \%$, lo que significa que el modelo obtenido clasifica a víctimas y no víctimas mejor que la mera adivinación.

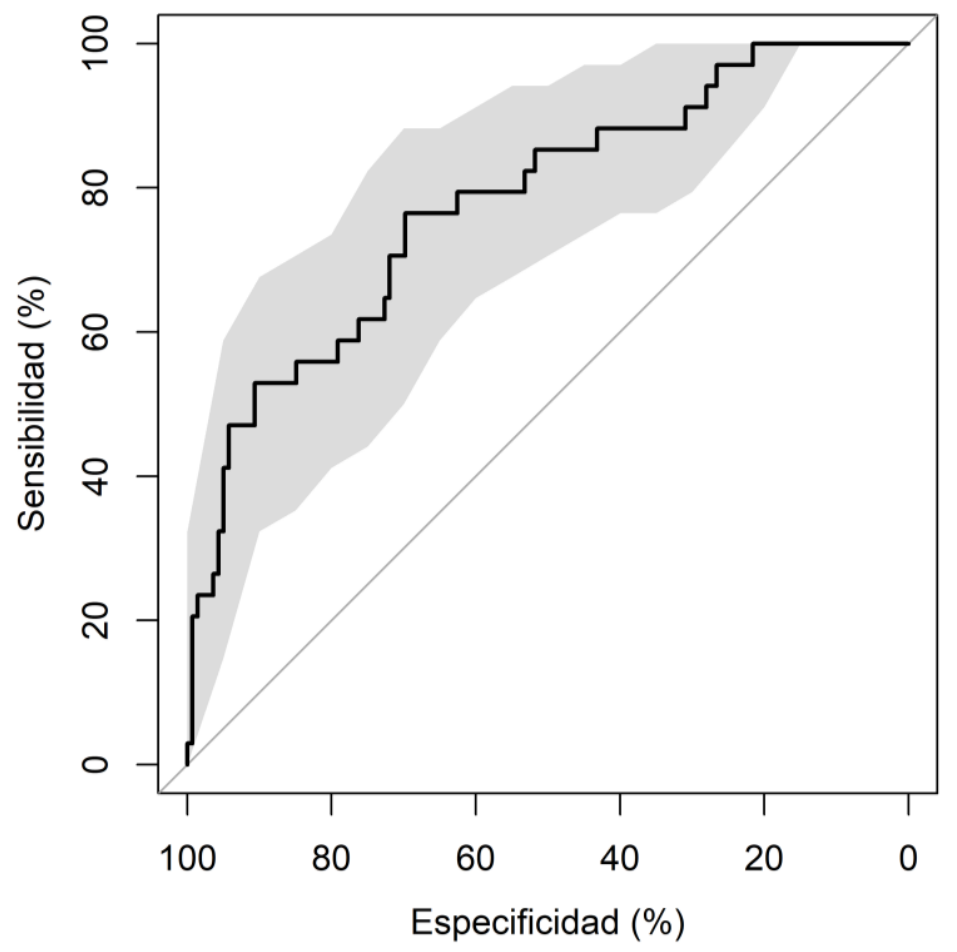

Figura 15. Curva ROC del modelo reducido para víctimas.

\section{Modelo simplificado para agresores}

Finalmente, el modelo obtenido para los agresores requirió solo de 14 pasos. El resultado, un modelo con un ajuste apropiado según la prueba de bondad de ajuste de Hosmer y Lameshow $\left(\chi^{2}=5.22, \mathrm{gl}=8 ; p=.733\right)$. El modelo resultante, con solo cuatro variables, logra explicar un $36.4 \%$ de la varianza de la agresión, con una tasa de clasificación del $90.1 \%$.

El modelo obtenido estuvo compuesto por las variables orientación sexual y agresión proactiva a nivel individual, y por la popularidad y satisfacción escolar a nivel escuela. En este caso, tanto la orientación sexual, como la agresión y la popularidad resultaron ser factores de riesgo, ya que estaban directamente asociadas con la posibilidad de ser agresores. Tal como se aprecia en la Tabla 21, tener una orientación sexual diferente 
a la heterosexual aumenta hasta 3.6 veces la posibilidad de ser agresor. Por su parte, tener puntuaciones altas en agresión proactiva, aumenta hasta un $42 \%$ esta posibilidad.

Finalmente, la popularidad, aumenta hasta 2.5 veces la agresión. Contrario a éstas, la satisfacción escolar resultó ser un factor de protección al estar asociada de forma negativa a la agresión, pues aquellos participantes que estaban más satisfechos con su vida escolar tenían hasta $37 \%$ menos posibilidades de ser agresores.

Tabla 21.

Modelo simplificado para agresores.

\begin{tabular}{lcrcccc}
\hline \multicolumn{1}{c}{ Variables } & B & Wald & Sig. & O.R. & \multicolumn{2}{c}{ I.C. (95\%) para O.R. } \\
\cline { 6 - 7 } & & & & & Inferior & Superior \\
\hline Orientación sexual $^{1}$ & & & & & & \\
Agresión proactiva & 0.350 & 10.360 & 0.001 & 1.420 & 1.147 & 1.757 \\
Popularidad & 0.941 & 9.360 & 0.002 & 2.562 & 1.402 & 4.680 \\
Satisfacción escolar & -0.455 & 10.223 & 0.001 & 0.635 & 0.480 & 0.839 \\
Constante & -5.773 & 10.907 & 0.001 & 0.003 & & \\
\hline
\end{tabular}

Nota: O.R. = Odds Ratio o razón de momios; I.C.= Intervalo de confianza. 1 = Variable ficticia como referencia: ser heterosexual.

Evaluación del modelo simplificado para los agresores. Finalmente, el modelo se evaluó de la misma forma que el modelo simplificado para víctimas, obteniendo los valores pronosticados (probabilidad pronosticada), y utilizando la curva ROC. Tal como se aprecia en la Figura 16, se obtuvo un modelo que permite clasificar a las víctimas mejor que el azar a partir de las puntuaciones de las cuatro variables. Se obtuvo un área bajo la curva de $81.9 \%$, con un intervalo de confianza del $95 \%$ que va del $73.5 \%$ al $90.3 \%$, lo que significa que el modelo obtenido clasifica a agresores y no agresores mejor que la mera adivinación, incluso mejor que el modelo de víctimas. 


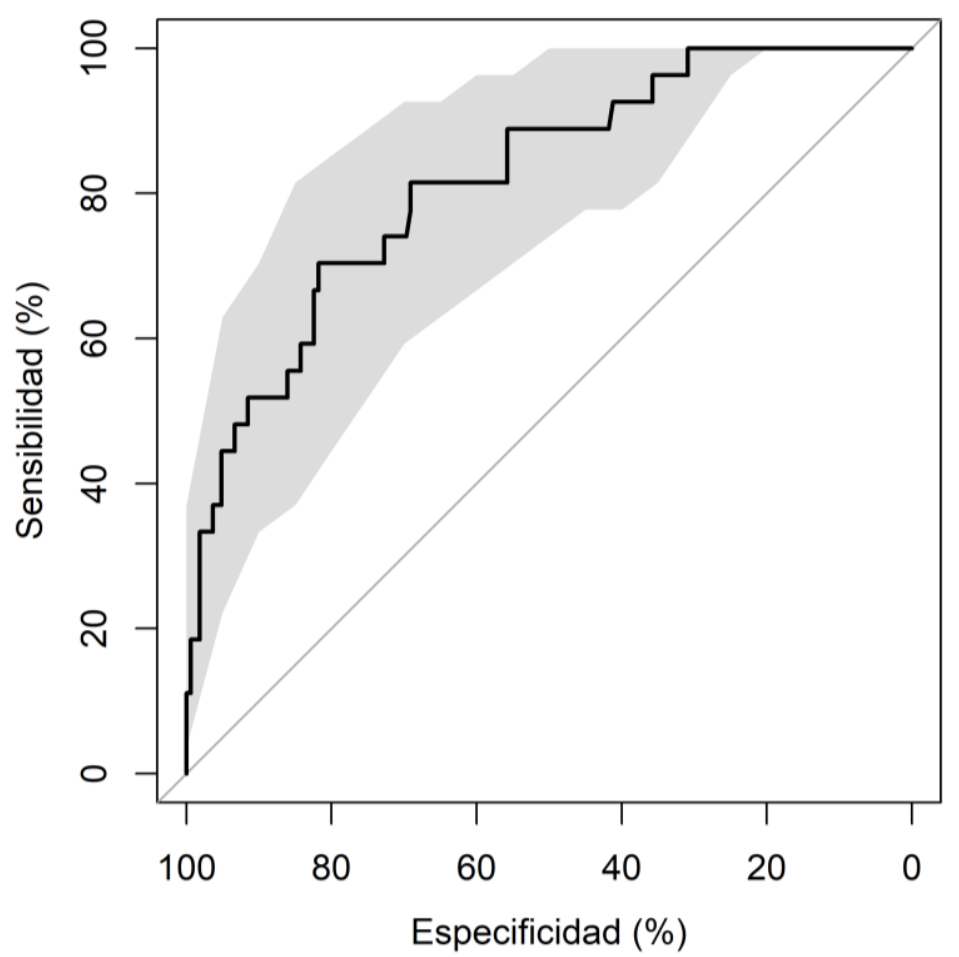

Figura 16. Curva ROC del modelo reducido para agresores. 


\section{Capítulo 5.}

\section{Conclusiones}

El presente capítulo aborda la discusión y contraste de los resultados encontrados con las investigaciones previas; desde la parte de los descriptivos, hasta los modelos analizados. De igual forma, se concluye sobre las aportaciones de este trabajo a nivel teórico sobre el objeto de estudio. Y finalmente, se brindan las limitaciones y sus respectivas recomendaciones en función de lo obtenido.

\section{Discusión}

\section{Sobre prevalencias y descriptivos}

De primera mano, cabe destacar los resultados encontrados con respecto a la prevalencia estimada en el presente estudio. Los resultados arrojan prevalencias cercanas al $20 \%$ para las víctimas, y del 14\% para los agresores. Estos resultados son menores a los encontrados en estudios previos como el reportado por Modecki et al., (2014) donde se estiman prevalencias cercanas al 35\% tanto para víctimas y agresores en el acoso escolar cara a cara. Sin embargo, cabe recalcar que esto posiblemente se deba a que los estudios sintetizados por Modecki son estudios que incluyen "muestras de adolescentes (con un rango de edad incluyendo jóvenes de al menos entre 12 a 18 años)" (p. 604); situación que no es compartida con este estudio realizado en población de adultos jóvenes.

Los estudios con poblaciones similares por su parte han encontrado resultados diversos. Por ejemplo, se han encontrado estimaciones relativamente bajas, del $6.7 \%$ para víctimas y $2.5 \%$ para agresores (Chapell et al., 2006); mientras que otros han encontrado prevalencias relativamente cercanas a las de este estudio, de un 10.6 para víctimas y $12.4 \%$ para agresores (Hoyos de los Ríos et al., 2012). Los estudios que no han hecho distinción entre víctimas o agresores, reportan resultados mucho más variados, yendo desde un 7\%, hasta un 43\% (Rospenda et al., 2013). Sin embargo, en su mayoría se pueden observar prevalencias menores a los encontrados en el meta-análisis de Modecki et al.

Lo anterior es posible que se deba a que las dinámicas de acoso escolar suelen cambiar conforme a la edad; pues se ha encontrado que los estudiantes suelen expresar acoso escolar de una forma más frecuente durante la secundaria, con una posterior disminución en niveles educativos superiores (Björkqvist et al., 1992; Juvonen y Graham, 
2014). Por tanto, es posible que esta menor prevalencia encontrada en el estudio a comparación de lo hallado por Modecki se deba a estas diferencias asociadas a las etapas del desarrollo.

Otro aspecto analizado es la relación entre el acoso escolar con el sexo. Los estudios señalan que los varones suelen presentar mayores conductas de acoso directo que las mujeres, y por el contrario, las mujeres presentan mayores conductas de acoso indirecto que los hombres (Björkqvist et al., 1992; Juvonen y Graham, 2014). Al respecto, este estudio encontró resultados similares. Si bien de forma multivariada no se encontraron diferencias entre ambas categorías de agresión; sí se encontraron diferencias a nivel univariado; siendo las mujeres las que presentan diferencias significativas al generar chismes y rumores en comparación con los hombres (es decir, agresión indirecta o relacional); y los hombres los que expresan mayores amenazas que las mujeres (un tipo de agresión categorizado como directa). Estas diferencias posiblemente se deben a cuestiones relacionadas a la socialización de patrones y roles de género, que influyen en la expresión de la agresión (Felix y Green, 2010).

Relacionado a lo anterior; también se reportaron resultados concernientes a los tipos de acoso escolar presentados en la muestra de participantes; en donde destacan con mayores frecuencias el acoso a tipo indirecto o relacional, como el poner apodos, esparcir rumores o chismes, la exclusión social o el ciberbullying; y con mucha menor frecuencia el acoso de tipo directo como las agresiones físicas, las amenazas o el robo y destrucción de pertenencias. Estos resultados son consistentes con las investigaciones previas, pues los estudios con estudiantes de nivel superior señalan que precisamente es el acoso de tipo indirecto o relacional el que tiene una mayor prevalencia; tanto en estudios internacionales (Mukhtar, 2011), como en países latinoamericanos (Hoyos de los Ríos et al., 2012), e incluso a nivel nacional (Prieto-Quezada et al., 2015). Nuevamente es posible que esto se deba a las diferencias existentes en el desarrollo psicológico de los participantes en comparación con los estudios que se han realizado en niveles educativos básicos.

Para finalizar con los resultados descriptivos, también se exploró el lugar de expresión del acoso escolar. Los resultados señalan que son por mucho (83\%) las aulas; seguido por actividades extraescolares o pasillos. Estos resultados nuevamente son 
consistentes con las investigaciones previas, que han señalado que existe una relación entre el lugar y la etapa de desarrollo de los alumnos. Por ejemplo, Rivers y Smith (1994) encontraron que los alumnos de niveles básicos suelen expresar el acoso en espacios como los patios escolares; mientras que los alumnos de grados superiores suelen reportar las aulas y los pasillos. De hecho este patrón también fue encontrado en el reporte técnico del estudio de validación original del instrumento utilizado, donde se encontró que los alumnos mayores suelen reportar acoso con mayor frecuencia en los salones, y los alumnos más pequeños en los patios escolares (Furlong et al., 2006).

\section{Sobre los factores de riesgo y los modelos}

Otro aspecto importante de la investigación es la consistencia de algunos factores de riesgo y protección. Por ejemplo, las víctimas tuvieron como factores asociados significativamente la agresión reactiva, la satisfacción escolar, y la violencia familiar. Todos estos son factores de riesgo que han señalado que su presencia incrementa las posibilidades de que los alumnos sean identificados como víctimas de acoso escolar (Álvarez-García et al., 2015; Baldry, 2003; Juvonen et al., 2012; Wang et al., 2014). Otros factores, como el sexo, edad, la ascendencia indígena, origen, orientación sexual, empatía, impulsividad, apoyo social, popularidad, normas, estilos de crianza o uso de las TIC no fueron significativas para el modelo de víctimas.

Es posible que estos resultados se deban a que si bien estas otras variables habían sido identificadas como consistentemente asociadas al acoso escolar (Álvarez-García et al., 2015), hay que recordar que una gran mayoría de los estudios de acoso escolar se realizan con estudiantes a nivel primaria, secundaria o preparatoria (Dibomicucci Brazil et al., 2015; Valdés Cuervo et al., 2016), por lo que es posible que la significancia de esas variables lo sean para esos niveles educativos, pero no necesariamente para el nivel superior; tal como se encontró en este estudio. Estas apreciaciones son similares a lo encontrado con los agresores, donde variables como la agresión proactiva, la orientación sexual, la popularidad, la satisfacción escolar o el tener amigos que realizan conductas antisociales resultaron significativos de forma consistente con otros estudios (Álvarez-García et al., 2015); pero no así el resto de las variables. Sin embargo, hay que hacer mención especial de un factor de riesgo en particular para la agresión: la orientación sexual. 
Los resultados encontrados con respecto a la orientación sexual como un factor de riesgo para realizar conductas de agresión sin duda es algo inesperado. Si bien las investigaciones previas han relacionado a la orientación sexual como un factor de riesgo para el acoso, estas investigaciones lo han relacionado con el ser víctima (bullying por homofobia) y no como factor de riesgo para ser agresor (Álvarez-García et al., 2015; Espelage et al., 2017, 2008). Sin embargo, lo cierto es que hay estudios que han encontrado resultados similares. Por ejemplo, Pinhey y Brown (2005) encontraron que las mujeres homosexuales presentan mayores niveles de agresión que las mujeres heterosexuales, o que los hombres homosexuales. Estos resultados han sido similares a los encontrados por Berlan et al., (2010) donde las mujeres bisexuales y mayormente heterosexuales reportan mayores niveles de agresión que las mujeres heterosexuales. Y Wensley y Campbell (2012) encontraron que tanto hombres y mujeres no heterosexuales presentan mayor involucramiento en acoso escolar tanto como víctimas como agresores cuando se comparan con participantes heterosexuales.

Es posible que este fenómeno tenga su origen en los roles de género asociados al sexo. Por ejemplo, Gini y Pozzoli (2006) encontraron que la identificación con la masculinidad estaba asociada a la expresión de bullying físico. Y otros estudios han encontrado que el poco apego a rasgos y comportamientos estereotípicamente masculinos o femeninos están asociados a la victimización (Navarro, Larrañaga, y Yubero, 2016). De hecho se ha encontrado también que los hombres con rasgos e identificación con roles de género femeninos suelen expresar agresiones indirectas o relacionales (formas de agresión más propias de las mujeres) a diferencia de sus pares heteronormados (Ewing Lee y TroopGordon, 2011). Es posible que esto explique por qué se encontró a la orientación sexual como un factor de riesgo para ser agresor, dado que la agresión indirecta o relacional fue una de las más frecuentes en este nivel educativo, por lo que es posible que los hombres no heterosexuales reporten una mayor frecuencia de conductas agresivas de tipo indirecta $\mathrm{o}$ relacional. Sin duda este es un hallazgo que debe explorarse con más detenimiento y de manera sistematizada.

Otro aspecto importante para mencionar es la utilidad del modelo ecológico para el estudio del bullying. Si bien los resultados del presente estudio señalan que hay diversos 
factores que aportan a explicar la agresión o victimización en diferentes niveles, lo cierto es que puede apreciarse una interacción entre estos factores. Esto se concluye debido a que algunas variables resultaron significativas en algunos niveles de forma independiente, pero ante la presencia de otras variables o niveles dejaron de serlo, como, por ejemplo, la violencia familiar en las víctimas. Aún más, en la evaluación por bloques de los diferentes niveles del modelo ecológico para víctimas, se señala que los factores individuales no son significativos por si solos, pero si cuando se considera la aportación de los factores a nivel escolar. Es decir, los factores individuales por si solos no aportan, sino aportan cuando interaccionan con variables a nivel escolar. Lo anterior no ocurre con el modelo para agresores, donde los factores individuales y escolares resultan significativos por si solos, o también en la interacción de ambos bloques. Esto recalca la importancia de considerar la interacción entre factores del modelo ecológico (Espelage y Swearer, 2010; Hong y Espelage, 2012), y no estudiar las variables de forma aislada las unas de las otras.

Finalmente, hay que destacar los modelos simplificados obtenidos. Estos resultados señalaron un modelo para víctimas que contiene únicamente dos variables (agresión reactiva y satisfacción escolar), y un modelo para agresores con cuatro variables (orientación sexual, agresión proactiva, popularidad y satisfacción escolar); siendo el modelo de agresores el que presento un mejor ajuste al explicar un 36\% de la varianza y una tasa de clasificación de $90.1 \%$; en comparación con el de víctimas que solo explicó un $16 \%$ de la varianza y tuvo una tasa de clasificación del 78.6\%. Si bien ambos modelos tuvieron resultados mejores que el azar; de alguna forma se demuestra que es más sencillo el poder identificar a los agresores que a las víctimas. Lo anterior no es único de este fenómeno, sino en general, los estudios de valoración del riesgo de violencia han sido más desarrollados para identificar a agresores que a víctimas, y esto se refleja en que en su mayoría se han desarrollado instrumentos para evaluar a los agresores y pocos para víctimas (Andrés-Pueyo y Echeburúa, 2010).

\section{Conclusiones}

En general, pueden concluirse cinco aspectos relevantes: 1) el fenómeno del acoso escolar o bullying existe y ocurre en el nivel superior; pues uno de cada cinco estudiantes es víctima de ello; 2) sus formas de expresión y dinámicas son diferentes a las encontradas a 
nivel básico, pues son más frecuentes las agresiones indirectas o relacionales; y estas suelen ocurrir en los salones de clases más que en los espacios recreativos; 3) No todos los factores relacionados al acoso escolar encontrados en estudios a nivel básico fueron consistentes con los identificados a nivel superior; lo que sugiere una dinámica diferente en este nivel, y por tanto, aproximaciones de investigación e intervención que consideren estas particularidades; 4) que la orientación sexual no solo puede ser un factor de riesgo para ser víctima, sino que también está asociada con la agresión; y 5) que resulta más consistente la identificación de agresores que de víctimas; por lo que resulta importante seguir estudiando los factores de estas últimas.

Estas conclusiones además deben considerarse en el contexto de las limitaciones que tiene el presente estudio. En específico, se consideran importante señalar las limitaciones del muestreo y de posibles imprecisiones de los instrumentos de medición. Al respecto, tiene que contemplarse que la investigación utilizó un muestreo no probabilístico, y cuyo tamaño es relativamente pequeño para los estudios positivistas; por lo que las conclusiones anteriores no pueden considerarse como representativas de la población de alumnos de nivel superior; sino que a lo mucho de universidades privadas y con características similares a la escuela participante. Además, tienen que considerarse la posible imprecisión de ciertas medidas, como la violencia familiar o la orientación sexual, que son medidas que presentan una alta deseabilidad social, por lo que la utilización de instrumentos autoinformados pueden presentar sesgos perceptivos de los participantes, Por lo que es importante interpretar con cautela estas variables y otras similares.

\section{Recomendaciones}

Primeramente, es importante señalar algunas recomendaciones metodológicas importantes para estudios futuros. Principalmente sobre la instrumentación utilizada para medir el acoso escolar, ya que este elemento metodológico ha sido una de las principales preocupaciones en el estudio del acoso escolar (Bovaird, 2010; Furlong, Sharkey, Felix, Tanigawa, y Green, 2010; Swearer, Siebecker, Johnsen-Frerichs, y Wang, 2010). El California Bullying Victimizacion Scale resulta un instrumento idóneo para la medición del acoso escolar; ya que no solo es fácil de aplicar (Felix et al., 2011), sino que también utiliza lineamientos señalados para la adecuada identificación del acoso escolar, como el criterio 
de dos a tres agresiones en el último mes (Solberg y Olweus, 2003); o también la inclusión del criterio de desbalance de poder (Ybarra et al., 2014). Por tanto, se recomienda su uso en futuras investigaciones, o en su defecto, instrumentos que consideren estos elementos en su construcción (Vivolo-Kantor et al., 2014).

En segundo lugar, hay que destacar la aproximación sobre el análisis de datos y diseño; pues como se mencionó con anterioridad, resulta esencial considerar la interacción entre los diversos factores y sus niveles; por lo que se recomienda continuar estudiando el acoso escolar siguiendo el enfoque del modelo ecológico y sus diferentes niveles; a través de diversos métodos de regresión que permita el análisis de los diferentes niveles.

En tercer lugar, también se recomienda considerar otras posibles líneas de investigación. La primera, el considerar no solo los factores de riesgo y protección; sino también las consecuencias en el nivel superior. Este estudio únicamente consideró los primeros, y no se exploraron las posibles consecuencias del acoso escolar en la salud mental o sus efectos en el área académica de los involucrados; por lo que se recomienda que futuras investigaciones estudien estas consecuencias con estudiantes de nivel superior. Una segunda recomendación es la exploración de la orientación sexual como un factor de riesgo para la agresión. Si bien se han encontrado resultados similares en otros estudios (Berlan et al., 2010; Pinhey y Brown, 2005; Wensley y Campbell, 2012), la información que se tiene al respecto es escasa; por lo que se recomienda estudiar con mayor detenimiento este fenómeno en particular; haciendo énfasis en el posible efecto de los roles de género en esta situación.

Finalmente, también se recomienda tomar en consideración las implicaciones prácticas del estudio. En primer lugar, la importancia del diagnóstico en este nivel educativo, que ha sido poco estudiado en comparación con otros niveles; en segundo lugar considerar la interacción entre los niveles del modelo ecológico halladas en esta investigación al momento de planificar programas de intervención contra el acoso escolar en el nivel superior; y finalmente, a nivel de política educativa, que también debe considerar este fenómeno a nivel universitario y no solo a nivel básico como algunas legislaciones locales realizan (Congreso del Estado de Yucatán, 2012); pues este fenómeno existe también a nivel superior; por lo que la política pública y la política educativa en 
especial, deben responder ante este fenómeno; por lo que se recomienda en particular a los posibles involucrados en la política pública tomar en consideración estas sugerencias finales. 


\section{Referencias}

Albores-Gallo, L., Sauceda-García, J. M., Ruiz-Velasco, S. y Roque-Santiago, E. (2011). El acoso escolar (bullying) y su asociación con trastornos psiquiátricos en una muestra de escolares en México. Salud Publica de Mexico, 53(3), 220-227.

Alikasifoglu, M., Erginoz, E., Ercan, O., Uysal, O. y Albayrak-Kaymak, D. (2007).

Bullying behaviours and psychosocial health: Results from a cross-sectional survey among high school students in Istanbul, Turkey. European Journal of Pediatrics, 166(12), 1253-1260. https://doi.org/10.1007/s00431-006-0411-X

Allan, E. J. y Madden, M. (2012). The nature and extent of college student hazing. International Journal of Adolescent Medicine and Health, 24(1), 83-90. https://doi.org/10.1515/ijamh.2012.012

Álvarez-García, D., García, T. y Núñez, J. C. (2015). Predictors of school bullying perpetration in adolescence: A systematic review. Aggression and Violent Behavior, 23, 126-136. https://doi.org/10.1016/j.avb.2015.05.007

American Educational Research Association. (2013). Prevention of Bullying in Schools, Colleges, and Universities. Washington, DC: American Educational Research Association.

Andrés-Pueyo, A. y Echeburúa, E. (2010). Valoración del riesgo de violencia: instrumentos disponibles e indicaciones de aplicación. Psicothema, 22(3), 403-409.

Andreu, J., Peña, E. y Ramirez, J. (2009). Cuestionario de agresión reactiva y proactiva: un instrumento de medida de la agresión en adolescentes. Revista de Psicopatología y Psicología Clínica, 14(1), 37-49.

Andrews, D. A. y Bonta, J. (2010). The Psychology of Criminal Conduct (5a ed.). New Providence: Anderson Publishing.

Argimon Pallás, J. M. y Jiménez Villa, J. (2004). Métodos de Investigación Clínica y Epidemiológica. Madrid: Elsevier España.

Asociación Nacional de Universidades e Instituciones de Educación Superior. (2014). Procedimiento, Requisitos y Tipología para el Ingreso de Instituciones de Educación a la ANUIES, A.C. Ciudad de México: ANUIES.

Atik, G. y Guneri, O. Y. (2012). California Bullying Victimization Scale: Validity and 
Reliability Evidence for the Turkish Middle School Children. Procedia - Social and Behavioral Sciences, 46, 1237-1241. https://doi.org/10.1016/j.sbspro.2012.05.281

Baldry, A. C. (2003). Bullying in schools and exposure to domestic violence. Child Abuse and Neglect, 27(7), 713-732. https://doi.org/10.1016/S0145-2134(03)00114-5

Banse, R., Koppehele-Gossel, J., Kistemaker, L. M., Werner, V. a. y Schmidt, A. F. (2013). Pro-criminal attitudes, intervention, and recidivism. Aggression and Violent Behavior, 18(6), 673-685. https://doi.org/10.1016/j.avb.2013.07.024

Barboza, G. E., Schiamberg, L. B., Oehmke, J., Korzeniewski, S. J., Post, L. A. y Heraux, C. G. (2009). Individual characteristics and the multiple contexts of adolescent bullying: An ecological perspective. Journal of Youth and Adolescence, 38(1), 101121. https://doi.org/10.1007/s10964-008-9271-1

Baruch-Dominguez, R., Infante-Xibille, C. y Saloma-Zuñiga, C. E. (2016). Homophobic bullying in Mexico: Results of a national survey. Journal of LGBT Youth, 13(1-2), 18-27. https://doi.org/10.1080/19361653.2015.1099498

Bauman, S., Toomey, R. B. y Walker, J. L. (2013). Associations among bullying, cyberbullying, and suicide in high school students. Journal of Adolescence, 36(2), 341-350. https://doi.org/10.1016/j.adolescence.2012.12.001

Baumrind, D. (1971). Current patterns of parental authority. Developmental Psychology, 4(1, Pt.2), 1-103. https://doi.org/10.1037/h0030372

Berlan, E. D., Corliss, H. L., Field, A. E., Goodman, E. y Bryn Austin, S. (2010). Sexual Orientation and Bullying Among Adolescents in the Growing Up Today Study. Journal of Adolescent Health, 46(4), 366-371. https://doi.org/10.1016/j.jadohealth.2009.10.015

Bernstein, J. Y. y Watson, M. W. (1997). Children Who Are Targets of Bullying: A Victim Pattern. Journal of Interpersonal Violence, 12, 483-498. https://doi.org/10.1177/088626097012004001

Björkqvist, K., Lagerspetz, K. M. J. y Kaukiainen, A. (1992). Do girls manipulate and boys fight? developmental trends in regard to direct and indirect aggression. Aggressive Behavior, 18(2), 117-127. https://doi.org/10.1002/1098-2337(1992)18:2<117::AIDAB2480180205>3.0.CO;2-3 
Bovaird, J. A. (2010). Scales and Surveys: Some problems with measuring bullying behavior. En S. R. Jimerson, S. M. Swearer y D. L. Espelage (Eds.), Handbook of Bullying in Schools: An International Perspective (pp. 277-292). New York: Routledge.

Bowes, L., Joinson, C., Wolke, D. y Lewis, G. (2015). Peer victimisation during adolescence and its impact on depression in early adulthood: prospective cohort study in the United Kingdom. BMJ, 350(jun02 2), h2469-h2469. https://doi.org/10.1136/bmj.h2469

Bradshaw, C. P., Waasdorp, T. E., Goldweber, A. y Johnson, S. L. (2013). Bullies, Gangs, Drugs, and School: Understanding the Overlap and the Role of Ethnicity and Urbanicity. Journal of Youth and Adolescence, 42(2), 220-234. https://doi.org/10.1007/s10964-012-9863-7

Brank, E. M., Hoetger, L. A. y Hazen, K. P. (2012). Bullying. Annual Review of Law and Social Science, 8(1), 213-230. https://doi.org/10.1146/annurev-lawsocsci-102811173820

Brock, C. H., Oikonomidoy, E. M., Wulfing, K., Pennington, J. L. y Obenchain, K. M. (2014). "Mean girls" go to college: Exploring female-female relational bullying in an undergraduate literacy methods course. Peace and Conflict: Journal of Peace Psychology, 20(4), 516-535. https://doi.org/10.1037/pac0000035

Brofenbrenner, U. (1977). Toward an Experimental Ecology of Human Development. American Psychologist, 32(7), 513-531. https://doi.org/10.1037/0003-066X.32.7.513

Carrillo Regalado, S. y Ríos Almodóvar, J. G. (2013). Trabajo y rendimiento escolar de los estudiantes universitarios. El caso de la Universidad de Guadalajara, México. Revista de la educación superior, 42(166), 9-34.

Casas, J. A., Del Rey, R. y Ortega-Ruiz, R. (2013). Bullying and cyberbullying: Convergent and divergent predictor variables. Computers in Human Behavior, 29(3), 580-587. https://doi.org/10.1016/j.chb.2012.11.015

Cassiani-Miranda, C. A., Gómez-Alhach, J., Cubides-Munévar, A. M. y HernándezCarrillo, M. (2014). Prevalencia de bullying y factores relacionados en estudiantes de bachillerato de una institución educativa de Cali, Colombia, 2011. Rev. salud pública, 
16(1), 14-26. https://doi.org/10.15446/rsap.v16n1.43490

Castillo Rocha, C. (2011). Juicio moral en conductas de maltrato entre iguales en una escuela secundaria de Mérida, Yucatán. En XI Congreso Nacional de Investigación Educativa (pp. 1-9). Ciudad de México.

Castillo Rocha, C. y Pacheco Espejel, M. M. (2008). Perfil del maltrato (bullying) entre estudiantes de secundaria en la Ciudad de Mérida, Yucatán. Revista Mexicana de Investigación Educativa, 13(38), 825-842.

Castillo Rocha, C. y Pacheco Espejel, M. M. (2009). El maltrato entre iguales desde la percepción de los adolescentes: hacia una perspectiva sistémica. En X Congreso Nacional de Investigación Educativa (pp. 1-9).

Cava, M. J., Estévez López, E., Buelga Vázquez, S. y Musitu Ochoa, G. (2013). Propiedades psicométricas de la Escala de Actitudes hacia la Autoridad Institucional en adolescentes (AAI-A). Anales de psicología, 29(2), 540-548.

Centro de Estudios para el Adelanto de las Mujeres y la Equidad de Género. (2013). Marco jurídico del acoso escolar (Bullying). México: Cámara de Diputados LXII Legislatura.

Chapell, M., Casey, D., De la Cruz, C., Ferrell, J., Forman, J., Lipkin, R., ... Whittaker, S. (2004). Bullying In College By Students and Teachers. Adolescence, 39(153), 53-64.

Chapell, M., Hasselman, S. L., Kitchin, T., Lomon, S. N., MacIver, K. W. y Sarullo, P. L. (2006). Bullying in elementary school, high school, and college. Adolescence, 4l(164), 633-648.

Chen, Y.-Y. y Huang, J.-H. (2014). Precollege and in-college bullying experiences and health-related quality of life among college students. Pediatrics, 135(1), 18-25. https://doi.org/10.1542/peds.2014-1798

Comisión de Derechos Humanos del Estado de Yucatán. (2014). Encuesta Estatal sobre Discriminación. Mérida: CODHEY.

Congreso del Estado de Yucatán. Ley para la Prevención, Combate y Erradicación de la Violencia en el Entorno Escolar del Estado de Yucatán, Diario Oficial del Gobierno del Estado de Yucatán § (2012). Mérida, México: Congreso del Estado de Yucatán. Recuperado a partir de http://www.transparencia.yucatan.gob.mx/datos/2013/sep/Ley_Prevencion_Combate_ 
Erradicacion_Violencia_Entorno_Escolar_300913.pdf

Cook, C. R., Williams, K. R., Guerra, N. G., Kim, T. E. y Sadek, S. (2010). Predictors of bullying and victimization in childhood and adolescence: A meta-analytic investigation. School Psychology Quarterly, 25(2), 65-83. https://doi.org/10.1037/a0020149

Cornell, D. G. y Bandyopadhyay, S. (2010). The Assessment of Bullying. En S. R. Jimerson, S. M. Swearer y D. L. Espelage (Eds.), Handbook of Bullying in Schools: An International Perspective (pp. 265-276). New York: Routledge.

Corsi, J. (1994). Una mirada abarcativa sobre el problema de la violencia familiar. México: Paidos.

Cozby, P. C. y Bates, S. C. (2015). Methods in Behavioral Research (12a.). New York: McGraw-Hil Education.

Crothers, L. M. y Levinson, E. M. (2004). Assessment of Bullying: A Review of Methods and Instruments. Journal of Counseling \& Development, 82(4), 496-503. https://doi.org/10.1002/j.1556-6678.2004.tb00338.x

de Bruyn, E. H., Cillessen, a. H. N. y Wissink, I. B. (2009). Associations of Peer Acceptance and Perceived Popularity With Bullying and Victimization in Early Adolescence. The Journal of Early Adolescence, 30(4), 543-566. https://doi.org/10.1177/0272431609340517

DeSouza, E. R. (2005). Bullying and Sexual Harassment Among Brazilian High School Students. Journal of Interpersonal Violence, 20(9), 1018-1038. https://doi.org/10.1177/0886260505277731

Dibomicucci Brazil, M., Basso Meneghini, V., de Souza Costa, P. y Lemes, S. (2015). School Bullying Profile: a Bibliometric Study From 2000 To 2013. International Research Journal of Education and Innovation (IRJEI), 1(March), 120-131.

Doğruer, N. y Yaratan, H. (2014). Developing a Bullying Scale for Use With University Students. Social Behavior \& Personality: an international journal, 42(2008), 81-92. https://doi.org/10.1007/s11528-011-0481-0

Dorantes Carrión, J. J. (2015). El ciberbullying, una experiencia vivida en la Universidad Veracruzana/México. En XIII Congreso Nacional de Investigación Educativa (pp. 1- 
12). Chihuahua.

Dresler-Hawke, E. y Whitehead, D. (2009). The behavioral ecological model as a

framework for school-based anti-bullying health promotion interventions. The Journal of school nursing : the official publication of the National Association of School Nurses, 25(3), 195-204. https://doi.org/10.1177/1059840509334364

Echeverría Echeverría, R. (2016). Estereotipos y discriminación hacia personas indígenas mayas: su expresión en las narraciones de jóvenes de mérida yucatán. Aposta Revista de Ciencias Sociales, 71(4), 95-127.

Eisenbraun, K. D. (2007). Violence in schools: Prevalence, prediction, and prevention. Aggression and Violent Behavior, 12(4), 459-469.

https://doi.org/10.1016/j.avb.2006.09.008

Escartín, J., Arrieta, C. y Rodríguez, A. (2010). “Mobbing” o acoso laboral: revisión de los principales aspectos teórico-metodológicos que dificultan su estudio. Actualidades en Psicología, 23(110), 1-19.

Espelage, D. L., Aragon, R., Birkett, M. y Koenig, W. (2008). Homophobic teasing, psychological outcomes, and sexual orientation among high school students: What influence do parents and schools have? School Psychology Review, 37(2), 202.

Espelage, D. L., Hong, J. S., Merrin, G. J., Davis, J. P., Rose, C. A. y Little, T. D. (2017). A Longitudinal Examination of Homophobic Name-Calling in Middle School: Bullying, Traditional Masculinity, and Sexual Harassment as Predictors. Psychology of Violence, (January), 1-10. https://doi.org/10.1037/vio0000083

Espelage, D. L., Low, S., Rao, M. A., Hong, J. S. y Little, T. D. (2014). Family violence, bullying, fighting, and substance use among adolescents: A longitudinal mediational model. Journal of Research on Adolescence, 24(2), 337-349. https://doi.org/10.1111/jora.12060

Espelage, D. L. y Swearer, S. M. (2010). A social-ecological model for bullying prevention and intervention: Understanding the impact of adults in the social ecology of youngsters. En S. R. Jimerson, S. M. Swearer y D. L. Espelage (Eds.), Handbook of Bullying in Schools: An International Perspective (pp. 61-72). New York: Routledge.

Ewing Lee, E. A. y Troop-Gordon, W. (2011). Peer socialization of masculinity and 
femininity: Differential effects of overt and relational forms of peer victimization.

British Journal of Developmental Psychology, 29(2), 197-213.

https://doi.org/10.1111/j.2044-835X.2010.02022.x

Farrington, D. P. y Baldry, A. C. (2010). Individual risk factors for school bullying.

Journal of Aggression, Conflict and Peace Research, 2(April), 4-16.

https://doi.org/10.5042/jacpr.2010.0001

Felix, E. D. y Green, J. G. (2010). Popular girls and brawny boys: The role of gender in bullying and victimization experiences. En S. R. Jimerson, S. M. Swearer y D. L. Espelage (Eds.), Handbook of Bullying in Schools: An International Perspective (pp. 173-186). New York: Routledge.

Felix, E. D., Sharkey, J. D., Green, J. G., Furlong, M. J. y Tanigawa, D. (2011). Getting precise and pragmatic about the assessment of bullying: The development of the California Bullying Victimization Scale. Aggressive Behavior, 37(3), 234-247. https://doi.org/10.1002/ab.20389

Francisco, S. M., Veiga Simão, A. M., Ferreira, P. C. y Martins, M. J. D. D. (2015). Cyberbullying: The hidden side of college students. Computers in Human Behavior, 43, 167-182. https://doi.org/10.1016/j.chb.2014.10.045

Furlong, M. J., Felix, E. D., Sharkey, J. D., Tanigawa, D., Green, J. G., Gonzalez, M., ... Michaca, S. (2006). Development of a Multi-Gating School Bullying Victimization Assessment: Technical Report and Study Results. Santa Bárbara, California.

Furlong, M. J. y Morrison, G. (2000). The school in school violence: Definitions and facts. Journal of Emotional and Behavioral Disorders, 8(2), 71-82. https://doi.org/10.1177/106342660000800203

Furlong, M. J., Sharkey, J. D., Felix, E. D., Tanigawa, D. y Green, J. G. (2010). Bullying Assessment: A call for increased precision of self-reporting procedures. En S. R. Jimerson, S. M. Swearer y D. L. Espelage (Eds.), Handbook of Bullying in Schools: An International Perspective (pp. 329-346). New York: Routledge.

Gahagan, K., Vaterlaus, J. M. y Frost, L. R. (2016). College student cyberbullying on social networking sites: Conceptualization, prevalence, and perceived bystander responsibility. Computers in Human Behavior, 55, 1097-1105. 
https://doi.org/10.1016/j.chb.2015.11.019

García Montañez, M. V. y Ascencio Martínez, C. A. (2015). Bullying y violencia escolar: diferencias, similitudes, actores, consecuencias y origen. Revista Intercontinental de Psicología y Educación, 17(2), 9-38.

Gaxiola Romero, J., Frías Armenta, M., Cuamba Osorio, N., Franco Betanzos, J. D. y Olivas Salido, L. C. (2006). Validación del cuestionario de prácticas parentales en una población mexicana. Enseñanza e Investigación en Psicología, 11(1), 115-128.

Gibb, Z. G. y Devereux, P. G. (2014). Who does that anyway? Predictors and personality correlates of cyberbullying in college. Computers in Human Behavior, 38, 8-16. https://doi.org/10.1016/j.chb.2014.05.009

Gini, G., Albiero, P., Benelli, B. y Altoè, G. (2007). Does empathy predict adolescents' bullying and defending behavior? Aggressive Behavior, 33(5), 467-476. https://doi.org/10.1002/ab.20204

Gini, G. y Pozzoli, T. (2006). The role of masculinity in children's bullying. Sex Roles, 54(7-8), 585-588. https://doi.org/10.1007/s11199-006-9015-1

Gini, G. y Pozzoli, T. (2009). Association between bullying and psychosomatic problems: a meta-analysis. Pediatrics, 123(3), 1059-1065. https://doi.org/10.1542/peds.2008-1215

Gini, G. y Pozzoli, T. (2013). Bullied Children and Psychosomatic Problems: A Metaanalysis. Pediatrics, 132(4), 720-729. https://doi.org/10.1542/peds.2013-0614

Gladden, R. M., Vivolo-Kantor, A., Hamburger, M. E. y Lumpkin, C. D. (2014). Bullying surveillance among youths: Uniform definitions for public health and recommended data elements, Version 1.0. Centers for Disease Control and Prevention Atlanta, Georgia. Atlanta: Centers for Disease Control and Prevention. https://doi.org/http://www.cdc.gov/violenceprevention/pdf/bullying-definitions-finala.pdf

Gonzalez, A. (1988). Indicadores del rendimiento escolar: relación entre pruebas objetivas y calificaciones. Revista de Educación, 287, 31-54.

Gregory, A., Cornell, D., Fan, X., Sheras, P., Shih, T.-H. y Huang, F. (2010). Authoritative school discipline: High school practices associated with lower bullying and victimization. Journal of Educational Psychology, 102(2), 483-496. 
https://doi.org/10.1037/a0018562

Gruber, J. E. y Fineran, S. (2007). The Impact of Bullying and Sexual Harassment on Middle and High School Girls. Violence Against Women, 13(6), 627-643. https://doi.org/10.1177/1077801207301557

Hamburger, M. E., Basile, K. y Vivolo, A. (2011). Measuring Bullying Victimization, Perpetration, and Bystander Experiences: A Commpendiumm of Assessment Tools. Centers for Disease Control and Prevention. Georgia: Centers for Disease Control and Prevention.

Hemphill, S. A., Kotevski, A., Tollit, M., Smith, R., Herrenkohl, T. I., Toumbourou, J. W. y Catalano, R. F. (2012). Longitudinal predictors of cyber and traditional bullying perpetration in Australian secondary school students. Journal of Adolescent Health, 5l(1), 59-65. https://doi.org/10.1016/j.jadohealth.2011.11.019

Hernández Sampieri, R., Fernández Collado, C. y Baptista Lucio, M. (2013). Metodología de la Investigación (6a ed.). Ciudad de México: McGraw-Hil.

Herrenkohl, T. I., Maguin, E., Hill, K. G., Hawkins, J. D., Abbott, R. D. y Catalano, R. F. (2000). Developmental risk factors for youth violence. The Journal of adolescent health : official publication of the Society for Adolescent Medicine, 26(3), 176-186. https://doi.org/10.1016/S1054-139X(99)00065-8

Hoeve, M. H., Dubas, J. S., Eichelsheim, V. I., Van Der Laan, P. H., Smeenk, W. y Gerris, J. R. M. (2009). The relationship between parenting and delinquency: A meta-analysis. Journal of Abnormal Child Psychology, 37(6), 749-775. https://doi.org/10.1007/s10802-009-9310-8

Holt, M. K., Green, J. G., Reid, G., DiMeo, A., Espelage, D. L., Felix, E. D., ... Sharkey, J. D. (2014). Associations between past bullying experiences and psychosocial and academic functioning among college students. Journal of American College Health, 62(8), 552-560. https://doi.org/10.1080/07448481.2014.947990

Hong, J. S. y Espelage, D. L. (2012). A review of research on bullying and peer victimization in school: An ecological system analysis. Aggression and Violent Behavior, 17(4), 311-322. https://doi.org/10.1016/j.avb.2012.03.003

Hosmer, D. W., Lemeshow, S. y Sturdivant, R. X. (2013). Applied Logistic Regression (3a 
ed.). Hoboken: John Wiley \& Sons, Inc.

Hoyos de los Ríos, O. L., Llanos Martínez, M. y Valega Mackenzie, S. J. (2012). El maltrato entre iguales por abuso de poder en el contexto universitario: incidencia, manifestaciones y estrategias de solución. Universitas psychologica, 11(3), 793-802.

Hunter, S. C., Boyle, J. M. E. y Warden, D. (2007). Perceptions and correlates of peervictimization and bullying. The British journal of educational psychology, 77(Pt 4), 797-810. https://doi.org/10.1348/000709906X171046

Hunter, S. C., Durkin, K., Boyle, J. M. E., Booth, J. N. y Rasmussen, S. (2014). Adolescent Bullying and Sleep Difficulties. Europe's Journal of Psychology, 10(4), 740-755. https://doi.org/10.5964/ejop.v10i4.815

Instituto Nacional de Estadística y Geografía. (2014). Encuesta de Cohesión Social para la Prevención de la Violencia y la Delincuencia (ECOPRED) 2014. Ciudad de México: Instituto Nacional de Estadística y Geografía. Recuperado a partir de http://www.beta.inegi.org.mx/proyectos/enchogares/especiales/ecopred/2014/

Instituto Nacional de Estadística y Geografía. (2015). Encuesta Nacional sobre Disponibilidad y Uso de las TIC en Hogares: Modulo de Ciberacoso. Ciudad de México: INEGI.

Jessor, R., Turbin, M. S. y Costa, F. M. (1998). Risk and Protection in Successful Outcomes Among Disadvantaged Adolescents. Applied Developmental Science, 2(4), 194-208. https://doi.org/10.1207/s1532480xads0204_3

Jimerson, S. R., Swearer, S. M. y Espelage, D. L. (2010). Handbook of bullying in schools: an international perspective. Handbook of bullying in schools: An international perspective. https://doi.org/10.1017/CBO9781107415324.004

Jolliffe, D. y Farrington, D. P. (2006a). Development and validation of the Basic Empathy Scale. Journal of Adolescence, 29(4), 589-611. https://doi.org/10.1016/j.adolescence.2005.08.010

Jolliffe, D. y Farrington, D. P. (2006b). Examining the relationship between low empathy and bullying. Aggressive Behavior, 32(6), 540-550. https://doi.org/10.1002/ab.20154

Juvonen, J., Espinoza, G. y Knifsend, C. (2012). The Role of Peer Relationships in Student Academic and Extracurricular Engagement. En Handbook of Research on Student 
Engagement (pp. 387-401). Boston, MA: Springer US. https://doi.org/10.1007/978-14614-2018-7_18

Juvonen, J. y Graham, S. (2014). Bullying in schools: the power of bullies and the plight of victims. Annual review of psychology, 65, 159-85. https://doi.org/10.1146/annurevpsych-010213-115030

Juvonen, J., Wang, Y. y Espinoza, G. (2011). Bullying Experiences and Compromised Academic Performance Across Middle School Grades. The Journal of Early Adolescence, 31, 152-173. https://doi.org/10.1177/0272431610379415

Klomek, A. B., Kleinman, M., Altschuler, E., Marrocco, F., Amakawa, L. y Gould, M. S. (2011). High school bullying as a risk for later depression and suicidality. Suicide and Life-Threatening Behavior, 41(5), 501-516. https://doi.org/10.1111/j.1943278X.2011.00046.X

Kochenderfer, B. J. y Ladd, G. W. (1996). Peer victimization: cause or consequence of school maladjustment? Child development, 67(4), 1305-1317. https://doi.org/10.2307/1131701

Kodish, T., Herres, J., Shearer, A., Atte, T., Fein, J. y Diamond, G. (2016). Bullying, Depression, and Suicide Risk in a Pediatric Primary Care Sample. Crisis, 37(3), 241246. https://doi.org/10.1027/0227-5910/a000378

Konishi, C., Hymel, S., Zumbo, B. D. y Li, Z. (2010). Do school bullying and studentteacher relationships matter for academic achievement? A Multilevel Analysis. Canadian Journal of School Psychology, 25(1), 19-39. https://doi.org/10.1177/0829573509357550

Kowalski, R. M., Giumetti, G. W., Schroeder, A. N. y Reese, H. H. (2012). Cyber bullying among college students: Evidence from multiple domains of college life. Cutting-Edge Technologies in Higher Education (Vol. 5). Emerald Group Publishing Ltd. https://doi.org/10.1108/S2044-9968(2012)0000005016

Kubiszewski, V., Fontaine, R., Potard, C. y Gimenes, G. (2014). Bullying, sleep/wake patterns and subjective sleep disorders: Findings from a cross-sectional survey. Chronobiology International, 31(4), 542-553. https://doi.org/10.3109/07420528.2013.877475 
Lindsay, M. y Krysik, J. (2012). Online harassment among college students: A replication incorporating new internet trends. Information, Communication and Society, 15(5), 703-719. https://doi.org/10.1080/1369118X.2012.674959

López, V., Bilbao, M. Á., Ascorra, P., Moya, I. y Morales, M. (2014). La Escala de Clima Escolar: Adaptación al Español y Validación en Estudiantes Chilenos. Universitas Psychologica, 13(3), 1111-1122. https://doi.org/10.11144/Javeriana.UPSY13-3.ecea

Low, S. y Espelage, D. (2014). Conduits from community violence exposure to peer aggression and victimization: contributions of parental monitoring, impulsivity, and deviancy. Journal of counseling psychology, 61(2), 221-31. https://doi.org/10.1037/a0035207

Lozano Verduzco, I. y Diaz Loving, R. (2010). Medición de la identidad sexual en México. Revista Puertorriqueña de Psicología, 21(1), 133-154.

Lucio López, L. y González González, J. (2012). El teléfono móvil como instrumento de violencia entre estudiantes de bachillerato en México. En IV Congreso Internacional Latina de Comunicación Social (pp. 1-10).

Luna Soca, F. J. (2012). Bienestar subjetivo y satisfacción escolar en la adolescencia. Universitat de Girona.

MacDonald, C. D. y Roberts-Pittman, B. (2010). Cyberbullying among college students: Prevalence and demographic differences. Procedia - Social and Behavioral Sciences, 9, 2003-2009. https://doi.org/10.1016/j.sbspro.2010.12.436

Machado Azeredo, C., Madalena Rinaldi, A. E., Leite de Moraes, C., Bertazzi Levy, R. y Rossi Menezes, P. (2015). School bullying: A systematic review of contextual-level risk factors in observational studies. Aggression and Violent Behavior, 22, 65-76. https://doi.org/10.1016/j.avb.2015.04.006

Marín-Martínez, A. y Reidl-Martinez, L. M. (2011). Validación Psicométrica Del Cuestionario “Así Nos Llevamos En La Escuela” para Evaluar el Hostigammiento Escolar (Bullying) en Primarias. Revista Mexicana de Investigación Educativa, 18(56), 11-36.

Marraccini, M. E., Weyandt, L. L. y Rossi, J. S. (2015). College Students’ Perceptions of Professor/Instructor Bullying: Questionnaire Development and Psychometric 
Properties. Journal of American College Health, 63(8), 563-572.

https://doi.org/10.1080/07448481.2015.1060596

Merino-Soto, C. y Grimaldo-Muchotrigo, M. (2015). Validación Estructural de la Escala

Básica de Empatía (Basic Empathy Scale) Modificada en Adolescentes: un Estudio

Preliminar. Revista Colombiana de Psicología, 24(2), 261-270.

https://doi.org/10.15446/rcp.v24n2.42514

Mitsopoulou, E. y Giovazolias, T. (2015). Personality traits, empathy and bullying behavior: A meta-analytic approach. Aggression and Violent Behavior, 21(February), 61-72. https://doi.org/10.1016/j.avb.2015.01.007

Modecki, K. L., Minchin, J., Harbaugh, A. G., Guerra, N. G. y Runions, K. C. (2014).

Bullying prevalence across contexts: A meta-analysis measuring cyber and traditional bullying. Journal of Adolescent Health, 55(5), 602-611.

https://doi.org/10.1016/j.jadohealth.2014.06.007

Mukhtar. (2011). Bullying of medical students. Journal of the College of Physicians and Surgeons--Pakistan : JCPSP, 21(9), 579; author reply 579.

https://doi.org/09.2011/JCPSP.579579

Muñoz Abúndez, G. (2008). Violencia escolar en méxico y en otros países. Revista Mexicana de Investigacion Educativa, 13, 1195-1228.

Muñoz, L. C., Qualter, P. y Padgett, G. (2011). Empathy and bullying: Exploring the influence of callous-unemotional traits. Child Psychiatry and Human Development, 42(2), 183-196. https://doi.org/10.1007/s10578-010-0206-1

Navarro, R., Larrañaga, E. y Yubero, S. (2016). Gender Identity, Gender-Typed Personality Traits and School Bullying: Victims, Bullies and Bully-Victims. Child Indicators Research, 9(1), 1-20. https://doi.org/10.1007/s12187-015-9300-z

Newman, M. L., Holden, G. W. y Delville, Y. (2011). Coping With the Stress of Being Bullied: Consequences of Coping Strategies Among College Students. Social Psychological and Personality Science, 2(2), 205-211. https://doi.org/10.1177/1948550610386388

Nordhausen, K. y Oja, H. (2011). Multivariate L1 Statistical Methods: The Package MNM. Journal of Statistical Software, 43(5), 1-28. 
https://doi.org/http://dx.doi.org/10.18637/jss.v043.i05

Novick, R. M. y Isaacs, J. (2010). Telling is compelling: the impact of student reports of bullying on teacher intervention. Educational Psychology, 30(3), 283-296. https://doi.org/10.1080/01443410903573123

Oja, H. (2010). Multivariate Nonparametric Methods with R: An Approach Based on Spatial Signs and Ranks. Londres: Springer Science \& Business Media. https://doi.org/10.1007/978-1-4612-5056-2

Olweus, D. (1993). Bulying at school: What we know and what we can do. WileyBlackwell.

Olweus, D. (2010). Understanding and Researching Bullying: Some Critical Issues. En S. R. Jimerson, S. M. Swearer y D. L. Espelage (Eds.), Handbook of Bullying in Schools: An International Perspective (pp. 9-34). New York: Routledge.

ONU. (2015). Objetivos de Desarrollo Sostenible. Recuperado el 23 de febrero de 2017, a partir de http://www.un.org/sustainabledevelopment/es/objetivos-de-desarrollosostenible/

Organización Mundial de la Salud. (2002). Informe mundial sobre la violencia y la salud. Washington: Organización Mundial de la Salud.

Pepler, D., Jiang, D., Craig, W. y Connolly, J. (2008). Developmental trajectories of bullying and associated factors. Child Development, 79(2), 325-338. https://doi.org/10.1111/j.1467-8624.2007.01128.x

Pinhey, T. K. y Brown, M. M. (2005). Asian-pacific islander adolescent sexual orientation and defensive aggression. Social Science Quarterly, 86(4), 898-911. https://doi.org/10.1111/j.0038-4941.2005.00362.x

Pituch, K. A. y Stevens, J. P. (2016). Applied Multivariate Statistics for the Social Sciences (6a.). New York: Routledge.

Prieto-Quezada, M. T., Carrillo Navarro, J. C. y Lucio López, L. A. (2015). Violencia virtual y acoso escolar entre estudiantes universitarios: el lado oscuro de las redes sociales. Innovación Educativa, 15(68), 33-47.

Raine, A., Dodge, K., Loeber, R., Gatzke-Kopp, L., Lynam, D., Reynolds, C., ... Liu, J. (2006). The reactive-proactive aggression questionnaire: differential correlates of 
reactive and proactive aggression in adolescent boys. Aggressive Behavior, 32(2), 159-171. https://doi.org/10.1002/ab.20115

Ramos Herrera, M. A. y Vázquez Valls, R. (2011). Bullying en el nivel superior. En XI Congreso Nacional de Investigación Educativa (pp. 1-6). Ciudad de México.

Rech, R. R., Halpern, R., Tedesco, A. y Santos, D. F. (2013). Prevalence and characteristics of victims and perpetrators of bullying. Jornal de Pediatria, 89(2), 164-170. https://doi.org/10.1016/j.jped.2013.03.006

Riaño-Hernández, D., Guillen Riquelme, A. y Buela-Casal, G. (2015). Conceptualización y evaluación de la impulsividad en adolescentes: una revisión sistemática. Universitas Psychologica, 14(3), 1077-1090. https://doi.org/10.11144/Javeriana.upsy14-3.ceia

Rivers, I. y Smith, P. K. (1994). Types of bullying behaviour and their correlates. Aggressive Behavior, 20(5), 359-368. https://doi.org/10.1002/10982337(1994)20:5<359::AID-AB2480200503>3.0.CO;2-J

Rospenda, K. M., Richman, J. A., Wolff, J. M. y Burke, L. A. (2013). Bullying victimization among college students: negative consequences for alcohol use. Journal of addictive diseases, 32(4), 325-42. https://doi.org/10.1080/10550887.2013.849971

Salmivalli, C. (1999). Participant role approach to school bullying: implications for interventions. Journal of adolescence, 22(4), 453-459. https://doi.org/10.1006/jado.1999.0239

Schenk, A. M. y Fremouw, W. J. (2012). Prevalence, Psychological Impact, and Coping of Cyberbully Victims Among College Students. Journal of School Violence, 11(1), 2137. https://doi.org/10.1080/15388220.2011.630310

Schenk, A. M., Fremouw, W. J. y Keelan, C. M. (2013). Characteristics of college cyberbullies. Computers in Human Behavior, 29(6), 2320-2327. https://doi.org/10.1016/j.chb.2013.05.013

Schneider, S. K., O’Donnell, L., Stueve, A. y Coulter, R. W. S. (2012). Cyberbullying, school bullying, and psychological distress: A regional census of high school students. American Journal of Public Health, 102(1), 171-177. https://doi.org/10.2105/AJPH.2011.300308

Sentse, M., Kretschmer, T. y Salmivalli, C. (2015). The Longitudinal Interplay between 
Bullying, Victimization, and Social Status: Age-related and Gender Differences. Social Development, 24(3), 659-677. https://doi.org/10.1111/sode.12115

Shetgiri, R., Espelage, D. L. y Carroll, L. (2015). Practical Strategies for Clinical

Management of Bullying. Cham: Springer International Publishing. https://doi.org/10.1007/978-3-319-15476-3

Slonje, R. y Smith, P. K. (2008). Cyberbullying: Another main type of bullying? Scandinavian Journal of Psychology, 49(2), 147-154. https://doi.org/10.1111/j.14679450.2007.00611.x

Smith, P. K., Cowie, H., Olafsson, R. R. y Liefooghe, A. P. (2002). Definitions of bullying: A comparison of terms used, and age and gender differences, in a Fourteen-Country international comparison. Child Development, 73(4), 1119-1133. https://doi.org/10.1111/1467-8624.00461

Smith, P. K., Mahdavi, J., Carvalho, M., Fisher, S., Russell, S. y Tippett, N. (2008). Cyberbullying: Its nature and impact in secondary school pupils. Journal of Child Psychology and Psychiatry and Allied Disciplines, 49(4), 376-385. https://doi.org/10.1111/j.1469-7610.2007.01846.x

Smith, P. K. y Slonje, R. (2010). Cyberbullying: The nature and extent of a new kind of bullying, in and out of school. En S. R. Jimerson, S. M. Swearer y D. L. Espelage (Eds.), Handbook of Bullying in Schools: An International Perspective (pp. 249-262). New York: Routledge. https://doi.org/10.1007/s13398-014-0173-7.2

Solberg, M. E. y Olweus, D. (2003). Prevalence Estimation of School Bullying with the Olweus Bully/Victim Questionnaire. Aggressive Behavior, 29(3), 239-268. https://doi.org/10.1002/ab.10047

Sticca, F. y Perren, S. (2013). Is Cyberbullying Worse than Traditional Bullying? Examining the Differential Roles of Medium, Publicity, and Anonymity for the Perceived Severity of Bullying. Journal of Youth and Adolescence, 42(5), 739-750. https://doi.org/10.1007/s10964-012-9867-3

Swearer, S. M. (2011). Bully Survey. Recuperado el 29 de septiembre de 2017, a partir de http://www.bullysurvey.com/author_html

Swearer, S. M. y Doll, B. (2001). Bullying in Schools: An Ecological Framework. Journal 
of Emotional Abuse, 2(2-3), 7-23. https://doi.org/10.1300/J135v02n02_02

Swearer, S. M., Siebecker, A. B., Johnsen-Frerichs, L. A. y Wang, C. (2010). Assessment of Bullying/Victimization: The problem of comparability across studies and across methodologies. En S. R. Jimerson, S. M. Swearer y D. L. Espelage (Eds.), Handbook of Bullying in Schools: An International Perspective (pp. 305-328). New York: Routledge.

Tippett, N. y Wolke, D. (2014). Socioeconomic status and bullying: A meta-analysis. American Journal of Public Health, 104(6), 48-59. https://doi.org/10.2105/AJPH.2014.301960

Townsend, L., Flisher, A. J., Chikobvu, P., Lombard, C. y King, G. (2008). The relationship between bullying behaviours and high school dropout in Cape Town, South Africa. South African Journal of Psychology, 38(1), 21-32. https://doi.org/10.1177/008124630803800102

Ttofi, M. M., Farrington, D. P., Lösel, F., Crago, R. V y Theodorakis, N. (2016). School bullying and drug use later in life: A meta-analytic investigation. School Psychology Quarterly, 31(1), 8-27. https://doi.org/10.1037/spq0000120

Tuñón, I. y Poy, S. (2016). Factores asociados a las calificaciones escolares como proxy del rendimiento educativo. Revista Electronica de Investigacion Educativa, 18(1), 98111.

Undheim, A. M., Wallander, J. y Sund, A. M. (2016). Coping Strategies and Associations With Depression Among 12- to 15-Year-Old Norwegian Adolescents Involved in Bullying. The Journal of Nervous and Mental Disease, 204(4), 274-279. https://doi.org/10.1097/NMD.0000000000000474

Valadez, B. (2014, mayo 23). México es el primer lugar de bullying a escala internacional. Milenio.com. Ciudad de México. Recuperado a partir de http://www.milenio.com/politica/Mexico-primer-bullying-escalainternacional_0_304169593.html

Valdés Cuervo, Á. A., Alcántar Nieblas, C., Tánori Quintana, J. y Torres Acuña, G. M. (2016). Apuntes y análisis de la investigación acerca de la violencia entre estudiantes en México. En R. García Flores, S. V. Mortis Lozoya, J. Tánori Quintana y T. I. 
Sotelo Quiñonez (Eds.), Educación y Salud: Evidencias y propuestas de investigación en Sonora (pp. 70-78). Sonora: Instituto Tecnológico de Sonora.

van Noorden, T. H. J., Haselager, G. J. T., Cillessen, A. H. N. y Bukowski, W. M. (2014). Empathy and Involvement in Bullying in Children and Adolescents: A Systematic Review. Journal of Youth and Adolescence, 44(3), 637-657. https://doi.org/10.1007/s10964-014-0135-6

Varjas, K., Henrich, C. C. y Meyers, J. (2009). Urban Middle School Students' Perceptions of Bullying, Cyberbullying, and School Safety. Journal of School Violence, 8(2), 159176. https://doi.org/10.1080/15388220802074165

Vázquez-Vázquez, A., Azcorra, H., Falfán, I., Argáeź, J., Kantun, D. y Dickinson, F. (2013). Effects of maya ancestry and environmental variables on knee height and body proportionality in growing individuals in Merida, Yucatan. American Journal of Human Biology, 25(5), 586-593. https://doi.org/10.1002/ajhb.22417

Vega Báez, J. A. (2007). La pandemia de bullying en México: políticas sociales urgentes. Revista Trabajo Social UNAM, 73-90.

Vega Cauich, J. I. y Cisneros-Cohernour, E. J. (2017). Estudio piloto para la adaptación del California Bullying Victimization Scale (CBVS) con estudiantes mexicanos. En XIV Congreso Nacional de Investigación Educativa (pp. 1-11). San Luis Potosí: Consejo Mexicano de Investigación Educativa. Recuperado a partir de http://www.comie.org.mx/congreso/memoriaelectronica/v14/doc/1285.pdf

Velázquez Reyes, L. M. (2009). Ciberbullying. El crudo problema de la victimización en linea. X congreso nacional de investigación educativa, 1-10.

Velázquez Reyes, L. M. (2011). Sexting, Sexcasting, Sextorsión, Grooming y Cyberbullyying. El lado oscuro de las TICs. XI Congreso Nacional de Investigación Educativa, 1-9.

Vivolo-Kantor, A. M., Martell, B. N., Holland, K. M. y Westby, R. (2014). A systematic review and content analysis of bullying and cyber-bullying measurement strategies. Aggression and Violent Behavior, 19(4), 423-434. https://doi.org/10.1016/j.avb.2014.06.008

Volk, A. A., Craig, W., Boyce, W. y King, M. (2006). Adolescent risk correlates of 
bullying and different types of victimization. International journal of adolescent medicine and health, 18(4), 575-586. https://doi.org/10.1515/IJAMH.2006.18.4.575

Volk, A. A., Dane, A. V. y Marini, Z. A. (2014). What is bullying? A theoretical redefinition. Developmental Review. https://doi.org/10.1016/j.dr.2014.09.001

Volk, A. A., Veenstra, R. y Espelage, D. L. (2017). So you want to study bullying? Recommendations to enhance the validity, transparency, and compatibility of bullying research. Aggression and Violent Behavior, 36(July), 34-43. https://doi.org/10.1016/j.avb.2017.07.003

Waasdorp, T. E. y Bradshaw, C. P. (2015). The overlap between cyberbullying and traditional bullying. Journal of Adolescent Health, 56(5), 483-488. https://doi.org/10.1016/j.jadohealth.2014.12.002

Wang, W., Vaillancourt, T., Brittain, H. L., McDougall, P., Krygsman, A., Smith, D., ... Hymel, S. (2014). School climate, peer victimization, and academic achievement: Results from a multi-informant study. School psychology quarterly: the official journal of the Division of School Psychology, American Psychological Association, 29(3), 360-77. https://doi.org/10.1037/spq0000084

Wensley, K. y Campbell, M. (2012). Heterosexual and Nonheterosexual Young University Students' Involvement in Traditional and Cyber Forms of Bullying. Cyberpsychology, Behavior, and Social Networking, 15(12), 649-654. https://doi.org/10.1089/cyber.2012.0132

West, D. (2015). An investigation into the prevalence of cyberbullying among students aged 16-19 in post-compulsory education. Research in Post-Compulsory Education, 20(1), 96-112. https://doi.org/10.1080/13596748.2015.993879

Witvliet, M., Olthof, T., Hoeksma, J. B., Goossens, F. A., Smits, M. S. I. y Koot, H. M. (2010). Peer group affiliation of children: The role of perceived popularity, likeability, and behavioral similarity in bullying. Social Development, 19(2), 285-303. https://doi.org/10.1111/j.1467-9507.2009.00544.x

Wolke, D. y Lereya, S. T. (2014). Bullying and Parasomnias: A Longitudinal Cohort Study. Pediatrics, 134(4), e1040-e1048. https://doi.org/10.1542/peds.2014-1295

Ybarra, M. L., Espelage, D. L. y Mitchell, K. J. (2014). Differentiating youth who are 
bullied from other victims of peer-aggression: The importance of differential power and repetition. Journal of Adolescent Health, 55(2), 293-300.

https://doi.org/10.1016/j.jadohealth.2014.02.009

You, S., Furlong, M. J., Felix, E., Sharkey, J. D., Tanigawa, D. y Green, J. G. (2008).

Relations among school connectedness, hope, life satisfaction, and bully victimization. Psychology in the Schools, 45(5), 446-460. https://doi.org/10.1002/pits.20308

Zhou, Y., Guo, L., Lu, C., Deng, J., He, Y., Huang, J., ... Gao, X. (2015). Bullying as a Risk for Poor Sleep Quality among High School Students in China. PLOS ONE, 10(3), e0121602. https://doi.org/10.1371/journal.pone.0121602 


\section{Apéndice A. \\ Estudios de bullying en México hasta marzo de 2017.}

Albores-Gallo, L., Sauceda-García, J. M., Ruiz-Velasco, S., y Roque-Santiago, E. (2011). El acoso escolar (bullying) y su asociación con trastornos psiquiátricos en una muestra de escolares en México. Salud Publica de Mexico, 53(3), 220-227.

Alcántar Nieblas, C., Tánori Quintana, J., y Álvarez Zamora, A. K. (2015). Relación de la crianza no restaurativa y tipos de espectadores en la dinámica del bullying: En escuelas secundarias de Sonora. En XIII Congreso Nacional de Investigación Educativa (pp. 1-10). Chihuahua.

Alcántar Nieblas, C., Tánori Quintana, J., y Valdés Cuervo, Á. A. (2016). Relación entre el rol de espectador, la empatía y la victimización en la violencia escolar. En R. Díaz Loving, I. Reyes Lagunes, S. Rivera Aragón, J. E. Hernández Sánchez, y R. García Falconi (Eds.), La Psicología social en México Volumen XVI (pp. 463-468). Ciudad de México: Asociación Mexicana de Psicología Social.

Alcántar Nieblas, C., Tánori Quintana, J., Valdés Cuervo, Á. A., y Reyes Rodríguez, A. C. (2016). Manejo de la vergüenza de estudiantes de bachillerato con y sin reportes de ciberbullying hacia los pares. En J. A. Vera Noriega y Á. A. Valdés Cuervo (Eds.), La violencia escolar en México. Temáticas y perspectivas de abordaje (pp. 41-50). Hermosillo: Centro de Investigación en Alimentación y Desarrollo, A.C.

Alcántar Nieblas, C., Tánori Quintana, J., Vera Noriega, J. A., Valdés Cuervo, Á. A., y Bautista Hernández, G. (2016). Recursos psicológicos de espectadores alentadores en situaciones de acoso escolar. En M. Urías Murieta, S. B. Echeverría Castro, Á. A. Valdés Cuervo, y C. O. Acosta Quiroz (Eds.), Procesos Educativos, familia y violencia escolar. Resultados de Investigaciones (pp. 163-171). Ciudad Obregón: Instituto Tecnológico de Sonora.

Avendaño Coronel, S., y Figueroa Campos, M. (2013). Un estudio del acoso cibernético "cyberbullying" en estudiantes de la ENP y CCH de la UNAM: Incidencia y tipos, perfiles de agresores y víctimas y acciones de afrontamiento. En XII Congreso Nacional De Investigación Educativa (pp. 1-11).

Avilés-Dorantes, D. S., Zonana-Nacach, A., y Anzaldo-Campos, M. C. (2012). Prevalencia de acoso escolar (bullying) en estudiantes de una secundaria pública. Salud Publica de Mexico, 54(4), 362-363. https://doi.org/10.1590/S0036-36342012000400002

Ayala-Carrillo, M. del R. (2015). Violencia Escolar: Un Problema Complejo. Ra Ximhai, 11(4), 493-509.

Baeza-Herrera, C., Vidrio-Patrón, F., Martínez-Leo, B. A., y Godoy-Esquivel, A. H. (2010). Acoso severo entre iguales ("bullying"). El enemigo entre amigos. Acta Pediátrica de México, 31(4), 149-152. Recuperado a partir de http://www.redalyc.org/articulo.oa?id=423640324002

Barragán Ledesma, L. E., Valadez Figueroa, I. de la A., Garza Aguilar, H. R., Barragán Amador, A. L., Lozano de la Cruz, A. J., Pizarro Villalobos, H., y Martínez Trujillo, B. D. (2010). Elementos del concepto de intimidación entre iguales que comparten protagonistas y estudiosos del fenómeno. Revista mexicana de investigación educativa, 15(45), 553-569.

Baruch-Dominguez, R., Infante-Xibille, C., y Saloma-Zuñiga, C. E. (2016). Homophobic bullying in Mexico: Results of a national survey. Journal of LGBT Youth, 13(1-2), 18-27. https://doi.org/10.1080/19361653.2015.1099498

Bautista Hernández, G., Valdés Cuervo, A. A., y Vera Noriega, J. A. (2013). Diferencias en el autoconcepto y clima familiar de subgrupos de estudiantes víctimas del bullying: víctimas y víctimas-agresores. En XII Congreso Nacional De Investigación Educativa (pp. 1-10). Guanajuato. 
Benjet, C., Thompson, R. J., y Gotlib, I. H. (2010). 5-HTTLPR moderates the effect of relational peer victimization on depressive symptoms in adolescent girls. Journal of Child Psychology and Psychiatry, 51(2), 173-179. https://doi.org/10.1111/j.1469-7610.2009.02149.x

Buelga, S., Cava, M. J., y Musitu, G. (2012). Validación de la escala de victimización entre adolescentes a través del teléfono móvil y de internet. Revista Panamericana de Salud Pública, 32(1), 36-42. https://doi.org/10.1590/S1020-49892012000700006

Calleja, N. (2016). Bullying y Tabaco: ¿Se Encuentran Asociados? Acta de Investigación Psicológica, 6(1), 2350-2367. https://doi.org/10.1016/S2007-4719(16)30055-2

Castellanos Abundiz, M. G. (2015). Los rostros del bullying. Los malos tratos entre las y los jóvenes. En XIII Congreso Nacional de Investigación Educativa (pp. 1-9). Chihuahua.

Castellanos Abundiz, M. G., y Solís Mendoza, F. J. (2015). Cuando la diversidad sexo-genérica desencadena el acoso escolar: Una mirada al bullying homofóbico en la educación media superior. En XIII Congreso Nacional de Investigación Educativa (pp. 1-10). Chihuahua.

Castillo Rocha, C. (2011). Juicio moral en conductas de maltrato entre iguales en una escuela secundaria de Mérida, Yucatán. En XI Congreso Nacional de Investigación Educativa (pp. 19). Ciudad de México.

Castillo Rocha, C., y Pacheco Espejel, M. M. (2009). El maltrato entre iguales desde la percepción de los adolescentes: hacia una perspectiva sistémica. En X Congreso Nacional de Investigación Educativa (pp. 1-9).

Castillo Rocha, C., y Pacheco Espejel, M. M. (2008). Perfil del maltrato (bullying) entre estudiantes de secundaria en la Ciudad de Mérida, Yucatán. Revista Mexicana de Investigación Educativa, 13(38), 825-842.

Castillo, A. E. (2010). Descriptive study about bullying' coping strategies among Mexican teachers. Electronic Journal of Research in Educational Psychology, 8(1), 353-372.

Chacón Sotelo, Y. G., Yáñez Molina, A. A., y Cruz Rodríguez, S. L. (2011). Caracterización psicosocial del bullying en la escuela primaria. En XI Congreso Nacional de Investigación Educativa (pp. 1-10). Ciudad de México.

Clemente-Estevan, R. A., Villanueva-Badenes, L., y Cuervo-Gómez, K. (2013). Evolución y reconocimiento de las transgresiones morales y socioconvencionales en menores. Convergencia. Revista de Ciencias Sociales, 20(61), 15-34.

Corral-Verdugo, V., Fraijo-Sing, B., Frías-Armenta, M., y Tapia-Fonllem, C. (2011). Environmental and personal variables predicting school bullying: A study with Mexican adolescents. En M. Frías-Armenta y V. Corral-Verdugo (Eds.), Bio-Psycho-Social Perspectives on Interpersonal Violence (pp. 193-215). New York: Nova Science Publishers, Inc. Recuperado a partir de http://www.scopus.com/inward/record.url?eid=2-s2.084896409980\&partnerID=40\&md5=1fdc3f8db2c82110c0a6541b8fa7107d

Couvillier Ybarra, R., Alcántar Nieblas, C., y Valdés Cuervo, Á. A. (2016). Creencias de estudiantes alentadores sobre su conducta de apoyo al agresor. En 8vo. Congreso Internacional de Educación (pp. 802-812). Ciudad Obregón.

Del Bosque, L. P., y Garza, S. E. (2016). Prediction of Aggressive Comments in Social Media: An Exploratory Study. IEEE Latin America Transactions, 14(7), 3474-3480. https://doi.org/10.1109/TLA.2016.7587657

Dorantes Carrión, J. J. (2015). El ciberbullying, una experiencia vivida en la Universidad Veracruzana/México. En XIII Congreso Nacional de Investigación Educativa (pp. 1-12). Chihuahua.

Gámez-Guadix, M., Villa-George, F., y Calvete, E. (2014). Psychometric Properties of the Cyberbullying Questionnaire (CBQ) Among Mexican Adolescents. Violence and Victims, 29(2), 232-247. https://doi.org/10.1891/0886-6708.VV-D-12-00163R1 
García Gómez, L. A., Mendoza Menéndez, C. G., Olivares Arizavalo, K., García Pacheco, M., y García Monteñez, M. V. (2015). Descripción de funciones neuropsicológicas y de inteligencia en chicos en conflicto con la ley relacionados con bullying. Revista Intercontinental de Psicología y Educación, 17(2), 36-62.

García Montañez, M. V., y Ascencio Martínez, C. A. (2015). Bullying y violencia escolar: diferencias, similitudes, actores, consecuencias y origen. Revista Intercontinental de Psicología y Educación, 17(2), 9-38. Recuperado a partir de http://web.a.ebscohost.com/ehost/pdfviewer/pdfviewer?sid=27188a51-61bf-46fc-ba131d9da89f0f67\%40sessionmgr4008\&vid=9\&hid $=4212$

García-Maldonado, G., Martínez-Salazar, G. J., Saldívar-González, A. H., Sánchez-Nuncio, R., Martínez-Perales, G. M., y Barrientos-Gómez, M. del C. (2012). Factores de riesgo y consecuencias del cyberbullying en un grupo de adolescentes. Asociación con bullying tradicional. Boletin Medico del Hospital Infantil de Mexico, 69(6), 463-474.

Gómez Nashiki, A. (2013). Bullying: El poder de la violencia. Una Perspectiva cualitativa sobre acosadores y víctimas en escuelas primarias de Colima. Revista mexicana de Investigación Educativa, 18(58), 839-870.

Gómez Nashiki, A., y López Molina, S. (2011). Bullying e institución educativa. Una perspectiva cualitativa del maltrato entre (des)iguales. En XI Congreso Nacional de Investigación Educativa (pp. 1-10).

González, B. M., Cabrera, F. J. P., y Martínez, K. I. M. (2014). Prácticas de Crianza Positiva: Entrenamiento a padres para reducir Bullying. Acta de Investigación Psicológica, 4(3), 17941809. https://doi.org/10.1016/S2007-4719(14)70980-9

González, B. M., Morales Reynoso, T., y Gómez, Y. A. (2015). Variables Proximales relacionados con Violencia Escolar y Bullying en alumnado de bachillerato. Psychology, Society, \& Education, 7(2), 185-199. Recuperado a partir de www.psye.org

Haro-Solís, I., García-Cabrero, B., y Reidl-Martínez, L. M. (2013). Experiencias de culpa y vergüenza en situaciones de maltrato entre iguales en alumnos de secundaria. Revista Mexicana de Investigacion Educativa, 18(59), 1047-1075.

Joffre-Velázquez, V. M., García-Maldonado, G., Saldívar-González, A. H., Martínez-Perales, G., Lin-Ochoa, D., Quintanar-Martínez, S., y Villasana-Guerra, A. (2011). Bullying en alumnos de secundaria. Características generales y factores asociados al riesgo. Boletín médico del Hospital Infantil de México, 68(3), 193-202.

Leonor Guadalupe Delgadillo, F. J. A. (2013). El bullying: manifestaciones de deterioro en la interaccion social entre pares. Red de revista cientifica de america latina, 9(3), 65-80.

Lucio López, L. A. (2009). El Cyberbullying en estudiantes del nivel medio superior en México. $X$ Congreso Nacional de Investigación Educativa, (1998), 1-11. Recuperado a partir de http://www.comie.org.mx/congreso/memoriaelectronica/v10/pdf/area_tematica_17/ponencias/ 0901-F.pdf

Madrid López, E. J., Ochoa Arreola, J. A., Valdés Cuervo, Á. A., Tánori Quintana, J., y Urías Murrieta, M. (2016). Prácticas de autoridad y manejo de la vergüenza en agresores y no involucrados en el bullying. En R. Díaz Loving, I. Reyes Lagunes, S. Rivera Aragón, J. E. Hernández Sánchez, y R. García Falconi (Eds.), La Psicología social en México Volumen XVI (pp. 451-456). Ciudad de México: Asociación Mexicana de Psicología Social.

Madrid López, E. J., Valdés Cuervo, A. A., y Vera Noriega, J. A. (2015). Diferencias en los estilos de afrontamiento de estudiantes víctimas y no involucrados en el bullying. En XIII Congreso Nacional de Investigación Educativa (pp. 1-9). Chihuahua.

Marín-Martínez, A., y Reidl-Martínez, L. M. (2013). Validación psicométrica del cuestionario “Así nos llevamos en la escuela" para evaluar el hostigamiento escolar (bullying) en primarias. Revista mexicana de Investigación Educativa, 18(56), 11-36. 
Martínez González, G., Álverez Vega, J. M., González Balcázar, A., y Zazueta Bastida, L. A. (2013). Violencia interpersonal constante y prolongada: Reacción de los sujetos ante el maltrato tipo bullying. En XII Congreso Nacional De Investigación Educativa (pp. 1-9). Guanajuato.

Mendoza-González, B., Cervantes-Herrera, A. del R., Pedroza-Cabrera, F. J., y AguileraRubalcava, S. J. (2015). Estructura factorial y consistencia interna del "Cuestionario para medir bullying y violencia escolar". CienciaUAT, 10(1), 6-16.

Morales San Juan, M. (2015). La Webquest como recurso didáctico en la Realización del proyecto "Bullying Prevention”. En XIII Congreso Nacional de Investigación Educativa (pp. 1-7). Chihuahua.

Murrieta, P., Ruvalcaba, N. A., Caballo, V. E., y Lorenzo, M. (2014). Cambios en la percepción de la violencia y el comportamiento agresivo entre niños a partir de un programa de habilidades socioemocionales. Psicología Conductual: Revista Internacional Clínica y de la Salud, 22(3), 569-584. Recuperado a partir de http://search.ebscohost.com/login.aspx?direct=true \&db=psyh\&AN=2014-55699010\&site=ehost-live\%5Cnmurrisp4@cucea.udg.mx

Nava Preciado, J. M., y Méndez Huerta, M. (2011). Vícitmas, silencios y complicidades: rostros del maltrato escolar. En XI Congreso Nacional de Investigación Educativa (pp. 1-8). Ciudad de México.

Ocampo, D. B., Serrano, P. A., Archundia, M. A., y Valdez, D. D. (2015). La sintomatología depresiva y el desempeño académico como factores asociados al bullying en niños. Revista Intercontinental de Psicología y Educación, 17(2), 63-76. Recuperado a partir de http://www.redalyc.org/articulo.oa?id=80247939004

Ochoa Arreola, J. A., Valdés Cuervo, A. A., y Carlos Martínez, E. A. (2015). Diferencias en la percepción del clima escolar y las prácticas docentes de víctimas y no involucrados en el bullying. En XIII Congreso Nacional de Investigación Educativa (pp. 1-10). Chihuahua.

Ochoa, A., Ponce, J., Jaramillo, R., Ornelas, F., Hernández, A., Azpeitia, D., ... Hernández, A. (2011). Analysis of cyber-bullying in a virtual social networking. En Proceedings of the 2011 11th International Conference on Hybrid Intelligent Systems, HIS 2011 (pp. 229-234). https://doi.org/10.1109/HIS.2011.6122110

Ortiz-León, S., Jaimes-Medrano, A. L., Tafoya-Ramos, S. A., Mujica-Amaya, M. L., OlmedoCanchola, V. H., y Carrasco-Rojas, J. A. (2014). Experiencias de maltrato y hostigamiento en médicos residentes. Cirugia y Cirujanos, 82(3), 290-301.

Pérez Arellano, E., y Castañeda Ramírez, I. (2015). El impacto de los estilos parentales en la dinámica de bullying a nivel secundaria. Revista Intercontinental de Psicología y Educación, 17(2), 77-101. Recuperado a partir de http://www.redalyc.org/articulo.oa?id=80247939005

Pérez, P. J. C., Valdez, C. J. L., Ortiz, M. de G. C., Barrera, J. P. S., y Pérez, P. F. (2012). MISAAC: Instant messaging tool for ciberbullying detection. En Proceedings of the 2012 International Conference on Artificial Intelligence, ICAI 2012 (Vol. 2, pp. 1049-1052).

Recuperado a partir de https://www.scopus.com/inward/record.uri?eid=2-s2.084875181688\&partnerID=40\&md5=0c715853da1a8fbb5803de9b2922b1d4

Pesci Eguía, A. L. (2015). Prevención del bullying en México: El caso de los niños y adolescentes sobredotados. Revista de El Colegio de San Luis, 5(10), 104-133.

Prieto Quezada, M. T. (2012). La violencia que nos toca a todos: una mirada desde la historia del maltrato en la escuela. Ensaio: Avaliação e Políticas Públicas em Educação, 20(75), 243-260.

Prieto Quezada, M. T., Carrillo Navarro, J. C., y Jiménez Mora, J. (2005). La violencia escolar: Un estudio en el nivel medio superior. Revista Mexicana de Investigación Educativa, 10(27), $1027-1045$. 
Prieto-Quezada, M. T. (2016). Violencia de género. El bullying entre mujeres, por el amor de un hombre. Ra Ximhai, 12(1), 161-175.

Prieto-Quezada, M. T., Carrillo Navarro, J. C., y Lucio López, L. A. (2015). Violencia virtual y acoso escolar entre estudiantes universitarios: el lado oscuro de las redes sociales. Innovación Educativa, 15(68), 33-47. https://doi.org/10.11144/Javerianacali.PPSI14-1.rbcp

Ramírez Almaraz, M., Díaz, F., Arceo, B., y Flores, R. L. (2015). Maltrato entre escolares: Diagnóstico en estudiantes de nivel secundaria en la Ciudad de México. Psychology, Society, \& Education, 7(2), 169-182. Recuperado a partir de www.psye.org

Ramirez Zaragoza, M., Peña Ramos, M., Vera Noriega, J. A., Valdés Cuervo, Á. A., y Gamboa Robles, M. (2015). Victimización, clima familiar y el manejo de la culpa-vergüenza en el acoso escolar. Summa Psicológica UST, 12(2), 87-93. https://doi.org/10.18774/summavol12.num2-249

Ramos Castillos, J. (2013). Efectos del bullying en la deserción escolar en la educación media superior. En XII Congreso Nacional De Investigación Educativa (pp. 1-10). Guanajuato.

Ramos Herrera, M. A., y Vázquez Valls, R. (2011). Bullying en el nivel superior. En XI Congreso Nacional de Investigación Educativa (pp. 1-6). Ciudad de México.

Ramos-Jimenez, A., Wall-Medrano, A., Villar, O. E.-D., y Hernández-Torres, R. P. (2013). Design and validation of a self-administered test to assess bullying (bull-M) in high school Mexicans: a pilot study. BMC public health, 13(1), 334. https://doi.org/10.1186/1471-2458-13-334

Reyes Rodríguez, A. C., Valdés Cuervo, Á. A., Urías Murrieta, M., y Torres Acuña, G. M. (2014). Manejo de la vergüenza en estudiantes de bachillerato con y sin reportes de bullying. En S. B. Echeverría Castro, M. T. Fernández Nistal, E. Ochoa Ávila, y D. Y. Ramos Estrada (Eds.), Ambientes de Aprendizaje y contextos de desarrollo social (Ciudad de, pp. 75-83). Pearson.

Reyes Rodríguez, A. C., Valdés Cuervo, Á. A., y Vera Noriega, J. A. (2016). Relación entre liderazgo distribuido del Director y el clima escolar con la agresión entre estudiantes. En S. Rivera, L. Cruz, F. Méndez, C. Jaen, y G. Villanueva (Eds.), Aportaciones actuales de la psicología social (pp. 432-437). Ciudad de México: Asociación Mexicana de Psicología Social.

Reyes-Hernández, U., Castell-Roldán, E. P., Hernández-Lira, I., Reyes-Gómez, U., ReyesHernández, K. L., Reyes-Hernández, D. P., ... Urrutia, J. C. (2013). Una escolar con apendicitis traumática por bullying. Revista Mexicana de Pediatria, 80(1), 26-29.

Rivero Espinosa, E., Barona Ríos, C., y Saenger Pedrero, C. (2010). La violencia entre pares (Bullying). Un estudio exploratorio en escuelas secundarias en Morelos. En X Congreso Nacional de Investigación Educativa (pp. 1-10). Veracruz.

Rodulfo Gocobachi, J. A., Solís Palomares, M., y Lozano Chavarría, E. (2011). El bullying en Ciudad Juárez: Un análisis descriptivo del fenómeno. En XI Congreso Nacional de Investigación Educativa (p. 8). Ciudad de México. Recuperado a partir de http://www.comie.org.mx/congreso/memoriaelectronica/v11/docs/area_17/0316.pdf

Ruiz Armenta, M. B. (2015). Manifestaciones del cyberbullying a través de la red social Facebook y la telefonía móvil. En XIII Congreso Nacional de Investigación Educativa (pp. 1-14). Chihuahua.

Ruíz-Ramírez, R., Zapata-Martelo, E., García-Cué, J. L., Pérez-Olvera, A., Martínez-Corona, B., y Rojo-Martínez, G. (2016). Bullying en una universidad agrícola del Estado de México. $R a$ Ximhai, 12(1), 105-126.

Torres-Gómez, O. G., y Nava-López, J. A. (2012). Bullying y depresión en anestesiología. Revista Mexicana de Anestesiologia, 35(SUPPL1), 230-232.

Tronco Rosas, M. A., Ocaña López, S., y Peralta Quevedo, G. (2011). Acoso y Hostigamiento en el ámbito laboral y escolar. Estudio realizado en el Insituto Politécnico Nacional. XI Congreso Nacional de investigación educativa, 1-9. 
Valadez Figueroa, I. de la A., González Gallegos, N., Orozco Valerio, M. de J., y Montes Barajas, R. (2011). Atribuciones causales del maltrato entre iguales: la perspectiva de los alumnos y del personal de escuelas de enseñanza media básica. Revista Mexicana de Investigación Educativa, 16(51), 1111-1136.

Valadéz Figueroa, I., Amezcua Fernández, R., y González Gallegos, N. (2009). Maltrato entre iguales psicopatología e intento suicida. En $X$ Congreso Nacional de Investigación Educativa (pp. 1-15). Veracruz. Recuperado a partir de http://www.comie.org.mx/congreso/memoriaelectronica/v10/pdf/area_tematica_17/ponencias/ 0022-F.pdf

Valdés Cuervo, Á. A., Alcántar Nieblas, C., Reyes Rodríguez, A. C., Torres Acuña, G. M., y Urías Murrieta, M. (2014). Diferencias en el autoconcepto de estudiantes de bachillerato con y sin reportes de victimización por ciberbullying. La Sociedad Académica, 22(43), 35-39.

Valdés Cuervo, Á. A., Alcántar Nieblas, C., Tánori Quintana, J., y Torres Acuña, G. M. (2016). Apuntes y análisis de la investigación acerca de la violencia enrte estudiantes en México. En R. García Flores, S. V. Mortis Lozoya, J. Tánori Quintana, y T. I. Sotelo Quiñonez (Eds.), Educación y Salud: Evidencias y propuestas de investigación en Sonora (pp. 70-78). Sonora: Instituto Tecnológico de Sonora.

Valdés Cuervo, Á. A., Bautista Hernández, G., Vera Noriega, J. A., y Herrera Mateos, J. C. (2013). Variables que diferencian a estudiantes de secundarias con y sin reportes de bullying en la escuela. Psicología Iberoamericana, 21(1), 32-41. Recuperado a partir de http://148.215.2.11/articulo.oa?id=133929862005

Valdés Cuervo, Á. A., y Carlos Martínez, E. A. (2014). Relación entre el autoconcepto social, el clima familiar y el clima escolar con el bullying en estudiantes de secundarias. Avances en psicología latinoamericana, 32(3), 447-457. https://doi.org/10.12804/apl32.03.2014.07

Valdés Cuervo, Á. A., y Carlos Martínez, E. A. (2017). Relación entre disciplina parental restaurativa, manejo de la vergüenza, compasión y acoso escolar. Revista Mexicana de Psicología, 34(1), 37-45.

Valdés Cuervo, Á. A., Carlos Martínez, E. A., Tánori Quintana, J., y Madrid López, E. J. (2016). Relación entre funcionamiento familiar, emociones morales y violencia entre estudiantes de primaria. Revista Mexicana de Investigación Educativa, 21(71), 1093-1110.

Valdés Cuervo, Á. A., Carlos Martinez, E. A., Tanori Quintana, J., y Wendlandt Amezaga, T. R. (2014). Differences in Types and Technological Means by Which Mexican High Schools Students Perform Cyberbullying: Its Relationship with Traditional Bullying. Journal of Educational and Developmental Psychology, 4(1), 105-113. https://doi.org/10.5539/jedp.v4n1p105

Valdés Cuervo, Á. A., Carlos Martínez, E. A., y Torres Acuña, G. M. (2012). Diferencias en la situación socioeconómica, clima y ajuste familiar de estudiantes con reportes de bullying y sin ellos. Psicología desde el Caribe, 29(3), 616-631.

Valdés Cuervo, Á. A., Carlos Martínez, E. A., Wendlandt Amezaga, T. R., y Ramírez Zaragoza, M. (2016). Propiedades psicométricas de una escala para medir el manejo de la vergüenza en adolescentes (MOSS-SAST). Acta Colombiana de Psicología, 19(1), 13-34. https://doi.org/10.14718/ACP.2016.19.1.2

Valdés Cuervo, Á. A., Estévez Nenninger, E. H., y Manig Valenzuela, A. (2014). Creencias de docentes acerca del bullying. Perfiles Educativos, 36(145), 51-64. https://doi.org/10.1016/S0185-2698(14)70637-3

Valdés Cuervo, Á. A., Manig Valenzuela, A., Urías Murrieta, M., Ramírez Lango, M. G., Vera Noriega, J. A., Bautista Hernández, G., y Santis López, J. E. (2013). Creencias de docentes de secundarias acerca del bullying. En J. J. Vales García, Á. A. Valdés Cuervo, J. Angulo Armenta, C. García Hernández, y I. González Castro (Eds.), Investigación Psicoeducativa en 
Sonora. Resultados y propuestas de acción (pp. 55-65). Ciudad de México: Pearson. https://doi.org/10.13140/RG.2.11.1830.0889

Valdés Cuervo, Á. A., Ojeda García, A., Urías Murrieta, M., y Ponce Segura, D. B. (2013). Factores de riesgo en estudiantes de secundaria con conductas violentas hacia sus compañeros. En J. J. Vales García, Á. A. Valdés Cuervo, J. Angulo Armenta, C. García Hernández, y I. González Castro (Eds.), Investigación psicoeducativa en Sonora: Resultados y propuestas de acción (pp. 1-19). Ciudad de México: Pearson.

Valdés Cuervo, Á. A., Reyes Rodríguez, A. C., y Carlos Martínez, E. A. (2014). Dificultades en las habilidades sociales y victimización por pares en estudiantes de primaria. En S. Rivera Aragón, R. Díaz Loving, I. Reyes Lagunes, y M. M. Flores Galaz (Eds.), Aportaciones Actuales de la Psicología Social Volumen II (pp. 539-545). Ciudad de México: Asociación Mexicana de Psicología Social.

Valdés Cuervo, Á. A., Sanchez Escobedo, P. A., y Carlos Martínez, E. A. (2012). Autoconcepto social y ajuste escolar de estudiantes de educación media con conductas de hostigamiento en la escuela. Revista "Educación y Ciencia”, 2(40), 85-96. Recuperado a partir de http://www.educacionyciencia.org/index.php/educacionyciencia/article/view/294/pdf

Valdés Cuervo, Á. A., y Vera Noriega, J. A. (2015). El papel de las familias en el origen y la prevención del bullying: Estrategias para la acción. En A. Bazán Ramírez, D. Castellanos Simons, y A. Limón Fernández (Eds.), Familia-Escuela-Comunidad Volumen II: Investigación en Psicología y Educación (pp. 277-297). Cuernavaca: Universidad Autónoma del Estado de Morelos.

Valdés Cuervo, Á. A., Yañez Quijada, A. I., y Carlos Martínez, E. A. (2013). Diferencias entre subgrupos de estudiantes involucrados en el bullying: víctimas, agresores-víctimas y agresores. Liberabit, 19(2), 1729-4827.

Valdés-Cuervo, Á. A., Martínez-Ferrer, B., y Carlos-Martínez, E. A. (2017). El rol de las prácticas docentes en la prevención de la violencia escolar entre pares. Revista de Psicodidáctica, 22(2). https://doi.org/10.1387/RevPsicodidact.16434

Vega López, M. G., y González Pérez, G. J. (2016). Bullying en la escuela secundaria: Factores que disuaden o refuerzan el comportamiento agresor de los adolescentes. Revista Mexicana de Investigacion Educativa, 21(71), 1165-1189.

Vega López, M. G., González Pérez, G. J., y Quintero Vega, P. P. (2013). Ciberacoso: victimización de alumnos en escuelas secundarias públicas de Tlaquepaque, Jalisco, México. Revista de Educación y Desarrollo, 25(2), 13-20.

Vega López, M. G., González Pérez, G. J., Valle Barbosa, M. A., y Flores Villavicencio, M. E. (2016). Violencia entre adolescentes: la exposición al acoso emocional por sobrepeso y obesidad. En F. J. Gutiérrez Rodríguez (Ed.), Conducta violenta: impacto biopsicosocial (pp. 160-176). Guadalajara: Universidad de Guadalajara.

Vega López, M. G., González Pérez, G. J., Valle Barbosa, M. A., Flores Villavicencio, M. E., y Vega López, A. (2013). Acoso escolar en la zona metropolitana de Guadalajara, México: prevalencia y factores asociados. Salud Colectiva. Universidad Nacional de Lanús, 9(2), 183194.

Velasco Ariza, V., Pineda García, G., y Arámburo Vizcarra, V. (2013). Estudio piloto para conocer las respuestas y el grado de aceptación de una escala para detectar casos de bullying como víctima y espectador en escuelas secundarias de Ensenada, Baja California. En XII Congreso Nacional De Investigación Educativa (pp. 1-8). Guanajuato.

Velázquez Reyes, L. M. (2009). Ciberbullying. El crudo problema de la victimización en linea. X congreso nacional de investigación educativa, 1-10. 
Velázquez Reyes, L. M. (2011). Sexting, Sexcasting, Sextorsión, Grooming y Cyberbullyying. El lado oscuro de las TICs. XI Congreso Nacional de Investigación Educativa, 1-9. Recuperado a partir de http://www.comie.org.mx/congreso/memoriaelectronica/v11/docs/area_17/0121.pdf

Vera Noriega, J. A., Valdés Cuervo, Á. A., Torres Acuña, G. M., y Ponce Segura, D. B. (2012). Diferencias del autoconcepto social de estudiantes con y sin conductas violentas en la escuela. En 6to. Congreso Internacional de Educación (pp. 1190-1202). Ciudad Obregón.

Vilchis, R. M., Rivera, J. P., Arriga, K. J., Reynoso, T. M., Miranda, D. A., Maya, M. E. D., y Sánchez, V. C. (2015). Prevención de la violencia escolar cara a cara y virtual en bachillerato. Psychology, Society and Education, 7(2), 201-212. Recuperado a partir de https://www.scopus.com/inward/record.uri?eid=2-s2.084961962746\&partnerID=40\&md5=aa077a2a3e96ecc343cd011 c5bac8f48

Yescas Sánchez, R. (2013). Intervención educativa para resolver un caso de acoso escolar. Revista Semestral da Associação Brasileira de Psicologia Escolar e Educacional, 17(2), 339-354. https://doi.org/10.1590/S1413-85572013000200016

Zagaceta Sarmiento, M. (2015). El bullying escolar: Cada vez que me ciscaban me pegaban. En XIII Congreso Nacional de Investigación Educativa (pp. 1-11). Chihuahua. 


\section{Apéndice B.}

\section{Especificación de las variables y preguntas del instrumento}

\begin{tabular}{|c|c|c|c|}
\hline Variable & Definición conceptual & $\begin{array}{c}\text { Definición } \\
\text { operacional }\end{array}$ & Ítems \\
\hline Acoso Escolar & $\begin{array}{l}\text { Se considera que una persona sufre acoso } \\
\text { escolar cuando "es expuesto a acciones } \\
\text { negativas por una o más personas en repetidas } \\
\text { ocasiones a lo largo del tiempo, y donde se } \\
\text { excluyen casos en los cuales dos jóvenes de } \\
\text { igual fuerza física o fortaleza psicológica se } \\
\text { agreden" (Olweus, 1993, p. 9) }\end{array}$ & $\begin{array}{l}\text { Diagnóstico } \\
\text { brindado por el } \\
\text { California Bullying } \\
\text { Victimization Scale } \\
\text { (Felix et al. 2011). }\end{array}$ & $\begin{array}{l}\text { Págs. } 2-5 \\
\text { Preg. } 1.1 \text { a } 7.9\end{array}$ \\
\hline Sexo & La condición biológica de ser hombre o mujer. & $\begin{array}{l}\text { Datos } \\
\text { sociodemográficos }\end{array}$ & $\begin{array}{l}\text { Pág. } 2 \\
\text { Preg. } 2\end{array}$ \\
\hline Edad & $\begin{array}{l}\text { Tiempo en años, en los que ha vivido la } \\
\text { persona. }\end{array}$ & $\begin{array}{l}\text { Datos } \\
\text { Sociodemográficos }\end{array}$ & $\begin{array}{l}\text { Pág. } 2 \\
\text { Preg. } 3\end{array}$ \\
\hline $\begin{array}{l}\text { Ser diferente } \\
\text { (Etnia y } \\
\text { origen) }\end{array}$ & $\begin{array}{l}\text { - Ascendencia maya o indígena (cantidad } \\
\text { de apellidos mayas: } 0,1 \text { o ambos). } \\
\text { Origen, considerando si nació en Mérida, } \\
\text { en el interior del estado, en otro estado, o } \\
\text { en otro país. }\end{array}$ & $\begin{array}{l}\text { Datos } \\
\text { Sociodemográficos }\end{array}$ & $\begin{array}{l}\text { P. } 2 \\
\text { Preg. } 1,4\end{array}$ \\
\hline $\begin{array}{l}\text { Orientación } \\
\text { sexual }\end{array}$ & $\begin{array}{l}\text { La atracción amorosa, afectiva, física y sexual } \\
\text { que siente una persona, según su sexo. Esta } \\
\text { orientación puede ser heterosexual, } \\
\text { homosexual o bisexual y no es una decisión } \\
\text { consciente y meditada (Lozano Verduzco y } \\
\text { Diaz Loving, 2010). }\end{array}$ & $\begin{array}{l}\text { Modelo de } \\
\text { Preferencia Genérica } \\
\text { (Lozano Verduzco y } \\
\text { Diaz Loving, 2010) }\end{array}$ & $\begin{array}{l}\text { Pág. } 8 \\
\text { Preg. } 5.1 \text { a } 5.3\end{array}$ \\
\hline Empatía & $\begin{array}{l}\text { La empatía constituye una emoción moral, y es } \\
\text { considerada como una respuesta afectiva que } \\
\text { hace posible la comprensión de la condición o } \\
\text { estado emocional de otra persona (Eisenberg, } \\
\text { 2000). }\end{array}$ & $\begin{array}{l}\text { Escala Básica de } \\
\text { Empatía (Merino- } \\
\text { Soto y Grimaldo- } \\
\text { Muchotrigo, 2015) }\end{array}$ & $\begin{array}{l}\text { Pág. } 5 . \\
\text { Preg. } 1.1 \text { a } 1.9\end{array}$ \\
\hline Agresión & $\begin{array}{l}\text { La denominada agresión reactiva describe } \\
\text { aquellas conductas que se suscitan como } \\
\text { reacción a una provocación o a una amenaza } \\
\text { percibida (real o imaginada); mientras que la } \\
\text { agresión proactiva incluye acciones } \\
\text { desencadenadas intencionalmente para } \\
\text { resolver conflictos o para conseguir beneficios, } \\
\text { recompensas o refuerzos valorados por el } \\
\text { agresor (Andreu, Peña, y Ramírez, 2009). }\end{array}$ & $\begin{array}{l}\text { Cuestionario de } \\
\text { Agresión Reactiva y } \\
\text { Proactiva } \\
\text { (Andreu, Peña, y } \\
\text { Ramirez, 2009) }\end{array}$ & $\begin{array}{l}\text { Pág. } 6 \\
\text { Preg. } 2.1 \mathrm{a} \\
2.23\end{array}$ \\
\hline Impulsividad & $\begin{array}{l}\text { Un estilo de respuesta caracterizado por } \\
\text { responder rápido y sin demasiado análisis, y } \\
\text { que se genera cuando los individuos se } \\
\text { enfrentan a problemas que cuentan con varias } \\
\text { opciones de solución, pero solo una de ellas es } \\
\text { la correcta, por esta razón, se relaciona con }\end{array}$ & $\begin{array}{l}\text { ECOPRED } \\
\text { Sección } 4.4 \text { (p. } 4 \text { ) } \\
\text { Preguntas } 1,2 \text { y } 3 . \\
\text { (INEGI, 2014) }\end{array}$ & $\begin{array}{l}\text { Pág. } 7 \\
\text { Preg. } 3.1 \text { a } 3.3\end{array}$ \\
\hline
\end{tabular}




\begin{tabular}{|c|c|c|c|}
\hline Variable & Definición conceptual & $\begin{array}{c}\text { Definición } \\
\text { operacional }\end{array}$ & Ítems \\
\hline $\begin{array}{l}\text { Actitudes pro- } \\
\text { criminales }\end{array}$ & $\begin{array}{l}\text { procesos de evaluación y producción de } \\
\text { alternativas. } \\
\text { Se refiere a las actitudes que apoyan la } \\
\text { conducta criminal y delictiva (Andrews y } \\
\text { Bonta, 2010). }\end{array}$ & $\begin{array}{l}\text { Escala de Actitudes } \\
\text { hacia la Autoridad } \\
\text { Institucional en } \\
\text { adolescentes } \\
\text { (Cava, Estévez } \\
\text { López, Buelga } \\
\text { Vázquez, y Musitu } \\
\text { Ochoa, 2013) }\end{array}$ & $\begin{array}{l}\text { Pág. } 7 \\
\text { Preg. } 4.1 \text { a } \\
4.10\end{array}$ \\
\hline $\begin{array}{l}\text { Desempeño } \\
\text { escolar }\end{array}$ & $\begin{array}{l}\text { Se consideran las calificaciones como un } \\
\text { indicador del desempeño escolar, como } \\
\text { mencionan otros estudios previos que han } \\
\text { relacionado éstas con el aprovechamiento de } \\
\text { forma significativa (Tuñon y Poy, 2016). }\end{array}$ & Calificaciones & $\begin{array}{l}\text { Pág. } 2 \\
\text { Preg. } 6\end{array}$ \\
\hline Popularidad & $\begin{array}{l}\text { Según la Real Academia Española, se } \\
\text { considera popular cuando se es estimado o, al } \\
\text { menos, conocido por el público en general. }\end{array}$ & Elaboración propia & $\begin{array}{l}\text { Pág. } 8 \\
\text { Preg. } 1.1\end{array}$ \\
\hline $\begin{array}{l}\text { Calidad de la } \\
\text { relación con el } \\
\text { profesor }\end{array}$ & $\begin{array}{l}\text { El apoyo que se tiene de los profesores, y el } \\
\text { buen trato por parte del personal de la escuela, } \\
\text { es un factor de protección. (Alvaréz-García, et } \\
\text { al., 2015). }\end{array}$ & $\begin{array}{l}\text { Escala de Clima } \\
\text { Escolar } \\
\text { (López, Bilbao, } \\
\text { Ascorra, Moya, y } \\
\text { Morales, 2014) }\end{array}$ & $\begin{array}{l}\text { Pág. 8-9 } \\
\text { Preg. } 2.1 \text { a } \\
2.18\end{array}$ \\
\hline $\begin{array}{l}\text { Manejo de la } \\
\text { coexistencia en } \\
\text { el centro } \\
\text { (Reglas) }\end{array}$ & $\begin{array}{l}\text { La percepción del alumno sobre la claridad y } \\
\text { justicia de las reglas del centro escolar se } \\
\text { relaciona de forma significativa con el acoso } \\
\text { escolar (Alvaréz-García, et al., 2015). }\end{array}$ & $\begin{array}{l}\text { Escala de Clima } \\
\text { Escolar } \\
\text { (López, Bilbao, } \\
\text { Ascorra, Moya, y } \\
\text { Morales, 2014) }\end{array}$ & $\begin{array}{l}\text { Pág. 8-9 } \\
\text { Preg. } 2.1 \text { a } \\
2.18\end{array}$ \\
\hline $\begin{array}{l}\text { Satisfacción } \\
\text { escolar }\end{array}$ & $\begin{array}{l}\text { Puede definirse a la satisfacción escolar como } \\
\text { la evaluación cognitivo-afectiva de la } \\
\text { satisfacción con las experiencias escolares } \\
\text { (Luna Soca, 2012). }\end{array}$ & $\begin{array}{l}\text { Basado en el trabajo } \\
\text { de Luna Soca } \\
(2012) \text {. }\end{array}$ & $\begin{array}{l}\text { Pág. } 9 \\
\text { Preg. } 3.1 \text { a } 3.5\end{array}$ \\
\hline $\begin{array}{l}\text { Estilos de } \\
\text { crianza }\end{array}$ & $\begin{array}{l}\text { El conjunto de actividades que los padres } \\
\text { practican con sus hijos, así como la } \\
\text { administración de los recursos disponibles } \\
\text { orientados a apoyar el proceso de desarrollo } \\
\text { psicológico (Gaxiola Romero, Frías Armenta, } \\
\text { Cuamba Osorio, Franco Betanzos y Olivas } \\
\text { Salido, 2006). Una de las aproximaciones más } \\
\text { utilizadas es la medición de los estilos de } \\
\text { crianza basada en dimensiones, } \\
\text { específicamente dos: el control (vigilancia) y } \\
\text { apoyo/comunicación de los padres con los } \\
\text { hijos (Hoeve, Dubas, Eichelsheim, Van Der } \\
\text { Laan, Smeenk, \& Gerris, 2009). }\end{array}$ & $\begin{array}{l}\text { ECOPRED, sección } \\
2.5 \text { (p. 1). } \\
\text { Preguntas } 1 \text { a } 21 \\
\text { (INEGI, 2014) }\end{array}$ & $\begin{array}{l}\text { Pág. } 10 \\
\text { Preg. } 1.1 \mathrm{a} \\
1.21\end{array}$ \\
\hline $\begin{array}{l}\text { Violencia } \\
\text { familiar }\end{array}$ & $\begin{array}{l}\text { Todas las formas de abuso que tienen lugar en } \\
\text { las relaciones entre los miembros de una }\end{array}$ & $\begin{array}{l}\text { ECOPRED } \\
\text { Sección } 3.5 \text { (p. 2). }\end{array}$ & Pág. 11 \\
\hline
\end{tabular}




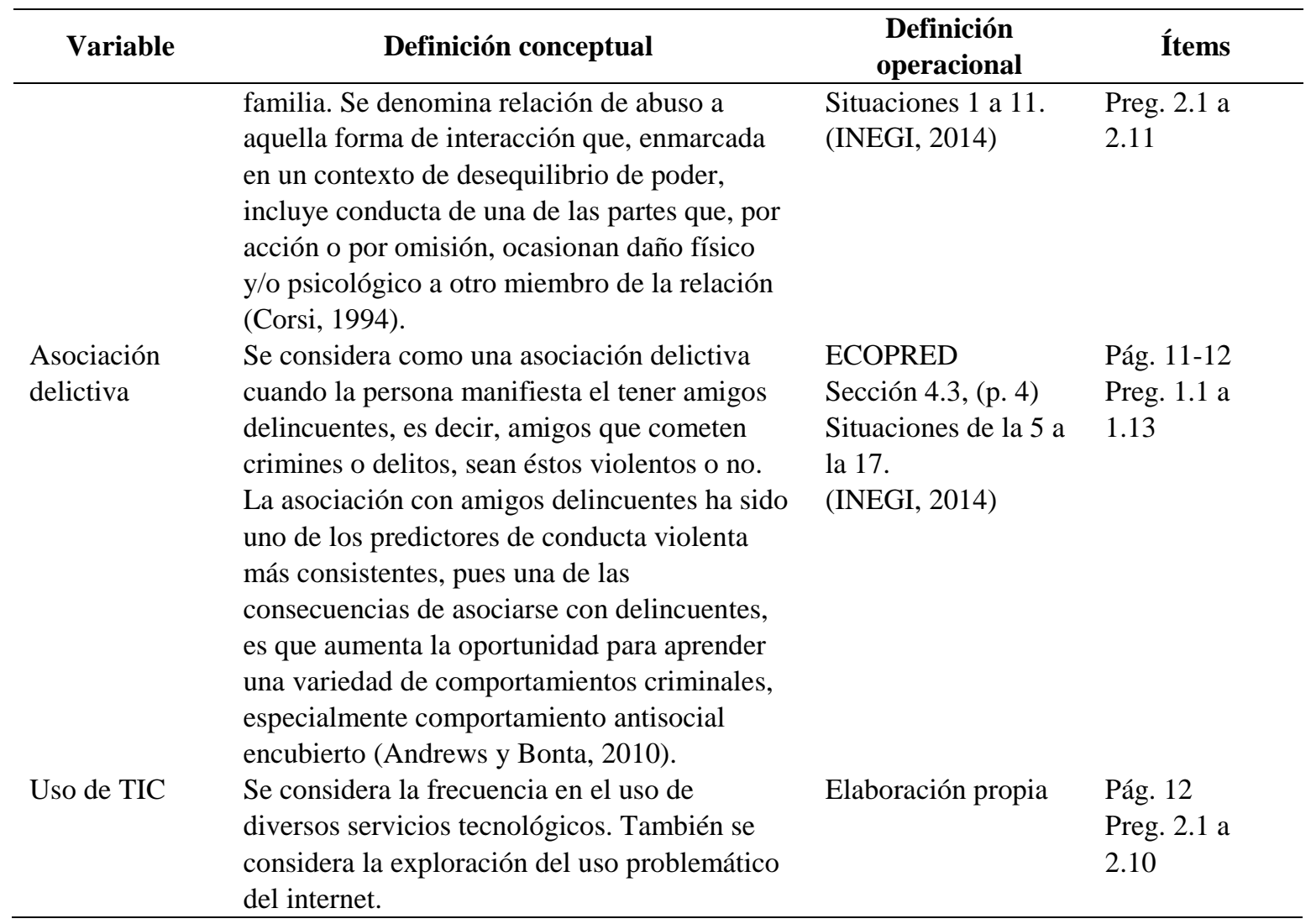

\section{Referencias de los Instrumentos:}

Andreu, J., Peña, E., y Ramirez, J. (2009). Cuestionario de agresión reactiva y proactiva: un instrumento de medida de la agresión en adolescentes. Revista de Psicopatología y Psicología Clínica, 14(1), 37-49.

Cava, M. J., Estévez López, E., Buelga Vázquez, S., y Musitu Ochoa, G. (2013). Propiedades psicométricas de la Escala de Actitudes hacia la Autoridad Institucional en adolescentes (AAI-A). Anales de psicología, 29(2), 540-548.

Felix, E. D., Sharkey, J. D., Green, J. G., Furlong, M. J., y Tanigawa, D. (2011). Getting precise and pragmatic about the assessment of bullying: The development of the California Bullying Victimization Scale. Aggressive Behavior, 37(3), 234-247. https://doi.org/10.1002/ab.20389

Instituto Nacional de Estadística y Geografía. (2014). Encuesta de Cohesión Social para la Prevención de la Violencia y la Delincuencia: Presentación Ejecutiva. Ciudad de México: INEGI.

López, V., Bilbao, M. Á., Ascorra, P., Moya, I., y Morales, M. (2014). La Escala de Clima Escolar: Adaptación al Español y Validación en Estudiantes Chilenos. Universitas Psychologica, 13(3), 1111-1122. https://doi.org/10.11144/Javeriana.UPSY13-3.ecea

Lozano Verduzco, I., y Diaz Loving, R. (2010). Medición de la identidad sexual en México. Revista Puertorriqueña de Psicología, 21(1), 133-154.

Luna Soca, F. J. (2012). Bienestar subjetivo y satisfacción escolar en la adolescencia. Universitat de Girona.

Merino-Soto, C., y Grimaldo-Muchotrigo, M. (2015). Validación Estructural de la Escala Básica de Empatía (Basic Empathy Scale) Modificada en Adolescentes: un Estudio Preliminar. Revista Colombiana de Psicología, 24(2), 261-270. https://doi.org/10.15446/rcp.v24n2.42514

Tuñón, I. y Poy, S. (2016). Factores asociados a las calificaciones escolares como proxy del rendimiento educativo. Revista Electronica de Investigacion Educativa, 18(1), 98-111. 


\section{Apéndice C. \\ Consentimiento informado}

\section{Estimado(a) alumno(a):}

Me es grato invitarte a participar en el estudio "Factores asociados al acoso escolar en un centro de educación superior". La finalidad es aportar más información sobre las dinámicas y situaciones que predisponen o protegen del acoso escolar en el nivel superior. Por tal motivo, tu participación es sumamente importante.

La participación consiste en responder una serie de cuestionarios con una duración aproximada de 20 minutos. La información que proporciones es totalmente anónima, ya que no se solicitará tu nombre; así como confidencial, pues los resultados solamente serán utilizados para fines estadísticos y de investigación. Por tal motivo, agradecemos tu sinceridad en las respuestas que aportes. Si decides participar, solo tienes que marcar la casilla correspondiente con tu firma; en caso contrario devuelve las pruebas al aplicador.

Recuerda que tu participación es de forma voluntaria, y puedes rehusarte a continuar contestando en el momento que así lo decidas sin temor a tener algún tipo de represalia. Incluso, si no deseas contestar alguna pregunta, puedes dejarla en blanco. Sin embargo, te agradecemos que intentes responder todas y cada una de las preguntas de ser posible, ya que tus respuestas nos ayudarán a comprender mejor el fenómeno del acoso escolar.

\section{¡Muchas gracias por tu participación y aportación a la ciencia!}

